NADIA JULIANA BERALDO GOULART BORGES

\title{
EFEITOS DA SUPLEMENTAÇÃO DA COLINA E DE FRUTOOLIGOSSACARÍDEOS NA ESTEATOSE HEPÁTICA EM RATOS WISTAR.
}

Ribeirão Preto

2008 
NADIA JULIANA BERALDO GOULART BORGES

\section{EFEITOS DA SUPLEMENTAÇÃO DA COLINA E DE FRUTOOLIGOSSACARÍDEOS NA ESTEATOSE HEPÁTICA EM RATOS WISTAR}

Dissertação apresentada ao Departamento de Clínica Médica - Divisão de Nutrologia da Faculdade de Medicina da USP/RP Universidade de São Paulo, para obtenção do Título de Mestre

Orientador: Dr. Julio Sérgio Marchini

Ribeirão Preto

2008 


\section{FICHA CATOLOGRÁFICA}

Preparada pela Biblioteca Central de Ribeirão Preto - USP

Borges, Nadia Juliana Beraldo Goulart

Efeitos da suplementação da colina e de frutooligossacarídeo

na esteatose hepática em ratos wistar.

130: il.; $29.7 \mathrm{~cm}$

Dissertação de Mestrado apresentada à Faculdade de Medicina de Ribeirão Preto/USP. Área de concentração: Clínica Médica

Orientador: Marchini, Julio Sérgio

1. Esteatose Hepática 2.Colina 3. Frutooligossacarídeo 


\section{DEDICATÓRIA}

À minha mãe, exemplo de força, luta, coragem e sabedoria, exemplo de vida, que me ensinou a olhar e encarar os desafios de frente e que sempre esteve ao meu lado nos momentos difíceis.

Ao meu pai, meu primeiro exemplo da atividade médica. Apesar da distância e do pouco convívio, você é uma referência para mim. Aos meus irmãos, Camila e Eduardo, minha sobrinha Sarah, pela leveza, pelos momentos de alegria que tanto me ajudam a encarar as dificuldades do dia a dia.

A minha querida amiga Juliana, presença constante e integral na minha vida. Meu apoio e ombro amigo de sempre...... A você Guilherme, pelo seu amor, afeto, alegria e companheirismo. Essa etapa só foi possivel de ser alcançada com você a meu lado.

\section{AGRADECIMENTOS}

Ao Professor Júlio Sérgio Marchini, meu orientador, que me proporcionou a oportunidade de levar esse projeto adiante. Nesse período de convivência profissional, suas qualidades como pesquisador, professor e ser humano só fizeram 
aumentar minha admiração. Sou imensamente grata pelas oportunidades que tive em atividades como congressos, simpósios e redação de capítulos de livros, indicados por ele.

Ao Professor Hélio Vannucchi, pela disponibilidade pessoal e de seu laboratório na realização de análises de estresse oxidativo, além da orientação e disponibilidade de compor a banca de dissertação de mestrado. Suas sugestões foram imensamente importantes na redação final desta dissertação.

Ao Professor Renato Ferreira da Silva, exemplo de pessoa, mestre e pesquisador. Esse projeto iniciou a partir do meu contato com a Unidade de Transplante de Fígado do Hospital de Base de São José do Rio Preto. A partir de então, toda minha admiração por este profissional foi capaz de despertar a curiosidade em me dedicar ao estudo da esteatose hepática.

Ao Professor Sérgio Zucoloto, pelo grande auxílio na análise histológica das amostras, realização de fotos das lâminas e infinitas e boas horas de conversa na sala de patologia.

Ao Alex Silva, do Departamento de Clinica Médica da FMRP-USP pela imensa ajuda na formatação do manuscrito final.

Aos técnicos do Biotério do Departamento de Clínica Médica da FMRP-USP, Adalberto Verceze, Maurício Arantes , Roni Charles Fabbris, muito obrigada pela paciência. Vocês tinham razão e realmente foram modestos, a fase experimental foi a mais divertida do projeto.

Aos técnicos de Laboratório de Nutrição do Departamento de Clínica Médica da FMRP-USP, Mônica Silva de Souza Meirelles, Renata Cristina Lázaro e Júlia que 
muito me auxiliaram na coleta, armazenamento e análises das amostras. Muito obrigada.

À FAPESP pelo auxílio financeiro concedido.

Enfim, essa dissertação não ocorreria sem três pessoas fundamentais, e não passaria de mais um projeto na gaveta, ou quem sabe no comitê de ética. Vocês foram importantíssimos na realização desse trabalho, desde o projeto piloto, até a elaboração do manuscrito final.

MUITO OBRIGADA: Sueli, Gilberto Padovan e José Marcos. 


\section{SUMÁRIO}

Lista de Abreviaturas e Siglas

Lista de Figuras

Listas de Tabelas

Resumo

Abstract

1. INTRODUÇÃO.

1.1. Definições, Epidemiologia e História Natural da Doença Hepática Gordurosa Não Alcoólica.................................................... 17

1.2. Fatores Predisponentes............................................ 20

1.3. Fisiopatologia................................................................. 24

1.4. Terapêutica.................................................................... 27

1.5. Considerações Gerais..................................................... 34

1.6. Modelos Animais de DHGNA ............................................... 35

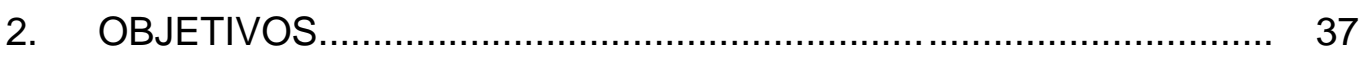

2.1. Geral.................................................................... 38

2.2 Específicos............................................................ 38

3. MATERIAL E MÉTODOS .......................................................... 39

3.1. Delineamento Experimental............................................. 40

3.2. Coleta do material biológico............................................... 44

3.2.1. Dosagens bioquímicas................................................. 45

3.2.2. Exames microscópicos................................................ 45

3.2.2.1. Inclusão de tecido em parafina.................................... 45

3.3. Métodos..................................................................... 46

3.3.1. Análise Urinária.......................................................... 46

3.3.1.1. Nitrogênio Urinário - Piroquimioluminescência.................. 46

3.3.1.2. Amônia Urinária............................................................. 48

3.3.2. Análise bioquímica do sangue ........................................... 49 


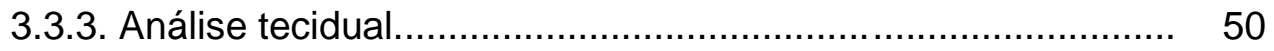

3.3.3.1. Nitrogênio tecidual....................................................... 50

3.3.3.2. Gordura tecidual total...................................................... 53

3.3.4. Análise do estresse oxidativo............................................. 54

3.3.4.1. Determinação de substâncias reativas ao ácido tiobarbitúrico (SRATB)................................................................ 54

3.3.4.2. Determinação tecidual de vitamina E.................................. 54

3.3.4.3. Glutationa reduzida....................................................... 55

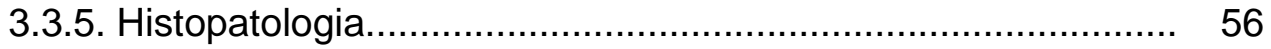

3.3.6. Análise Estatística............................................................. 56

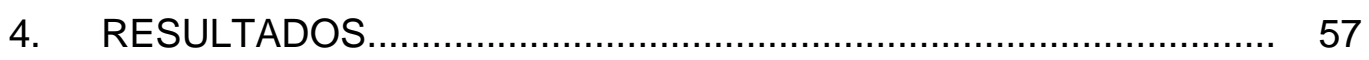

4.1. Ingestão alimentar semanal................................................. 58

4.2. Evolução do peso dos animais.............................................. 62

4.3. Análise do nitrogênio urinário................................................... 64

4.4. Análise da amônia urinária.................................................... 65

4.5. Análise do colesterol total e triacilgliceróis séricos..................... 66

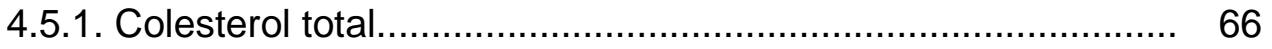

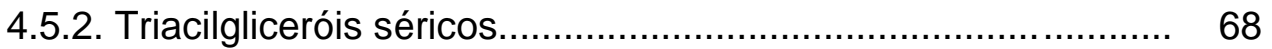

4.6. Análise do peso úmido de fígado e coração.............................. 70

4.6.1. Peso úmido do coração......................................................... 70

4.6.2. Peso úmido do fígado........................................................ 71

4.7. Análise do nitrogênio tecidual................................................ 72

4.7.1. Análise do nitrogênio tecidual hepático.................................. 72

4.7.2. Análise do nitrogênio tecidual cardíaco................................... 73

4.8. Análise da gordura tecidual................................................. 74

4.8.1. Análise da gordura tecidual hepática.................................... 74

4.8.2. Análise da gordura tecidual cardíaca..................................... 76

4.9. Análise do estresse oxidativo pela dosagem de vitamina $E$, malondialdeído (MDA) e glutationa reduzida (GSH) no tecido hepático..... 77

4.9.1. Dosagem de vitamina E................................................... 77 
9

4.9.2. Dosagem de malondialdeído (MDA)................................ 78

4.9.3. Dosagem de glutationa reduzida (GSH) ........................... 79

4.10.Análise histopatológica................................................... 80

4.10.1.Aspecto macroscópico................................................ 81

4.10.2. Aspecto microscópico..................................................... 82

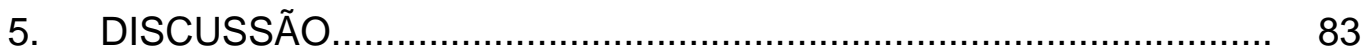

6. CONCLUSÕES ................................................................. 92

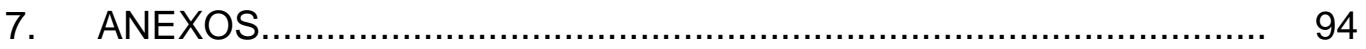

7.1. Ingestão alimentar semanal............................................... 95

7.2. Evolução do peso dos animais......................................... 97

7.3. Análise da amônia e nitrogênio urinário................................ 99

7.4. Análise do colesterol total e triacilgliceróis séricos................... 102

7.5. Análise do peso úmido de fígado e coração........................... 104

7.6. Análise do nitrogênio tecidual.............................................. 105

7.7. Análise da gordura tecidual................................................. 109

7.8. Análise do estresse oxidativo pela dosagem de vitamina $\mathrm{E}$, malondialdeído e glutationa no tecido hepático....................................... 113

7.9. Análise histopatológica....................................................... 114

7.10.Delineamento experimental........................................... 115

8. REFERÊNCIAS BIBLIOGRÁFICAS ....................................... 116 


\section{Lista de Abreviaturas e Siglas}

DHGNA - Doença hepática gordurosa não alcoólica

EH - Esteatose Hepática

VLDL - Lipoproteína de muita baixa densidade

EHNA - Esteatohepatite Não Alcoólica

NPT - Nutrição parenteral total

TN - Terapia Nutricional

AGL - Ácidos graxos livres

EROS - Espécies Reativas de Oxigênio

MDA - Malondialdeído

TNF - Fator de Necrose Tumoral

FOS - Frutooligossacarídeo

FMRP - Faculdade de Medicina de Ribeirão Preto

USP - Universidade de São Paulo

TGL- Triacilglicerol ( triglicerídeos)

CT- Colesterol Total

SRATB- Substâncias Reativas ao Ácido Tiobarbitúrico

HPLC - Cromatografia líquida de alta eficiência

GSH - Glutationa reduzida

HE - Hematoxilina-Eosina

ACC - Acetil CoA Carboxilase 


\section{Lista de Figuras}

Figura 1 - Fisiopatologia da esteatose hepática...................................... 18

Figura 2 - Efeitos indesejáveis da administração da Terapia Nutricional... 23

Figura 3 - Fisiopatologia da esteatohepatite não alcoólica........................ 25

Figura 4 - Fórmula estrutural da colina................................................ 30

Figura 5 - Efeitos do FOS no metabolismo da glicose e do colesterol........ 33

Figura 6 - Delineamento experimental................................................. 42

Figura 7 - Curva de calibração para metodologia de análise de nitrogênio urinário por piroquimioluminescência...................................... 47

Figura 8 - Extrator de Soxlet......................................................... 53

Figura 9 - Comparações entre os grupos segundo a ingestão alimentar

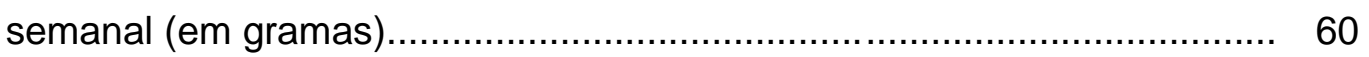

Figura 10 - Comparações entre os grupos segundo a segundo a evolução de peso semanal (em gramas)................................................. 63

Figura 11 - Comparações entre os grupos e entre as fases segundo a dosagem de colesterol total $(\mathrm{mg} / \mathrm{dL})$.

Figura 12 - Comparações entre os grupos e entre as fases segundo a dosagem de triacilgliceróis séricos $(\mathrm{mg} / \mathrm{dL})$.

Figura 13 - Comparações entre os grupos e entre as fases segundo a gordura tecidual hepática (em gramas).

Figura 14 - Macroscopia do fígado do Grupo I, controle, (A) e do Grupo que desenvolveu esteatose (B).

Figura 15 -Corte histológico hepático sem alterações, corado por HE.

Aumento 100X. Grupo controle. (Grupo I).

Figura 16 -Corte histológico hepático corados por HE, evidenciando vacúolos de lipídeos (esteatose macro e microgoticular). Aumento de 200x. Grupo III. Fase I.

Figura 17 -Corte histológico hepático corados por HE, evidenciando vacúolos de lipídeos (esteatose macro e microgoticular). Aumento 100X. Grupo II. Fase I. 


\section{Lista de Tabelas}

Tabela 1 - Prevalência de esteatose e esteatohepatite e alterações relacionadas ao fígado................................................................... 19

Tabela 2 - Principais fatores associados a DHGNA................................ 21

Tabela 3 - Amostra de alguns dos trabalhos realizados sobre a terapêutica da esteatohepatite não alcoólica........................................... 29

Tabela 4 - Valores de média e desvio padrão da ingestão alimentar (em gramas) dos grupos e comparação dos mesmos nas fases I e II.............. 58

Tabela 5 - Comparações entre as médias dos grupos segundo a ingestão alimentar semanal ( em gramas)............................................ 59

Tabela 6 - Valores de média e desvio padrão da evolução do peso (em gramas) dos grupos e comparação dos mesmos nas fases I e II................ Tabela 7 - Comparações entre as médias dos grupos segundo a evolução de peso semanal (em gramas)............................................... 62

Tabela 8 - Valores de média e desvio padrão do nitrogênio urinário $\left(\mathrm{gN}_{2}\right.$ / volume total / 24 hs) dos grupos e comparação intra e intergrupos.......... 64

Tabela 9 - Valores de média e desvio padrão da amônia urinária $\left(\mathrm{gN}_{2} /\right.$ volume total / 24 hs) dos grupos e comparação intra e intergupos ........... 65

Tabela 10 - Valores de média e desvio padrão do colesterol total ( $\mathrm{mg} /$ $\mathrm{dL}$ ) dos grupos e comparação intra e intergupos.

Tabela 11 - Valores de média e desvio padrão do triacilgliceróis sérico $(\mathrm{mg} / \mathrm{dL}$ ) dos grupos e comparação intra e intergrupos.

Tabela 12 - Valores de média e desvio padrão do peso úmido do coração (gramas) dos grupos e comparação intra e intergrupos.

Tabela 13 - Valores de média e desvio padrão do peso úmido do fígado (gramas) dos grupos e comparação intra e intergrupos

Tabela 14 - Valores de média e desvio padrão do nitrogênio tecidual hepático (gramas) dos grupos e comparação intra e intergrupos

Tabela 15 - Valores de média e desvio padrão do nitrogênio tecidual cardíaco (gramas) dos grupos e comparação intra e intergrupos.

Tabela 16 - Valores de média e desvio padrão da gordura tecidual hepática (gramas) dos grupos e comparação intra e intergrupos. 
Tabela 17 - Valores de média e desvio padrão da gordura tecidual cardíaca (gramas) dos grupos e comparação intra e intergrupos .............. 76

Tabela 18 - Valores de média e desvio padrão de vitamina $E$ tecidual ( $\mu$ mol Vitamina E/grama tecido) dos grupos e comparação intra e

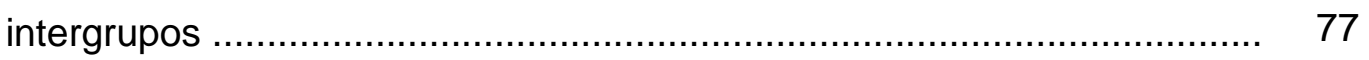

Tabela 19 - Valores de média e desvio padrão de MDA (nmoles/ mg proteína) dos grupos e comparação intra e intergrupos.............................. 78

Tabela 20 - Valores de média e desvio padrão de GSH ( $\mu \mathrm{mol}$ GSH/ grama proteína) dos grupos e comparação intra e intergrupos.................. 79

Tabela 21 - Animais que desenvolveram esteatose hepática na fase I..... 80

Tabela 22 - Animais que apresentaram esteatose hepática após fase II.... 80 


\section{Resumo}

BORGES NJBG. Efeitos da suplementação de colina e frutooligossacarídeo na esteatose hepática em ratos wistar [dissertação]. Ribeirão Preto: Faculdade de Medicina. Universidade de São Paulo.

A Doença Hepática Gordurosa Não Alcoólica (DHGNA) é uma condição clínicopatológica comum, caracterizada por depósito de lipídeos no hepatócito do parênquima hepático. A esteatose hepática (EH) é um dos componentes da DHGNA e caracteriza-se pela presença de vacúolos de lipídeos, principalmente triacilgliceróis (triglicerídeos), dentro dos hepatócitos. Alterações na oxidação das gorduras no fígado ou redução na exportação de lipoproteínas de muito baixa densidade (VLDL) a partir do órgão são os principais mecanismos etiopatogênicos envolvidos com a $\mathrm{EH}$. A patogênese da DHGNA é multifatorial e diversos fatores ou condições têm sido relacionados à predisposição para o seu desenvolvimento. Atualmente, diferentes tratamentos farmacológicos para DHGNA estão sendo propostos, mas ainda não há nenhum estudo comprobatório da sua eficácia. Objetiva-se avaliar os efeitos da suplementação da colina e do frutooligossacarídeo (FOS) na dieta de ratos Wistar, no modelo de esteatose hepática, induzido por dieta hiperglicídica. Foram utilizados 46 ratos machos, da raça Wistar adultos com peso variando entre 250 - 320 g, vindos do Biotério Central do Campus da USP Ribeirão Preto. Do lote inicial de animais foram distribuídos de forma aleatória nos diferentes grupos de estudo de I a IV, dependendo da indução ou não da esteatose. Considerou-se fase I o período correspondente a indução de esteatose e fase II quando se submeteu os animais a suplementação com nutrientes (Grupos III e IV), ou quando os animais receberam dieta padrão pós fase I (Grupo II). Os animais do Grupo I (controle) receberam ração padrão do biotério que foi igual para todos os animais, sendo separado um lote da mesma ração para todo o experimento. Foi analisado as seguintes variáveis: Ingestão alimentar semanal, evolução do peso dos animais, nitrogênio urinário, amônia urinária, colesterol total e triacilgliceróis séricos, peso úmido de fígado e coração, nitrogênio e gordura tecidual, dosagem de vitamina E, malondialdeído (MDA) e glutationa no tecido hepático e análise histopatológica. Observamos que nenhum dos nutrientes empregados (colina e FOS) foi eficaz na redução da quantidade de gordura do fígado pela análise histológica. Nenhum dos nutrientes adicionados foi capaz de proteger o fígado da ação dos radicais livres, já que o MDA, um marcador indireto da geração do estresse oxidativo, manteve-se com valores elevados mesmo na fase de tratamento. Ocorreu diminuição dos níveis de triacilgliceróis em todos os grupos submetidos à indução de esteatose, do início ao final do experimento. O frutooligossacarídeo foi capaz de reduzir os níveis de colesterol sérico, em relação aos seus níveis basais, quando suplementado após indução de esteatose. 


\begin{abstract}
Effects of choline and fructoologosaccharide supplementation on liver steatosis in rats wistar.

Non-alcoholic fatty liver disease (NAFLD) is a common clinical pathological condition characterized by fat accumulation in the the hepatic parenchyma hepatocyte. Liver steatosis (HS) is one of the components of NAFLD and is characterized by the presence of lipids vacuoles, mainly triacylglycerol, within the hepatocites. Alterations in fat oxidation in the liver or very low density proteins lipoproteins tranport from the organ are the main etiopatogenic mechanisms involved in HS. NAFLD patogeny is multifactor, thus several factors have been associated the propensity to develop it. Presently, many drug treatments for NAFLD are being suggested, however, there have been no studies that prove their efficacy so far.

The aim of this study was to assess the effects of choline and fructooligosaccharide (FOS) suplementation in Wistar rats with HS induced by high glicid diet. Forty six adult male Wistar rats weighing between $250 \mathrm{~g}$ and $320 \mathrm{~g}$ from the USP (Ribeirão Preto-USP) central vivarium were used. They were divided randomly into different study groups from I to IV depending on whether steatosis would be induced or not. Phase I of the study was the period corresponding to steatosis induction and phase II was when the animals received nutrient suplementation (Groups III and IV) or when they received standard diet (Group II).

Group I animals (control) received the usual vivarium food, which was the same for all of them. A certain amount of that same food was kept aside for the duration of the experiment. The following variables were analyzed: weekly food intake, weight gain, urine ammonia, urine nitrogen, total cholesterol and serum triacylglycerol, liver and heart humid weight, nitrogen and tissue fat, vitamin E, malondialdehyde (MDA) and glutathione content in the liver tissue and hitopathological analysis. As observed, neither of the nutrients (choline and FOS) was efficient in reducing the amount of fat in the liver. Neither of the nutrients added was able to protec the liver from free radicals, once the MDA, a indirect marker for oxidative stress generation, showed high levels even during the treatment phase. There was a reduction in triacylglycerol levels in all steatosis induced groups, from the beginning to the end of the experiment. Fructooligosaccharide was able to reduce the levels of serum cholesterol, in relation to its basal levels, when suplemented after steatosis induction.
\end{abstract}


1. INTRODUÇÃO

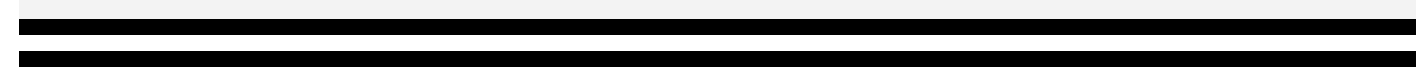




\subsection{Definições, Epidemiologia e História Natural da Doença Hepática Gordurosa Não Alcoólica}

A doença hepática gordurosa não alcoólica (DHGNA) é uma condição clínico-patológica comum, caracterizada por depósito de lipídeos no hepatócito do parênquima hepático (SASS et al., 2005; SHETH, 1997).

Foi descrita por Ludwig et al. (1980) onde observou quadro patológico semelhante ao da lesão hepática induzida pelo álcool, mas em indivíduos que não tinham ingestão etílica significativa. O espectro de lesão hepática varia de esteatose macrogoticular simples para esteatohepatite, fibrose avançada e cirrose (ANGULO et al.,1999; DAM-LARSEN et al., 2004).

A esteatose hepática (EH) é um dos componentes da DHGNA e caracteriza-se pela presença de vacúolos de lipídeos, principalmente triacilgliceróis, dentro dos hepatócitos, podendo ser caracterizada quantitativa e qualitativamente (ANGULO et al., 2006; ANGULO et al., 2007; MENDLER et al., 2005).

Alterações na oxidação das gorduras no fígado ou redução na exportação de lipoproteínas de muito baixa densidade (VLDL) a partir do órgão são os principais mecanismos etiopatogênicos envolvidos com a esteatose hepática (BROWNING et al., 2004; ISSELBACHER et al, 1961), Figura 1. 
Excesso na oferta de ácidos graxos ao fígado através da corrente sanguínea

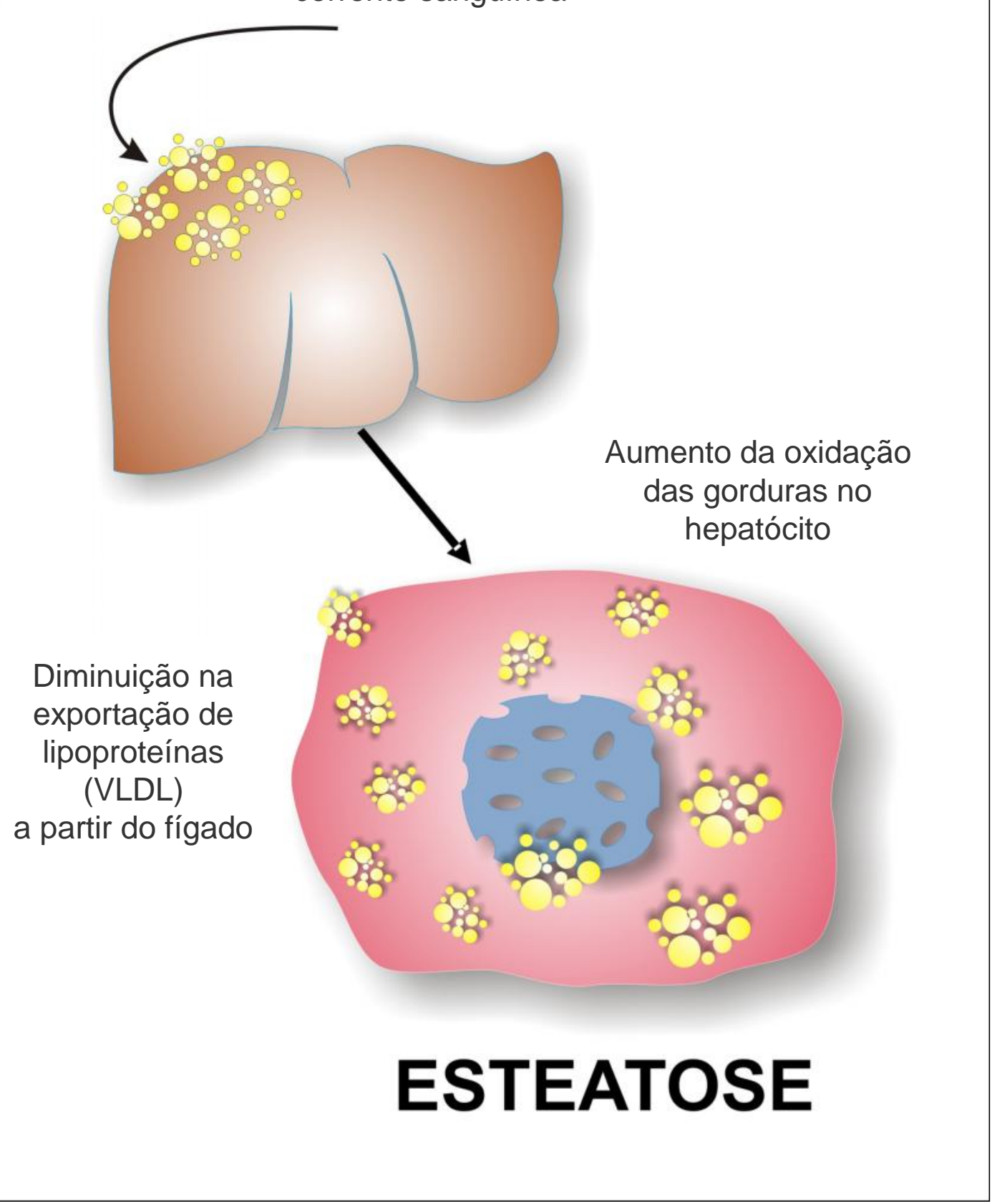

Figura 1 - Fisiopatologia da esteatose hepática 
A Esteatohepatite Não Alcoólica (EHNA) é caracterizada por apresentar uma esteatose macro/microgoticular, infiltrado inflamatório misto, balonização hepatocelular em zona III, podendo evoluir com fibrose, corpúsculos de Mallory e cirrose (BRUNT et al., 2003).

A prevalência global da DHGNA é estimada em $20 \%$, com variações de 10-40\% nas populações da América do Norte, Japão, Europa, Austrália e América do Sul (BROWINING et al., 2005; PORTINCASA et al., 2005; SAITO et al., 2007).

Estudos epidemiológicos avaliam que $20 \%$ a $34 \%$ dos adultos nos Estados Unidos são obesos (FLAMM et al., 2001). Estima-se que, cerca de $20 \%$ da população de obesos e $3 \%$ dos indivíduos normais sejam portadores de DGHNA naquele país e a prevalência da doença hepática gordurosa não alcoólica têm sido substancialmente maior que a prevalência da hepatite por vírus C. (ALTER, 2007; ALTER et al., 2006; ÂNGULO 1999). Tabela 1.

Tabela 1 - Prevalência de esteatose e esteatohepatite e alterações relacionadas ao fígado

\begin{tabular}{llc}
\hline Prevalência na população & Esteatose & $16-24 \%$ \\
& Esteatohepatite & $2-3 \%$ \\
Prevalência de doentes & Diabetes tipo $28-55 \%$ \\
& Obesidade & $60-95 \%$ \\
& Dislipidêmicos & $20-92 \%$ \\
Mortes relacionadas ao fígado & Em obesos & $20 \%$ \\
& Em diabéticos & $8 \%$ \\
\hline
\end{tabular}

Fonte: Angulo P, Keach JC, Batts KP, Lindor KD. Independent predictors of liver fibrosis in patients with nonalcoholic steatohepatitis. Hepatology 1999; 30:1356-62. 
No Brasil, embora há poucos estudos relacionados à DHGNA, uma avaliação realizada pela Sociedade Brasileira de Hepatologia registrou 2.232 casos de DHGNA (COTRIM et al., 1999a, 2005b, 2006c). Já em outro estudo com 912 indivíduos obesos, sem diabetes mellitus associado, em um ambulatório de nutrição, foi possível determinar, uma prevalência de esteatohepatite não alcoólica da ordem de 3.18\% (MATTOS, 2005). A prevalência da EHNA também está intimamente relacionada com pacientes portadores de obesidade visceral e síndrome metabólica (AKBAR et al., 2006; ANGELICO et al., 2005; HAMAGUCHI et al., 2005). MARCHESINI et al. (2006), demonstraram que a presença de três critérios da síndrome metabólica em pacientes com DHGNA eleva em 3.5 vezes o risco para desenvolver fibrose acentuada e doença hepática crônica.

\subsection{Fatores Predisponentes}

A patogênese da DHGNA é multifatorial e diversos fatores ou condições têm sido relacionados à predisposição para o seu desenvolvimento. Além da obesidade, síndrome metabólica, diabetes mellitus e dietas hipercalóricas, outros fatores predisponentes foram detectados como a presença de mutações e polimorfismos nos genes relacionados à resistência insulínica, bem como anormalidades no metabolismo lipídico e nos adipócitos (ENRIORI et al., 2006; QURESHI et al., 2007; SALGADO JUNIOR et al., 2006). A DHGNA pode estar associada às cirurgias de by-pass jejuno-ileal, desnutrição calórico-protéica, nutrição parenteral prolongada, uso de drogas e exposição ocupacional 
(ADAMS et al., 2005; BENCHIMOL et al., 2007; FREITAS et al., 2007).

Ainda que se conheçam os fatores predisponentes, e se saiba da cronicidade da esteatose, a verdadeira causa da DHGNA, ainda não está totalmente esclarecida (LOPEZ DIEGUEZ PUERTA et al., 2005; MOON et al., 2006). Quando não são identificados os fatores envolvidos, a DHGNA é rotulada como de causa desconhecida (Tabela 2 ).

Tabela 2 - Principais fatores associados a DHGNA

\begin{tabular}{|c|c|c|c|}
\hline Nutricionais & Cirurgias & Medicamentos e toxinas & $\begin{array}{l}\text { Erros inatos do } \\
\text { metabolismo }\end{array}$ \\
\hline Obesidade & By-pass jejuno-ileal & Amiodarona & Abetalipoproteinemia \\
\hline Diabetes mellitus & Gastroplastia para & Aspirina & Galactosemia \\
\hline Dislipidemia & tratamento de & Tetraciclina & Tirosinemia \\
\hline Perda de peso & obesidade mórbida & Bloqueador de canal de & Doença de Weber- \\
\hline rápida & Derivação bilio- & cálcio & Christian $^{\dagger}$ \\
\hline Desnutrição & pancreática & Maleato de perhexilene & Lipodistrofia \\
\hline protéico calórico & Ressecção extensa & Corticosteróide & Doença de Wolman ${ }^{\ddagger}$ \\
\hline grave & do intestino & Estrógenos sintéticos & \\
\hline Nutrição & delgado & Tamoxifeno & \\
\hline parenteral & & Agentes antivirais & \\
\hline prolongada & & químicos (hidrocarbonetos & \\
\hline Síndrome da & & mistos, cloreto de vinila, & \\
\hline realimentação & & $\begin{array}{l}\text { benzeno, tolueno, entre } \\
\text { outros) }\end{array}$ & \\
\hline \multicolumn{4}{|c|}{$\begin{array}{l}\text { † Doença que cursa com esteatose macrovesicular e decorre de um desequilíbrio entre a } \\
\text { síntese hepática e a exportação de lipídeos. } \\
\text { ‡ Doença que cursa com fosfolipidose hepática, por acúmulo de fosfolipídeos nos lisossomos. } \\
\text { Fonte: adaptado de Angulo P, Keach JC, Batts KP, Lindor KD. Independent predictors of liver } \\
\text { fibrosis in patients with nonalcoholic steatohepatitis. Hepatology 1999; 30:1356-62. }\end{array}$} \\
\hline
\end{tabular}


A Terapia Nutricional (TN) é outro fator envolvido na etiopatogenia da esteatose hepática. Esta ocorre em 25 a 100\% dos pacientes em uso de NPT, iniciando-se entre a primeira e quarta semana. Alterações das enzimas hepáticas ocorrem em $20 \%$ a $90 \%$ dos pacientes adultos e $9 \%$ a $42 \%$ das crianças sob NPT (NISHIMURA et al., 2006). Um dos mecanismos envolvidos na gênese da esteatose hepática relacionada à TN é a contínua oferta de carboidratos e a persistente hiperinsulinemia associada à formação de precipitados nos ductos biliares durante o jejum (ANGELICO et al., 2000; WANG et al., 2006). Se a terapia nutricional for administrada de forma incorreta, com administração em excesso de calorias e/ou carboidratos e/ou lipídeos ou quaisquer dos fatores citados no esquema (Figura 2) a seguir, o paciente pode desenvolver esteatose, esteatohepatite, colestase ou lama biliar (ANGELICO et al., 2000). 


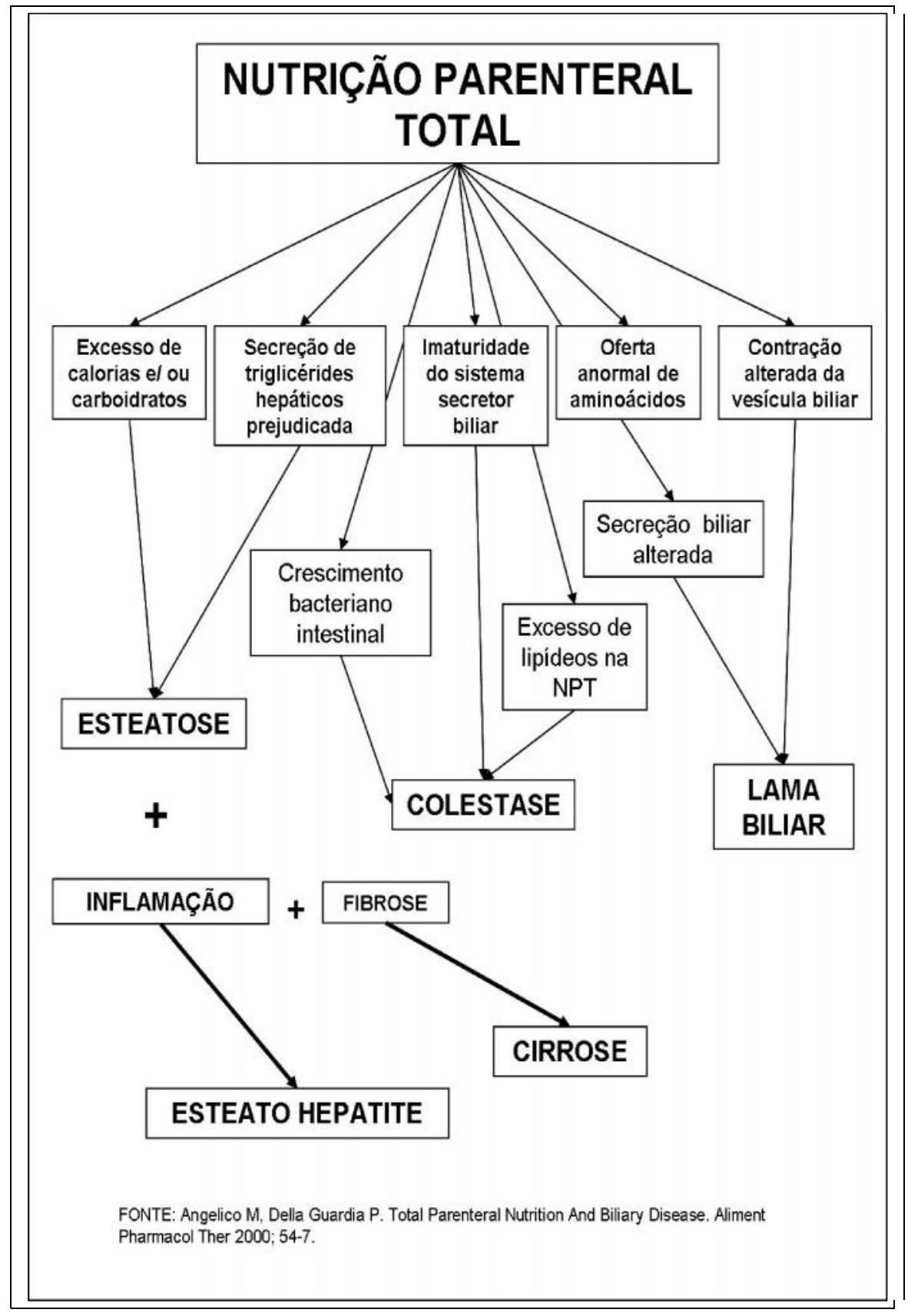

Figura 2 - Efeitos indesejáveis da administração da Terapia Nutricional 


\subsection{Fisiopatologia}

Segundo a teoria proposta por Day (2002), haveria dois estímulos desencadeadores envolvidos na gênese da DHGNA. Segundo este autor, a resistência insulínica seria a condição inicial desencadeante (primeiro estímulo), necessário para o acúmulo de ácidos graxos no hepatócito. Como segundo estímulo haveria o estresse oxidativo ou a endotoxemia crônica para o desenvolvimento de inflamação e fibrose. A fase inicial, segundo aquela teoria, seria o acúmulo de ácidos graxos no hepatócito, superando sua capacidade de metabolização e exportação conseqüente à ação lipogênica da insulina. A hiperinsulinemia que ocorre na obesidade e síndrome metabólica favoreceria a lipogênese hepática e aumentaria a lipólise periférica, aumentando a quantidade de ácidos graxos para o fígado, condições estas adequadas para o acúmulo de lipídeos no seu interior (DUVNJAK et al., 2007; QURESHI et al., 2007; TAMURA et al., 2005). O tecido adiposo libera a gordura na forma de ácidos graxos livres ( $A G L)$, mediante o estímulo da adrenalina, corticosteróide e outros hormônios como a insulina. Os AGL têm dois destinos após a entrada nos hepatócitos: são oxidados pelas mitocôndrias para gerar energia (ATP) ou são convertidos novamente em triacilgliceróis, acoplados às lipoproteínas de densidade muito baixa (VLDL) e exportados do fígado para o tecido adiposo (Figura 3). A deposição de triacilgliceróis no interior do hepatócito (esteatose) decorre principalmente da disponibilidade e mobilização de AGL, da síntese hepática aumentada de $A G L$ e da diminuição da mobilização hepática de triacilgliceróis sob a forma de VLDL (TSUKAMOTO, 2005). 


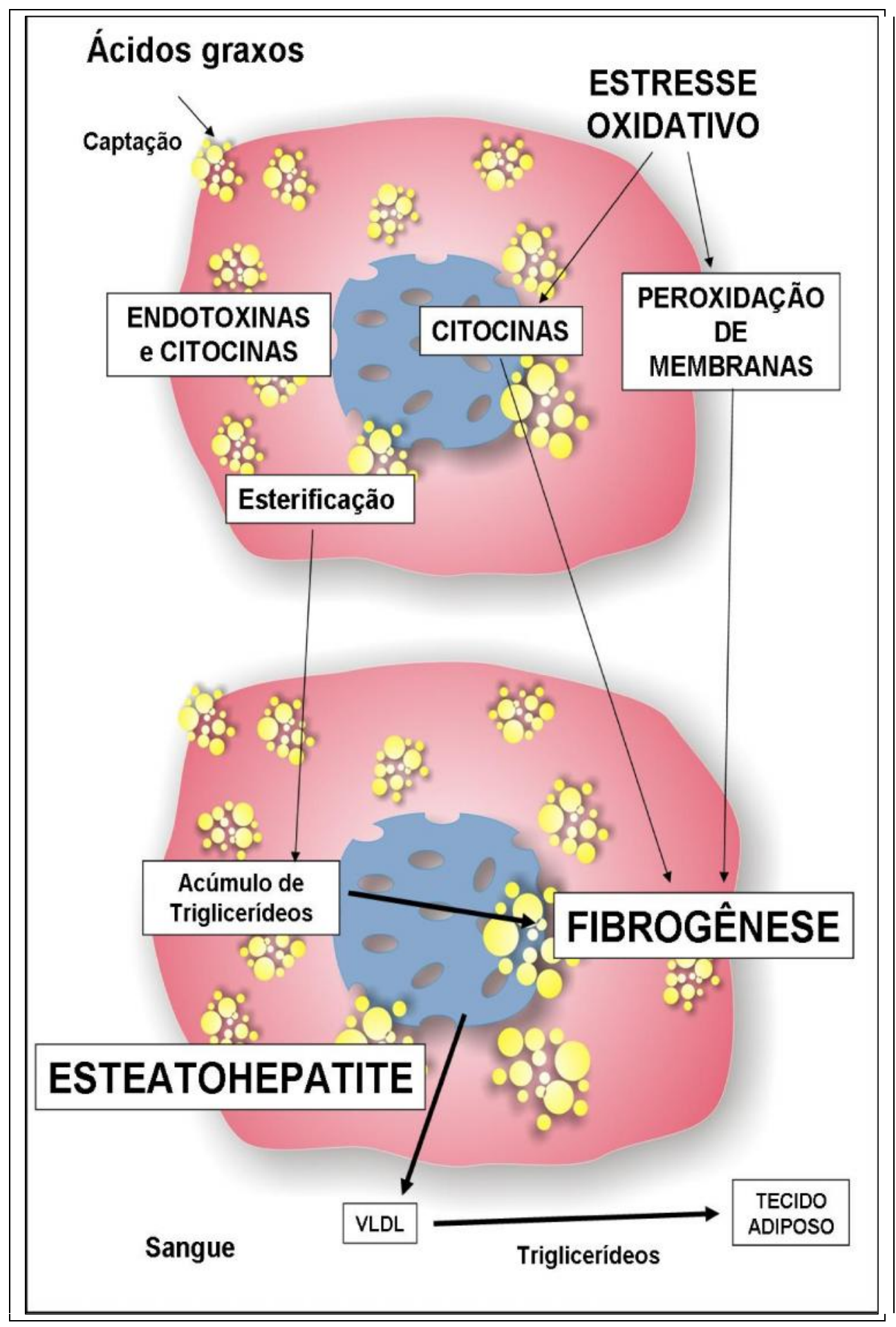

Figura 3 - Fisiopatologia da esteatohepatite não alcoólica 
Provavelmente, na DHGNA há uma combinação de todos estes fatores intensificados por alterações na lipólise pós-prandial relacionada à insulina, a qual provoca aumento de ácidos graxos liberados para o fígado; excesso de carboidratos na dieta que resulta em nova síntese de ácidos graxos hepáticos; falha na beta-oxidação mitocondrial e depleção de adenosina trifosfato; produção de citocinas pró-inflamátorias e um complexo mecanismo deficiente de transporte de triacilgliceróis (COPACl et al., 2006; DIEHI et al., 2002; REDDY et al., 2006). O estresse oxidativo (segundo estímulo), por sua vez, seria importante na evolução de esteatose para esteatohepatite e fibrose (OLIVEIRA et al., 2002; OLIVEIRA et al., 2006a). Durante o metabolismo normal, o oxigênio é reduzido a água e, nesse processo, os produtos intermediários são o radical superóxido $\left(\mathrm{O}_{2}^{-}\right)$, o peróxido de hidrogênio $\left(\mathrm{H}_{2} \mathrm{O}_{2}\right)$ e o radical hidroxil $(\mathrm{OH})$, denominados conjuntamente espécies reativas de oxigênio (EROS). O estresse oxidativo se estabelece quando as defesas intracelulares antioxidantes são insuficientes para detoxificar as EROS ou, também, quando há produção excessiva de EROS. Dentro desse contexto, o excessivo aporte de ácidos graxos ao fígado pode promover esgotamento da oxidação mitocondrial e aumento na produção de EROS, bem como ativação de outras vias de oxidação lipídica (via peroxissomal e microssomal) que geram, por sua vez, mais EROS aumentando o estresse oxidativo hepático. Esse aumento pode causar peroxidação lipídica, cujos produtos intermediários são importantes agentes pró-inflamatórios, favorecendo a fibrogênese (segundo estímulo) (LECLERCQ et al., 2000; LEE et al., 1995). Um dos 
produtos finais da peroxidação de lipídios é o malondialdeído (MDA) que ativa a produção de colágeno com conseqüente fibrose (LEE et al., 1995). O processo inflamatório também pode ser desencadeado pelo MDA que ativa citocinas como o fator de necrose tumoral (TNF), interleucina-8 e interleucina-6 (DIEHL et al., 2005). Outros estudos demonstraram em ratos, que a deposição crônica de gordura no fígado está associada à peroxidação de lipídios, e que o grau de peroxidação é proporcional à gravidade da esteatose (KOTEISH et al., 2003; OLIVEIRA et al., 2002; OLIVEIRA et al., 2006a). Outro estímulo importante, além do estresse oxidativo, na progressão para inflamação e fibrose na DHGNA, seria a endotoxemia crônica presente principalmente na obesidade. Esta condição clínica associada à síndrome metabólica são condições inflamatórias que conduzem à aterosclerose e a um processo inflamatório crônico (DAS, 2002; HARTGE et al., 2007). A elevação de proteínas de fase aguda e de citocinas pró-inflamatórias está demonstrada em obesos livres de traumas, infecções, artropatias crônicas, moléstias autoimunes e também na derivação jejuno-ileal (KERN et al, 1995; DUNCAN et al, 2000; TARANTINO, 2007). O tecido adiposo não é mais considerado um tecido inerte para reserva de energia ou de excesso de ácidos graxos livres; é altamente ativo como um órgão endócrino e originando numerosos produtos secretórios ativos, coletivamente chamados de adipocinas ou adipocininas (ENRIORI et al., 2006; SAHAl et al., 2004).

\subsection{Terapêutica}


Atualmente, o tratamento utilizado de rotina para a DHGNA é controlar os fatores que levaram ao seu aparecimento, não há tratamento medicamentoso efetivo. Isso pode decorrer do fato de que sua fisiopatologia e história natural ser pouco conhecida (PETERSEN et al., 2005; SIEBLER et al., 2006).

tratamento consiste em combater os fatores desencadeantes, como redução do peso de forma gradual com dieta de baixo teor de gorduras e carboidratos, controle metabólico na dislipidemia, diabetes mellitus e síndrome metabólica. Caso o paciente estiver em terapia nutricional parenteral, reduzir as calorias totais e infusão de carboidratos, administrar nutrição parenteral de forma cíclica e se possível administrar nutrição enteral concomitante (WANG et al., 2006). Em estudo retrospectivo conduzido por Solga et al. (2004), foi analisada a composição da dieta alimentar de pacientes submetidos à cirurgia bariátrica. Foi observado que pacientes que apresentaram maiores taxas de inflamação e fibrose à biópsia faziam uso de dieta rica em carboidratos. Porém se paciente já apresentava esteatose e esteatohepatite não alcoólica, creditouse à rápida perda de peso (>1.6kg/ semana) piora histológica e precipitação à falência hepática (BUGIANESI et al., 2005).

Diversos tratamentos farmacológicos para DHGNA estão sendo propostos, mas ainda não há nenhum estudo comprobatório da sua eficácia (ERSOZ et al., 2005; IWAKI et al., 2007; OLIVEIRA et al., 2003; OLIVEIRA et al., 2006b). As drogas utilizadas nos ensaios clínicos e estudos experimentais são: Genfibrozil (hipolipemiante), Ácido Ursodexocólico (reduz ácidos biliares, imunoprotetor e estabilizador de membrana), Betaine (induz aumento da Sadenosilmetionina, que é hepatoprotetora), N-acetilcisteína (aumenta 
glutationa, que protege contra estresse oxidativo), Vitamina E (antioxidante e imunomodulador), Metformina (biguanida que regula a produção hepática de glicose), Glitazonas (agentes sensibilizadores de insulina), Fibratos (agentes hipolipemiantes), Acarbose e Orlistat (inibidor da lipase lipoproteica) (ANGULO, 2002; ASSY et al., 2006; DUTTA et al., 2003; MADAN et al., 2005). Tabela 3.

Tabela 3 - Amostra de alguns dos trabalhos realizados sobre a terapêutica da esteatohepatite não alcoólica

\begin{tabular}{|c|c|c|c|c|}
\hline Referência & $\begin{array}{l}\text { Resultado da } \\
\text { biópsia }\end{array}$ & Medicamento & Dose & $\begin{array}{l}\text { Tempo de } \\
\text { tratamento }\end{array}$ \\
\hline Bugianesi,2004 & $\begin{array}{l}\text { Não houve } \\
\text { mudança }\end{array}$ & $\begin{array}{l}\text { Ácido } \\
\text { ursodexocólico } \\
\left(\text { Ursacol }^{\boxplus}\right)\end{array}$ & $13-15 \mathrm{mg} / \mathrm{kg} / \mathrm{dia}$ & 2 anos \\
\hline Uygun, 2004 & $\begin{array}{l}\text { Não houve } \\
\text { mudança }\end{array}$ & $\begin{array}{l}\text { Metformina } \\
\left.\text { (Glucoformin }^{\circledR}\right)\end{array}$ & 500 mg/dia & 6 meses \\
\hline Promrat,2004 & Melhora histológica & Pioglitazona (Atua ${ }^{\circledR}$ ) & $30 \mathrm{mg} / \mathrm{dia}$ & $\begin{array}{l}48 \\
\text { semanas }\end{array}$ \\
\hline Laurin,1996 & & Clofibrato de etila & 02 g/dia & 1 ano \\
\hline Lavine,2000 & $\begin{array}{l}\text { Não houve } \\
\text { mudança }\end{array}$ & Vitamina $\mathrm{E}$ & 400-1200IU / dia & 4-10 meses \\
\hline & $\begin{array}{l}\text { Não realizada } \\
\text { biópsia }\end{array}$ & & & \\
\hline
\end{tabular}

Em resumo, o tratamento medicamentoso para DHGNA ainda não está definido. Não há informações ou resultados suficientes para que possam ser utilizados na clínica diária (GEORGESCU et al., 2007).

Paralelamente e por muitas décadas, deficiências como, por exemplo, metionina e colina (Figura 4) foram implicadas na patogênese da lesão hepática (GRATTAGLIANO et al., 2000; MESTRE PRATES et al., 2002; SUNDARAM et al., 2005). 


\section{$\mathrm{HO}-\underset{\mathrm{H}_{2}}{\mathrm{C}}-\underset{\mathrm{H}}{\mathrm{C}}-\mathrm{N}^{+}-\left(\mathrm{CH}_{3}\right)_{3}$ \\ Colina}

Figura 4 - Fórmula estrutural da colina

A colina é uma amina quaternária que se encontra amplamente distribuída em alimentos e é essencial para a função normal de todas as células. Assegura a integridade estrutural e funções das membranas celulares afetando diretamente a neurotransmissão colinérgica (ZEISEL, 2007).

A colina é um precursor para a biossíntese de fosfolipídeos, fosfatidilcolina, lisofosfatidilcolina e esfingomielina, todos constituintes de menbranas. É necessária para a formação de fosfatidilcolina que é essencial na mobilização de lipoproteínas de muita baixa densidade a partir do fígado.

Nos alimentos, a colina ocorre principalmente na forma de lecitina, mas também pode estar na forma livre ou como componente de outros fosfolípides, como a esfingomielina (ASSUMPÇÃO et al., 2006).

A colina foi reconhecida como presente em tecidos de mamíferos em 1862. Sua importância como nutriente essencial foi primeiramente demonstrada em um estudo sobre a insulina em 1930. onde cães pancreatectomizados mantidos em terapia com insulina desenvolviam fígado gorduroso e morriam. A administração de pâncreas cru preveniu o desenvolvimento de fígado gorduroso devido ao seu conteúdo de colina na forma de lecitina. Como resultado, a colina e outras substâncias que preveniam 
o fígado gorduroso foram chamadas desde então de lipotrópicas. (ASSUMPÇÃO et al, 2006; JAFFE et al., 1950; RAUBENHEIMER et al., 2006).

Estudos em animais demonstraram que uma dieta deficiente em colina promove a carcinogênese hepática. A doença inicia-se com o acúmulo de lipídios hepáticos, já que a lecitina é imprescindível para a síntese de proteínas de muito baixa densidade (VLDL), a mais importante via de saída dos triacilgliceróis hepáticos. De fato, o fígado gorduroso é um dos sinais clássicos da deficiência de colina em animais (ASSUMPÇÃO et al, 2006; DE LIMA et al., 2007).

Muito embora a colina seja um nutriente essencial para várias espécies animais, não foi durante muitos anos considerada essencial para os humanos. Contudo, estudos clínicos recentes demostraram que a colina é essencial para uma função hepática normal (HASLER, 2000; ZEISEL, 2007), e desde 1998 a Academia Nacional de Ciências dos Estados Unidos a reconheceu como um nutriente essecial. Em ratos de laboratório, deficiências de proteína dietética e fatores lipotrópicos (colina e metionina) podem produzir um fígado gorduroso, sendo relatado que o etanol aumenta as necessidades de colina no rato possivelmente pelo aumento da oxidação da mesma (ASSUMPÇÃO et al, 2006; KASHIREDDY et al., 2004).

Trabalhos recentes têm identificado outros nutrientes específicos (MAROTTA et al., 2006) que atuam na regulação do metabolismo de lipídeos podendo modular sua concentração sérica, como demonstrado em estudos prévios (DELZENNE et al., 1999; DELZENNE et al., 2001; KOK et al., 1998), onde foi adicionado frutooligossacarídeo (FOS) na dieta de ratos Wistar 
masculinos e observado diminuição dos níveis hepáticos e séricos de triglicerídeos. (Figura 5).

Atualmente, os oligossacarídeos ou polissacarídeos que contêm frutose (frutanos), como os FOS e a inulina, são estudados e comercializados (principalmente em mercados como Japão, EUA e Europa) como produtos para a indústria de alimentos com teor calórico reduzido (PASSOS et al., 2003).

Estudos em animais e humanos indicam que os frutanos, através de seus efeitos gastrintestinais, podem afetar indiretamente 0 metabolismo de carboidratos, de lipídeos e de minerais, bem como atuar na modulação da função imunológica (LUO et al., 2000; MOLIS et al., 1996). 


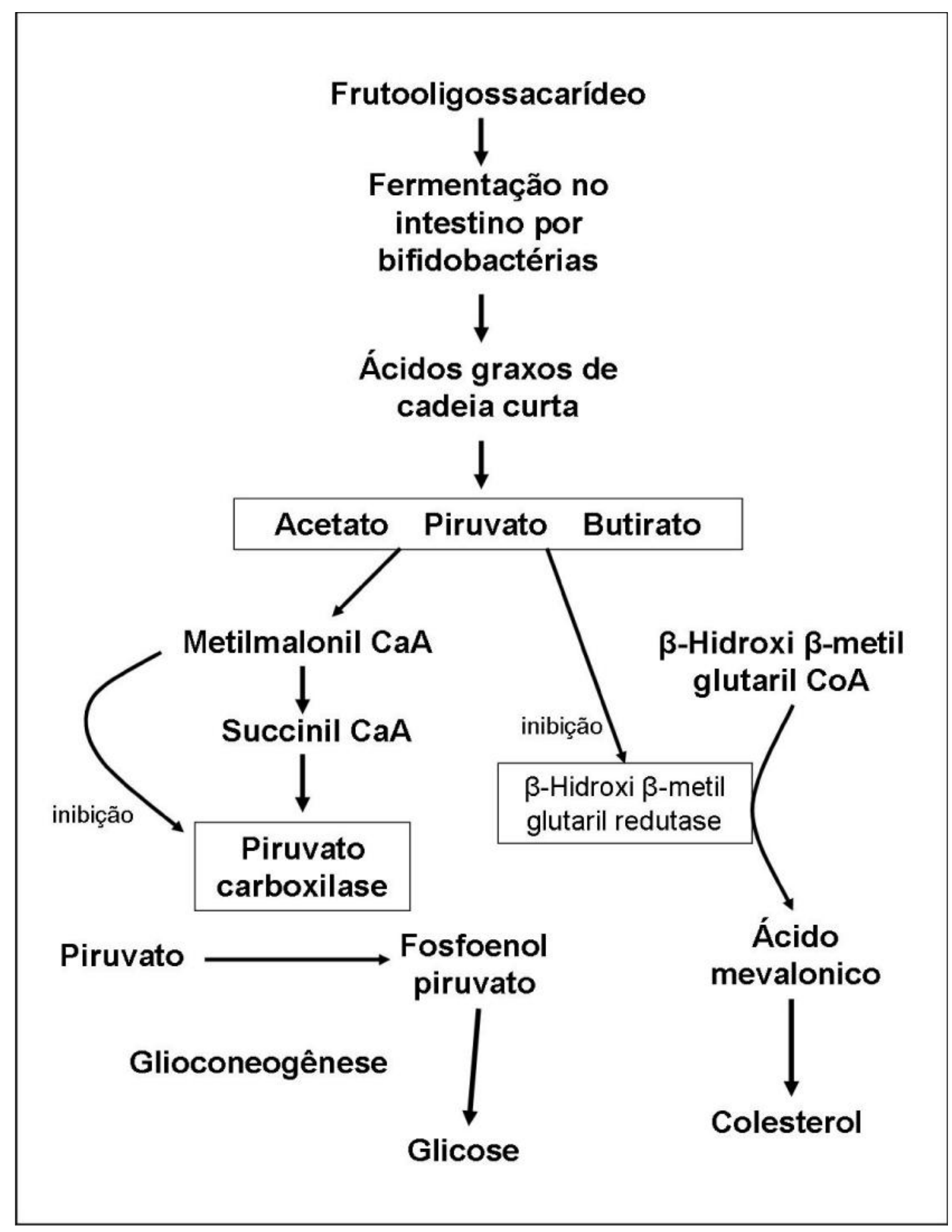

Figura 5 - Efeitos do FOS no metabolismo da glicose e do colesterol 
O frutooligossacarídeo (FOS) são oligossacarídeos de ocorrência natural em, principalmente produtos de origem vegetal. Atualmente FOS é o nome dado apenas a oligômeros de frutose e que podem ser divididos em dois grupos do ponto de vista comercial: o primeiro grupo é preparado por hidrólise enzimática da inulina e esse oligossacarídeo pode ser encontrado em grande variedade na natureza, principalmente em alcachofras, aspargos, beterraba, chicória, cebola, trigo e tomate, dentre outros. O segundo grupo é preparado por reação enzimática de transfrutosilação, em resíduos de sacarose (YOSHIKAWA et al., 2007).

Ambos os métodos de preparação proporcionam fermentação em ceco e cólon resultando em proliferação de bifidobactérias, prevenção de cáries dentárias, e redução dos níveis séricos de colesterol e lipídeos (KAUR et al., 2002; LESNIEWSKA et al., 2006; PASSOS et al., 2003).

Em estudos experimentais onde foi adicionado FOS em dieta padrão enriquecida com sacarose observou-se diminuição dos níveis séricos e hepáticos de triglicerídeos pela redução da síntese de ácidos graxos hepáticos (KOK et al., 1998).

\subsection{Considerações Gerais}

A história natural na doença hepática gordurosa ainda não é bem definida e acredita-se que possa variar de acordo com o tipo histológico da DHGNA (ZAMIN et al., 2002). 
Existem ainda muitas controvérsias tanto sobre a história natural quanto sobre o prognóstico da DHGNA, pois não são muitos os estudos prospectivos que contemplam pesquisas nessa área (PEREZ AGUILAR et al., 2004. REIS et al., 2001). Há diversos relatos e experimentos envolvendo o tratamento da esteatose hepática, porém os resultados são ainda conflitantes. Em relação aos nutrientes utilizados nesse trabalho há estudos que demonstram a eficácia, por exemplo, de próbióticos como o FOS na modulação dos níveis séricos de lipídeos, porém os mecanismos implicados nessa modulação ainda parecem obscuros.

Em relação à colina, sua deficiência acarreta em animais a esteatose hepática, porém ainda não se sabe se ela pode ser benéfica no tratamento da mesma causada por excesso dietético.

De qualquer maneira, é necessário mais pesquisas nessa área que possam contemplar a importância da esteatose hepática como entidade clínica. Entretanto, é concordante o fato de que embora essa doença tenha potencial para desenvolvimento de formas mais graves de doença hepática, seu curso é lento e insidioso.

\subsection{Modelos Animais de DHGNA}

Estudos em animais têm ajudado no conhecimento sobre os mecanismos fisiopatogênicos e terapêuticos de DHGNA. Atualmente existem vários modelos animais para estudar a DHGNA e EH, embora nenhum deles consiga reproduzir na totalidade, os componentes essenciais presentes na doença 
humana (LIEBER et al., 2004; NANJI, 2004).

Fatores ambientais como as dietas hipercalóricas ou deficientes em algum nutriente também são utilizadas para induzir DHGNA (DENTIN et al., 2006). A dieta deficiente em colina e metionina já é um modelo conhecido de indução de esteatose e esteatohepatite em animais de pequeno porte. A metionina é um aminoácido essencial não sintetizado pelo organismo e que deve, portanto, ser obtido através da alimentação. É essencial para a absorção, transporte e biodisponibilidade de lípides e atua também como agente lípotrófico na prevenção da formação de gordura em excesso no fígado. A colina, uma amina quaternária, é nutriente necessário para síntese de fosfolipídios como a esfingomielina e a fosfatidilcolina, essenciais na composição de todas as membranas celulares e de moléculas como lipoproteínas de baixíssima densidade (VLDL) (KOTEISH et al., 2003; NANJI, 2004).

Apesar de existirem estudos que representam um modelo clássico para indução de esteatose como as dietas com deficiência de metionina e colina (LIEBER et al., 2004; NANJI, 2004; OLIVEIRA et al., 2002), no presente estudo queríamos reproduzir uma dieta similar à ingerida pela população obesa, ou seja com alto teor de carboidratos (ALVES et al., 2006; SVEGLIATI-BARONI et al., 2006).

A hipótese do presente trabalho é de que a colina e o frutooligossacarídeo poderiam ser nutrientes para promover o tratamento da $\mathrm{EH}$, induzida por dieta hiperglicídica. 
2. OBJETIVOS

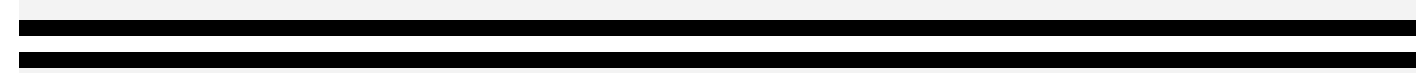




\subsection{Geral}

Avaliar a possibilidade de tratamento utilizando-se a colina e o frutooligossacarídeo, em ratos Wistar, submetidos previamente à indução de esteatose, por dieta hiperglicídica.

\subsection{Específicos}

1- Avaliar se a dieta hiperglicídica é um bom método de indução de esteatose hepática em ratos machos Wistar adultos.

2- Avaliar se a colina e o frutooligossacarídeo interferem nos níveis de triacilgliceróis e colesterol séricos, após indução de esteatose hepática.

3- Comparar os níveis de antioxidantes intrínsecos através dos níveis de glutationa reduzida e vitamina $\mathrm{E}$ no fígado de animais controle e de animais tratados com colina e frutooligossacarídeos, após indução de esteatose hepática com dieta hiperglicídica.

4- Comparar os níveis de peroxidação lipídica pela formação de malondialdeído no fígado de animais controle e de animais tratados com colina e frutooligossacarídeos, após indução de esteatose hepática por dieta hiperglicídica.

5- Avaliar pela histopatologia a presença de esteatose hepática após sua indução com dieta hiperglicídica e após tratamento com colina e frutooligossacarídeo. 
3. MATERIAL E MÉTODOS 
Este estudo foi aprovado pela Comissão de Ética no Uso de Animais de Experimentação (CEUA), da Faculdade de Medicina de Ribeirão Preto - USP.

\subsection{Delineamento Experimental}

Foram utilizados 46 ratos machos, da raça Wistar adultos com peso variando entre 250 - $320 \mathrm{~g}$, vindos do Biotério Central do Campus da USPRibeirão Preto e, posteriormente, mantidos no Biotério do Departamento de Clínica Médica da Faculdade de Medicina de Ribeirão Preto, USP. O regime de claro-escuro foi mantido constante, de 12 em 12 horas. Durante todo o experimento os animais foram mantidos em salas fechadas com ventilação natural, temperatura controlada de $24 \pm 2^{\circ} \mathrm{C}$, acomodados individualmente em gaiolas específicas com bebedouro e comedouro ou em gaiolas metabólicas (somente quando coletada amostra de urina). Para evolução do peso dos animais, foram realizadas pesagem pela manhã entre às 8 e 9 horas, 1 vez na semana, utilizando-se balança eletrônica, Filizola ${ }^{\circledR}$ capacidade máx. $1.5 \mathrm{~kg}$ graduada em 1 grama.

A partir de um lote inicial de 46 animais foram distribuídos de forma aleatória nos diferentes grupos de estudo de I a IV, dependendo da indução ou não da esteatose. Considerou-se fase I o período correspondente a indução de esteatose e fase II quando se submeteu os animais a suplementação com nutrientes (Grupos III e IV), ou quando os animais receberam dieta padrão pós fase I (Grupo II). Os animais do Grupo I 40 
(controle) receberam ração padrão do biotério que foi igual para todos os animais, sendo separado um lote da mesma ração para todo o experimento (Figura 6).

A utilizada no Grupo I é composta de $41.5 \%$ de carboidratos (milho integral moído), $22 \%$ de caseína, $4 \%$ de óleo de soja, $0.2 \%$ de colina; sendo o restante composto por mistura salina, vitamínica e aminoácidos como metionina e lisina.

Os animais dos Grupos II, III e IV (com esteatose induzida) receberam dieta hiperglicídica. A mesma foi preparada no Biotério da Clinica Médica do Campus da USP - Ribeirão Preto, a partir da mistura e homogeneização dos ingredientes ( $70 \%$ de açúcar; $16 \%$ de caseína; $7.8 \%$ de óleo de soja; $5 \%$ de mistura vitamínica; $1 \%$ de mistura salina e $0.2 \%$ de colina), utilizando-se o mesmo lote para os grupos. Foram seguidas as necessidades diárias de vitaminas e minerais da dieta AIN 93 (REEVES et al., 1993). O controle da ingestão da ração foi realizado diariamente e feito uma média ao final de cada semana.

Foram colhidos amostras de sangue (para análise de colesterol e triacilgliceróis) no dia zero (fase basal), $21^{\circ}$ dia (final da indução da esteatose)

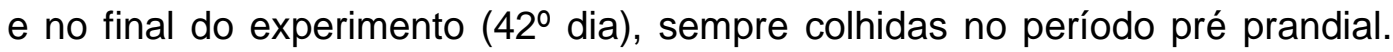
As amostras de urina foram colhidas ao final da fase I e fase II para análise de amônia e nitrogênio total. Para coleta urinária de 24 horas, os animais eram colocados em gaiolas metabólicas, sendo controladas a ingestão alimentar, bem como a diurese de $24 \mathrm{hs}$. Os tecidos hepático e cardíaco foram colhidos 
para avaliação histológica e bioquímica, no $21^{\circ}$ ou $42^{\circ}$ dia, mediante sorteio para o sacrifício. 


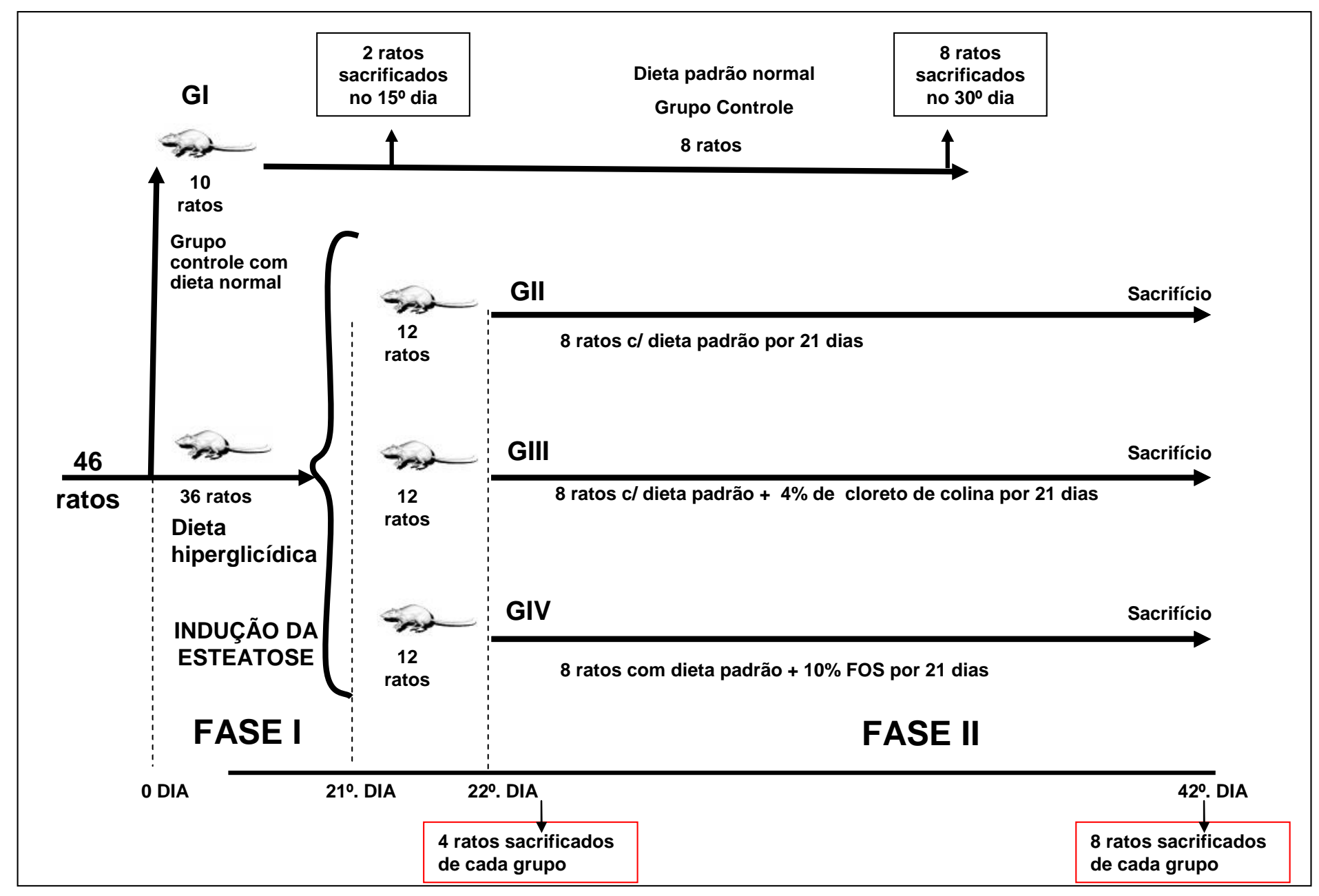

Figura 6 - Delineamento experimental 
Após o período experimental, todos os animais foram sacrificados por decapitação. A laparotomia, para retirada de vísceras, foi iniciada por uma incisão longitudinal mediana até a cavidade abdominal. A seguir foi coletado o fígado e coração conforme técnica previamente estabelecida no Biotério de Clínica Médica.

Grupo I (GI): com 10 animais alimentados com dieta padrão, por todo o período do experimento (30 dias). No final foi calculada a quantidade média de dieta ingerida diariamente. Dois desses animais foram sacrificados no $15^{\circ}$ dia (por sorteio, os animais 2 e 9) e os demais foram sacrificados no $30^{\circ}$ dia. Conseqüentemente, este grupo foi usado como Grupo controle.

Os 12 animais dos Grupos II, III e IV receberam dieta com $70 \%$ de sacarose por 21 dias. Quatro animais de cada grupo foram sacrificados, mediante sorteio, no $22^{\circ}$ dia. Os demais animais receberam dieta específica de acordo com o protocolo até o final do experimento.

Grupo II (GII): Após a fase de indução de esteatose (21 dias), esses animais seguiram até o final do experimento recebendo dieta padrão do Biotério.

Foram sacrificados após a fase I, os animais 2, 6, 7 e 11.

Esse grupo serviu de controle "negativo", pois não recebeu nutrientes específicos como os outros grupos (GIII e GIV). 
Grupo III (GIII): Após a fase de indução de esteatose (21 dias), esses animais continuaram até o final do experimento recebendo dieta padrão acrescida de $4 \%$ de cloreto de colina por 21 dias.

Foram sacrificados após a fase I, os animais 3, 5, 6 e 8.

Grupo IV (GIV): Após a fase de indução de esteatose (21 dias), esses animais permaneceram até o final do experimento recebendo dieta padrão acrescida de $10 \%$ de frutooligossacarídeo (Raftilose ${ }^{\circledR}$ P95 - Clariant S/A) por 21 dias.

Foram sacrificados após a fase I, os animais 4, 6, 9 e 10.

Obs.: Para as análises de ingestão alimentar e evolução de peso semanal dos animais dos Grupos II, III e IV, (quando comparou esses grupos com o Grupo controle) considerou-se a partir da terceira semana do experimento.

\subsection{Coleta do material biológico}

O sangue foi colhido e centrifugado a $2500 \mathrm{rpm} / 10$ min para separação do plasma, o qual foi armazenado em congelador a $-70^{\circ} \mathrm{C}$. Foram colhidas

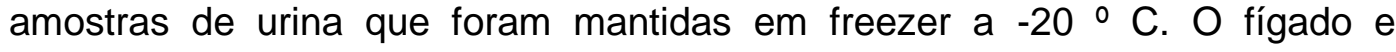
coração, após serem extraídos do animal, foram lavados em $\mathrm{NaCl} 0.9 \%$ (gelado) e pesados, sendo após destinados para as seguintes análises: 


\subsubsection{Dosagens bioquímicas}

Amostras do fígado (lobo direito) e coração foram pesadas, envolvidas em papel alumínio, colocadas em nitrogênio líquido e depois armazenadas em congelador a $-70^{\circ} \mathrm{C}$ para posteriores análises.

\subsubsection{Exames microscópicos}

\subsubsection{Inclusão de tecido em parafina}

Fragmentos cardíacos e do lobo direito hepático foram colhidos, seccionados em fatias de aproximadamente $3 \mathrm{~mm}$ de espessura, fixados em

formol tamponado 4\%, desidratados, diafanizados e incluídos em parafina (MENDLER et al., 2005). 


\subsection{Métodos}

\subsubsection{Análise Urinária}

\subsubsection{Nitrogênio Urinário - Piroquimioluminescência}

A técnica para análise do nitrogênio urinário (urina de 24 hs) utilizada foi a de piroquimioluminescência, aparelho Antek (720 e 771) Nitrogen Analyzers, Antek instruments, INC. Houston, USA, que envolve a pirólise oxidativa a uma temperatura de $1050^{\circ} \mathrm{C}$, a qual produz óxido nítrico (KONSTANTINIDES et al., 1988; SKOGERBOE et al., 1990).

O óxido nítrico é carreado para a câmara e misturado com ozônio, produzindo dióxido de nitrogênio instável. Esta instabilidade resulta no comprimento de onda específico, que emite uma luz diretamente proporcional a quantidade de nitrogênio da amostra mensurada por tubo fotomultiplicador. As reações de piroquimioluminescência são as sequintes:

\section{$\mathrm{R}-\mathrm{N}+\mathrm{O2} \rightarrow \mathrm{CO} 2+\mathrm{H} 2 \mathrm{O}+\mathrm{NO}$ \\ $\mathrm{NO}+03 \rightarrow \mathrm{N} 02+02$ \\ $\mathrm{NO2} \rightarrow \mathrm{NO}+\mathrm{hv}^{*}$}

Onde R é cadeia carbônica da amostra *comprimento de onda emitido da amostra.

As amostras de urina foram diluídas 1:200 com $100 \mathrm{mmollL} \mathrm{HCl}$. A leitura encontrada no aparelho foi comparada à uma curva padrão previamente estabelecida, com seguintes concentrações $0.5 ; 1.0 ; 1.5 ; 2.5 ; 4.0$ e 5.0 mmol/L de nitrogênio (Figura 7). 


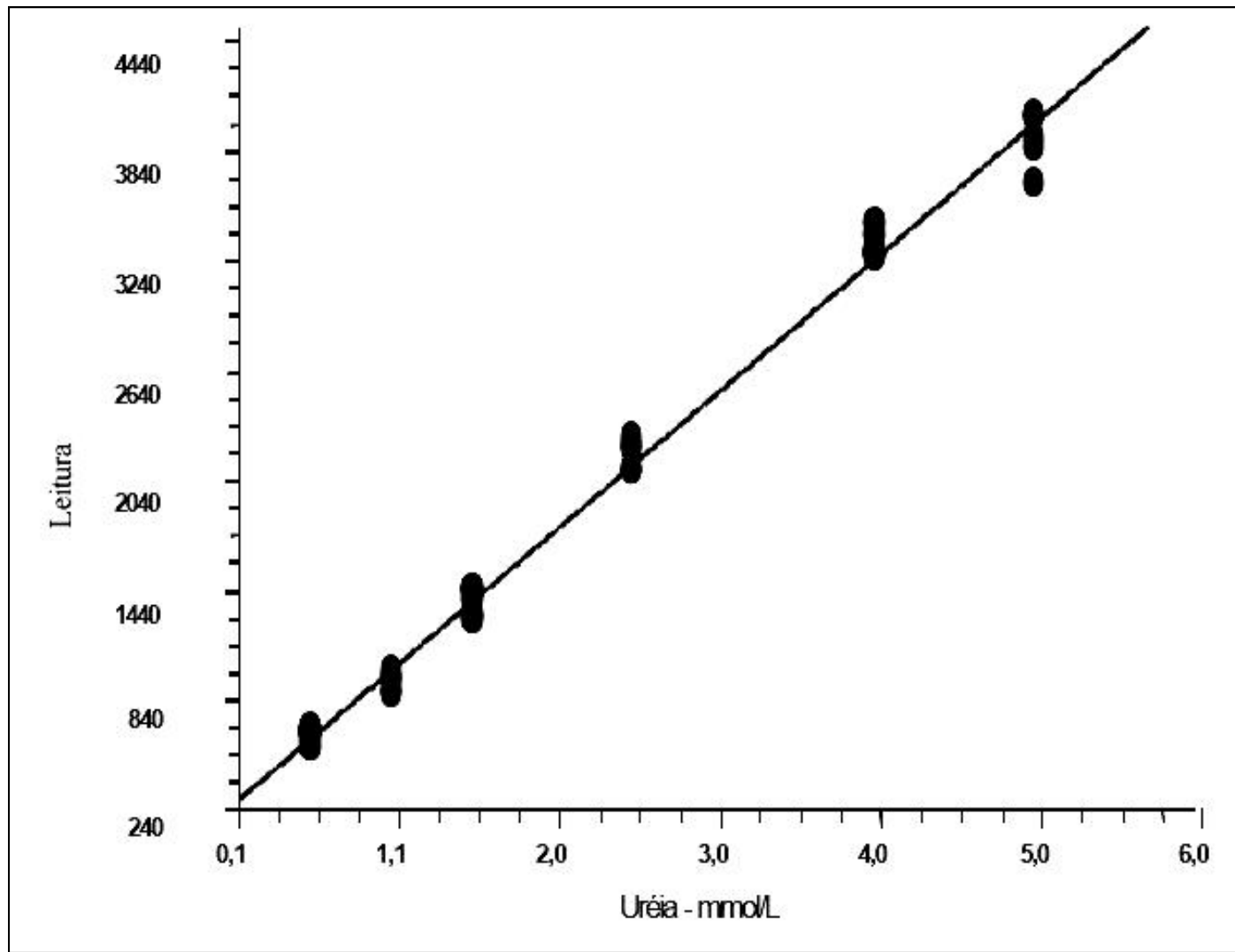

Figura 7 - Curva de calibração para metodologia de análise de nitrogênio urinário por piroquimioluminescência 


\subsubsection{Amônia Urinária}

O método de microdifusão Conway (1935) para determinação de amônia consiste na liberação da amônia pela alcalinização de $3 \mathrm{ml}$ de urina colocada na parte externa do disco de Conway com $2 \mathrm{ml}$ de carbonato de potássio saturado. Em pH alcalino a amônia é liberada e estando num recipiente fechado esta amônia volátil é absorvida pelos $2 \mathrm{ml}$ de ácido sulfúrico, presente na parte interna do disco de Conway. A amostra de amônia recolhida no ácido sulfúrico é destilada por arraste a vapor, sendo o meio neutralizado com $\mathrm{NAOH}$ a $50 \%$ na presença do indicador fenolftaleína. No final na destilação a amônia é recolhida em ácido bórico sendo o produto resultante titulado com ácido sulfúrico. Na titulação é utilizado o indicador mazuazaga, que é uma mistura do verde de bromocresol e vermelho de metila. Deste modo determina-se a quantidade total de nitrogênio proveniente da amônia urinária (MARCHINI et al., 2001).

No presente trabalho a amônia foi extraída de uma mesma amostra de urina de 24 horas, de um animal, sendo essa urina previamente acidificada pela adição de ácido clorídrico 1N. (CONWAY, 1935). 


\subsubsection{Análise bioquímica do sangue}

O colesterol total (CT) foi dosado usando o método automatizado calorimétrico, com o equipamento BT $3.000^{\circledR}$ plus Wiener lab. segundo método descrito por Stadtman em 1957.

A dosagem de triacilgliceróis (triglicerídeos -TGL) foi realizada utilizandose o método automatizado calorimétrico, através da hidrólise enzimática produzindo glicerol e ácidos graxos. O glicerol oxida-se com ácido periódico a formaldeído, o qual é quantificado como 3.5 diacetil-1.44 düdrolutidina, de acordo com Soloni (1971). O equipamento utilizado foi BT $3.000^{\circledR}$ plus Wiener lab. 


\subsubsection{Análise tecidual}

\subsubsection{Nitrogênio tecidual}

As amostras foram inicialmente descongeladas, pesadas e desidratadas em estufa a $100^{\circ} \mathrm{C}$ por $24 \mathrm{hs}$.

Após a estabilização da temperatura pesou-se novamente a amostra após o processo de desidratação.

Posteriormente procedeu-se a maceração, identificação e acondicionamento do material em estufa a $50{ }^{\circ} \mathrm{C}$, para início da dosagem da amostra.

Foram pesadas amostras em duplicata em balança de precisão, em torno de $0.02 \mathrm{~g}$ a $0.05 \mathrm{~g}$, sendo posteriormente transferidas para o tubo de ensaio e seguiu-se o método de Micro-Kjeldahl para dosagem de nitrogênio tecidual.

O método de Micro-Kjeldahl foi utilizado para determinar o nitrogênio em amostras teciduais. Tal método consiste de uma digestão ácida, onde o nitrogênio da amostra é transformado em amônio (NH4), o qual é posteriormente separado por destilação e finalmente dosado pela titulação. Neste método determina-se o nitrogênio total contido na amostra, incluindo o nitrogênio protéico propriamente dito e outros compostos nitrogenados não protéicos, tais como: aminas, amidas, lecitinas, aminoácidos e outros (AOAC, 1995).

\section{Técnica}

1. Pesar ou medir quantidades adequadas de amostra, que deve constar aproximadamente: $1 \mathrm{mg}$ de nitrogênio 
2. Transferir para um tubo de digestão de $50 \mathrm{ml}$ e adicionar $2 \mathrm{ml}$ de ácido sulfúrico concentrado e 3 gotas de solução 5\% de dióxido de selênio.

3. Aquecer brandamente no início e aumentar gradativamente até completar a digestão

Material orgânico

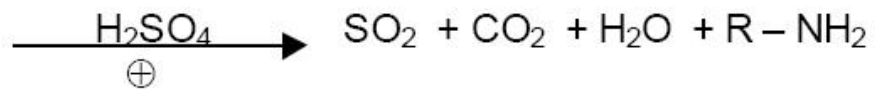

$\mathrm{R}-\mathrm{NH}_{2}+\mathrm{H}_{2} \mathrm{O}$

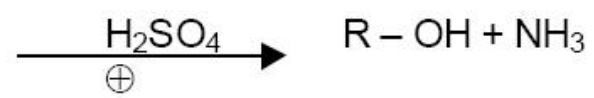

$\mathrm{R}-\mathrm{CO}-\mathrm{NH}_{2}+\mathrm{H}_{2} \mathrm{O}$

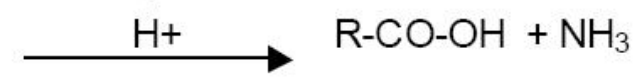

$2 \mathrm{NH}_{3}+\mathrm{H}_{2} \mathrm{SO}_{4}$ $\left(\mathrm{NH}_{4}\right)_{2} \mathrm{SO}_{4}$

Onde R é a cadeia carbônica da amostra

$\oplus$ aquecimento

\section{Esfriar à temperatura ambiente}

5. Transferir a solução para o destilador, juntamente com a água de lavagem. Adicionar corante fenolftaleína $1 \%$ e $\mathrm{NaOH} 50 \%$ em excesso, ou seja:

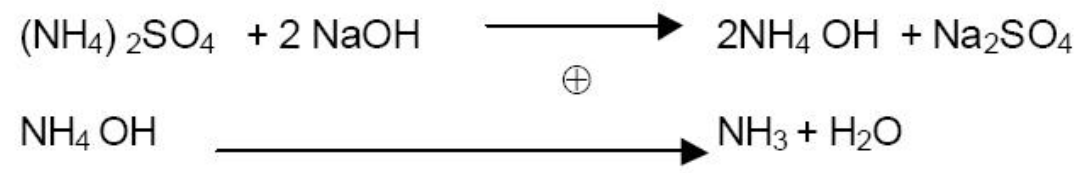

6. Recolher o destilado em um Erlenmeyer de $50 \mathrm{ml}$ com $5 \mathrm{ml}$ de ácido bórico a 4\% e 3 gotas de Mazuazaga (verde bromocresol e vermelho de metila) como indicador de mudança de cor.

$$
\mathrm{NH}_{3}+\mathrm{H}_{2} \mathrm{BO}_{3} \longrightarrow \mathrm{NH}_{4} \mathrm{H}_{3} \mathrm{BO}_{3}
$$

7. Titular com ácido sulfúrico $0.1 \mathrm{~N}$ até cor caramelo e anotar o volume gasto em $\mathrm{ml}$. 


$$
\mathrm{NH}_{4}^{+}+\mathrm{H}_{2} \mathrm{BO}_{3}+\mathrm{H}_{2} \mathrm{SO}_{4} \longrightarrow \mathrm{H}_{3} \mathrm{BO}_{3}\left(\mathrm{NH}_{4}\right)_{2} \mathrm{SO}_{4}
$$

8. Cálculo:

$$
\mathrm{g} \% \text { nitrogênio }=\frac{(\text { vol. encontrado da titulação }- \text { vol. branco }) \times \text { F.C }}{\text { vol. da amostra utilizada }}
$$

F.C: Fator de Cálculo (concentração de nitrogênio do sulfato de amônia em relação a concentração de acido sulfúrico $0.001 \mathrm{~N}$ ): 0.1574 . 


\subsubsection{Gordura tecidual total}

A técnica que foi utilizada para análise da gordura total no fígado e coração foi o método de extração de gordura aparelho Soxhlet $M A^{\circledR}-487 / 6 / 250$ (Feldsine et al., 2002). O método é baseado em três etapas: extração da gordura da amostra com solvente, eliminação do solvente por evaporação e a gordura extraída é quantificada por pesagem (Figura 8).

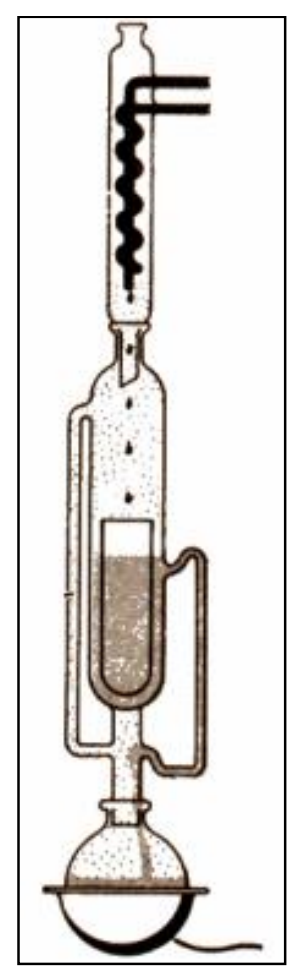

Figura 8 - Extrator de Soxlet 


\subsubsection{Análise do estresse oxidativo}

\subsubsection{Determinação de substâncias reativas ao ácido tiobarbitúrico (SRATB)}

Os níveis de peroxidação lipídica foram medidos por um método baseado na quantificação de substâncias reativas ao ácido tiobarbitúrico no plasma. Foi avaliada, por meio de espectrofotômetro (DU ${ }^{\circledR} 640$ - Beckman, USA) a coloração rosa produzida pela reação do ácido tiobarbitúrico com o malondialdeído (MDA), um subproduto da peroxidação lipídica. A dosagem de SRATB foi realizada de acordo com o método descrito por Buege e Aust (1979).

\subsubsection{Determinação tecidual de vitamina $E$}

As análises teciduais de vitamina E, em amostras de fígado e coração, foram realizadas por meio de HPLC (Cromatografia Líquida de Alta Eficiência), segundo Arnaud et al. (2003), com modificações. As condições cromatográficas utilizadas para as análises foram: cromatógrafo líquido de alta eficiência (Shimadzu, modelo LC10A) com sistema isocrático, detector espectrofotométrico (UV- visível, Shimadzu, modelo SPD - 10AV). O comprimento de onda para leitura foi de $292 \mathrm{~nm}$, utilizando coluna de fase reversa tipo ODS (C18) com $25 \mathrm{~cm}$ de comprimento e $4.6 \mathrm{~mm}$ de diâmetro interno. A fase móvel foi composta por acetonitrila, diclorometano e metanol numa proporção de 70:20:10. O fluxo da fase móvel foi de $1.0 \mathrm{ml} / \mathrm{min}$.

Para cada análise de tecido foi utilizado cerca de 0.5 de fígado homogeneizado em $2 \mathrm{~mL}$ de etanol, com o auxílio de um Politron manual (Post- 
mounted Homogenizer, OMNI 2000. EUA). Em seguida, foram adicionados 2 $\mathrm{mL}$ de $\mathrm{n}$-hexano e a amostra agitada por 2 minutos, em agitador de tubos (modelo 251. FANEM). A seguir foi feita a centrifugação por 10 minutos a $3000 \mathrm{rpm}$. Foi retirado $0.5 \mathrm{~mL}$ do sobrenadante e o $\mathrm{n}$-hexano foi evaporado sob fluxo de nitrogênio. Após a ressuspensão da amostra em $0.5 \mathrm{~mL}$ de fase móvel e filtração, uma alíquota de $100 \mu$ foi injetada no HPLC. Os resultados finais foram expressos em $\mu \mathrm{mol} / \mathrm{g}$ de tecido.

\subsubsection{Glutationa reduzida}

A dosagem de glutationa reduzida (GSH) foi realizada de acordo com método descrito por Sedlack e Lindsay (1968). Duzentos miligramas de fígado foram homogeneizados em um Potter com $8 \mathrm{~mL}$ de tampão EDTA (0.02M), sob gelo. Deste homogeneizado, $5 \mathrm{ml}$ foram retirados a $4 \mathrm{~mL}$ de água deionizada e $1 \mathrm{~mL}$ de ácido tricloroacético $50 \%$. Após 15 minutos de espera, agitando ocasionalmente, o tubo foi centrifugado por 15 minutos a $400 \mathrm{rpm}$. Do sobrenadante resultante, foram retirados $2 \mathrm{~mL}$ e a estes foram adicionados 4 $\mathrm{mL}$ de tampão TRIS $0.4 \mathrm{M}$ ( $\mathrm{ph}=4.8$ ) e $0.1 \mathrm{~mL}$ de DTNB $0.01 \mathrm{M}$ em metanol. A leitura foi feita no comprimento de onda de 412 nm, 5 minutos após adição do DTNB, tendo como parâmetro de comparação a cor do EDTA 0.02M, no lugar do sobrenadante. A concentração de GSH foi calculada baseando-se em curva padrão de GSH em EDTA 0.02M. 


\subsubsection{Histopatologia}

Fragmentos de tecidos hepático e cardíaco foram incluídos em parafina, cortados (espessura de $4 \mu \mathrm{m}$ ) e corados com HE (Hematoxilina de Harris e Eosina), com a finalidade de avaliar semi-quantitativamente a esteatose hepática, utilizando um microscópio de luz convencional (400x).

A esteatose foi classificada de acordo com a quantidade hepatócitos acometidos por vacúolos de gordura, conforme a seguir: ausência de esteatose, $25 \%$ dos hepatócitos acometidos, até $50 \%$, $75 \%$ e mais que $75 \%$ (BRUNT et al., 2003; KLEINER et al., 2005).

\subsubsection{Análise Estatística}

Os dados foram expressos em médias e desvio-padrão. As diferenças estatísticas entre os grupos foram determinadas utilizando Modelo Misto e diferenças estatísticas intra grupos foram determinadas através de Método Não Paramétrico de Univariância (ANOVA). Consideraram-se significativos valores de $p<0.05$. Para a análise dos dados utilizou-se o Programa Sas. 9.1. 
Material e Métodos 5

4. RESULTADOS 


\subsection{Ingestão alimentar semanal}

A média de ingestão diária dos animais do Grupo I foi de 195 gramas; do Grupo II de 145 gramas; Grupo III 155 gramas e Grupo IV 156 gramas.

Os animais do Grupo II tiveram maior ingestão na fase de tratamento do que na indução da esteatose, com $p<0.05$, o mesmo não ocorrendo nos demais Grupos (Tabela 4).

Observou-se que, em geral, a média da ingestão alimentar dos animais do Grupo controle foi superior a ingestão dos animais dos demais grupos (Tabela $5)$.

Tabela 4 - Valores de média e desvio padrão da ingestão alimentar (em gramas) dos grupos e comparação dos mesmos nas fases I e II

\begin{tabular}{ccccc}
\hline Grupo & controle & fase I & fase II & comparação \\
\hline I & $196 \pm 29$ & - & - & - \\
II & - & $140 \pm 22$ & $152 \pm 21$ & fase I - fase II * \\
III & - & $152 \pm 21$ & $159 \pm 25$ & fase I - fase II \\
IV & - & $160 \pm 20$ & $153 \pm 22$ & fase I - fase II \\
\hline
\end{tabular}

fase I: Indução da esteatose

fase II:Tratamento

${ }^{*} \mathrm{p}<0.05$ 
Tabela 5 - Comparações entre as médias dos grupos segundo a ingestão alimentar semanal ( em gramas)

\begin{tabular}{ccc}
\hline Comparações & $\begin{array}{c}\text { Média do } \\
\text { Grupo I }\end{array}$ & $\begin{array}{c}\text { Média de cada } \\
\text { grupo }\end{array}$ \\
\hline Semana I (Grupo I - Grupo II) * & 175 & 143 \\
(Grupo I - Grupo III) * & 175 & 154 \\
(Grupo I - Grupo IV) & 175 & 160 \\
\hline Semana II (Grupo I - Grupo II) * & 181 & 148 \\
(Grupo I - Grupo III) * & 181 & 138 \\
(Grupo I - Grupo IV) * & 181 & 150 \\
\hline Semana III (Grupo I - Grupo II) * & 213 & 175 \\
(Grupo I - Grupo III) * & 213 & 187 \\
(Grupo I - Grupo IV) * & 213 & 154 \\
\hline Semana IV (Grupo I - Grupo II) * & 213 & 134 \\
(Grupo I - Grupo III) * & 213 & 152 \\
(Grupo I - Grupo IV) * & 213 & 154 \\
\hline
\end{tabular}

Obs.: * $\mathrm{p}<0.05$

Semana I = fase final da indução da esteatose dos Grupos II, III e IV.

Semana II = primeira semana da fase II

Semana III = segunda semana da fase II

Semana IV = terceira semana da fase II 


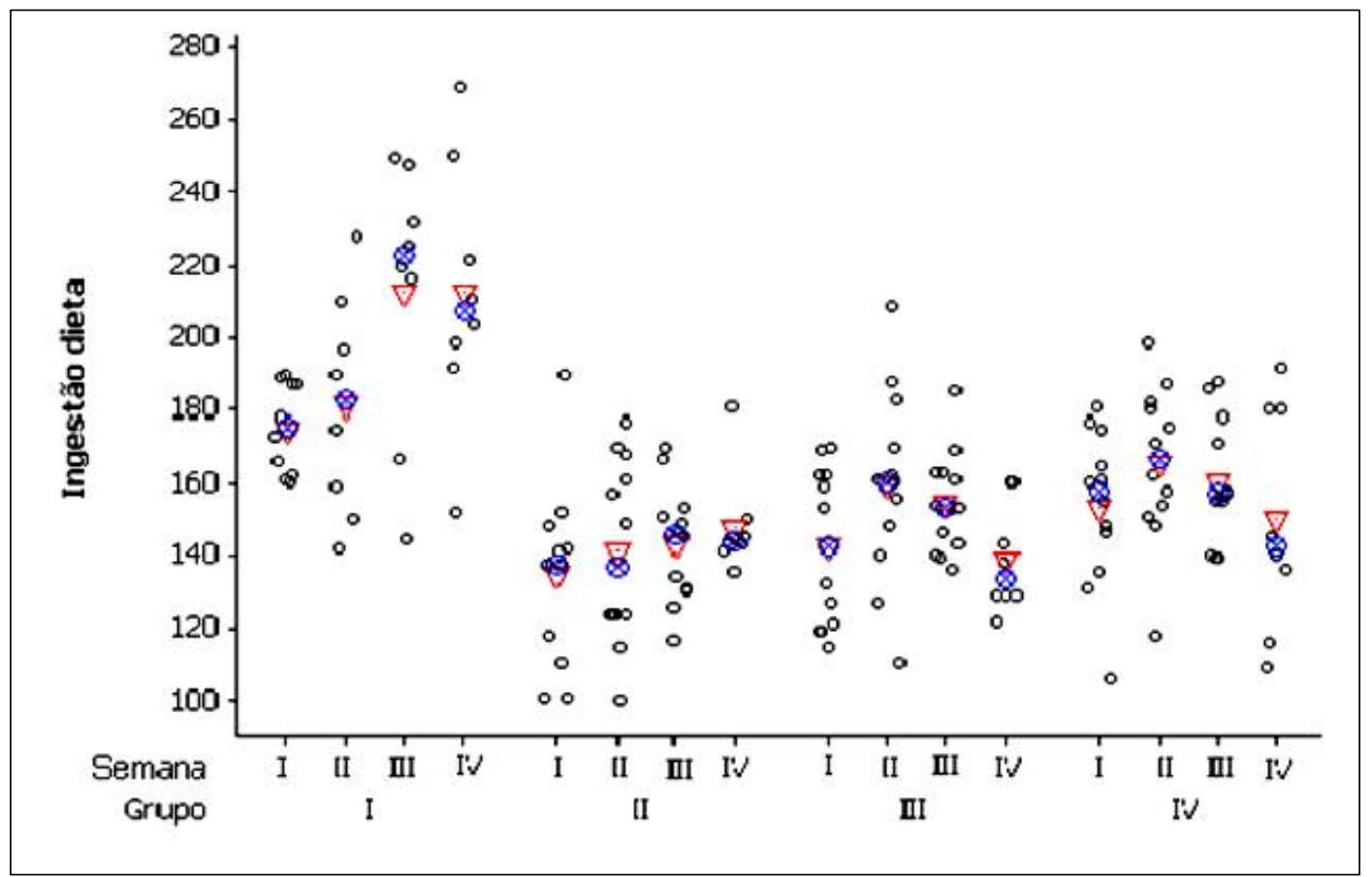

Figura 9 - Comparações entre os grupos segundo a ingestão alimentar semanal (em gramas)

Obs.:

Grupo I - 4 semanas dieta padrão.

Grupo II - indução de esteatose 3 semanas +3 semanas de tratamento com dieta padrão. Grupo III - indução de esteatose 3 semanas + 3 semanas de tratamento com dieta padrão acrescida de colina.

Grupo IV - indução de esteatose 3 semanas + 3 semanas de tratamento com dieta padrão acrescida de FOS.

O triângulo representa a média.

O círculo representa a mediana. 


\subsection{Evolução do peso dos animais}

Foi estatisticamente significante o ganho de peso dos animais de todos os grupos do início ao término do experimento (Tabela 6).

Observou-se que os animais do Grupo II, III e IV evoluíram com ganho de peso com $p<0.05$ principalmente nas primeiras semanas do experimento. Nas duas últimas semanas, porém, não houve diferenças significativas entre o ganho de peso quando se compara os grupos que receberam nutrientes (Grupo III e IV ) e o Grupo controle (Tabela 7).

Tabela 6 - Valores de média e desvio padrão da evolução do peso (em gramas) dos grupos e comparação dos mesmos nas fases I e II

\begin{tabular}{|c|c|c|c|c|}
\hline Grupo & controle & fase I & fase II & comparação \\
\hline I & $354 \pm 16$ & - & - & $\begin{array}{l}\text { Início - Final do } \\
\text { experimento * }\end{array}$ \\
\hline II & - & $344 \pm 28$ & $409 \pm 51$ & fase I-fase II * \\
\hline III & - & $356 \pm 40$ & $403 \pm 42$ & fase I-fase II * \\
\hline IV & - & $348 \pm 27$ & $385 \pm 57$ & fase I-fase II * \\
\hline
\end{tabular}

fase I: Indução da esteatose fase II:Tratamento ${ }^{*} p<0.05$ 
Tabela 7 - Comparações entre as médias dos grupos segundo a evolução de peso semanal (em gramas)

\begin{tabular}{rcc}
\hline Comparações & $\begin{array}{c}\text { Média do } \\
\text { Grupo I }\end{array}$ & $\begin{array}{c}\text { Média de cada } \\
\text { grupo }\end{array}$ \\
\hline Semana I (Grupo I - Grupo II) * & 318 & 385 \\
$($ Grupo I - Grupo III) * & 318 & 399 \\
$\left(\right.$ Grupo I - Grupo IV) ${ }^{*}$ & 318 & 391 \\
\hline Semana II (Grupo I - Grupo II) * & 346 & 393 \\
$($ Grupo I - Grupo III) * & 346 & 400 \\
$\left(\right.$ Grupo I - Grupo IV) ${ }^{*}$ & 346 & 383 \\
\hline Semana III (Grupo I - Grupo II) & 370 & 404 \\
$($ Grupo I - Grupo III) & 370 & 403 \\
$($ Grupo I - Grupo IV) & 370 & 381 \\
\hline Semana IV (Grupo I - Grupo II) * & 381 & 430 \\
$($ Grupo I - Grupo III) & 381 & 405 \\
$($ Grupo I - Grupo IV) & 381 & 389 \\
\hline
\end{tabular}

Obs.: ${ }^{*} \mathrm{p}<0.05$

Semana I = fase final da indução da esteatose dos Grupos II, III e IV.

Semana II = primeira semana da fase II

Semana III = segunda semana da fase II

Semana IV = terceira semana da fase II 


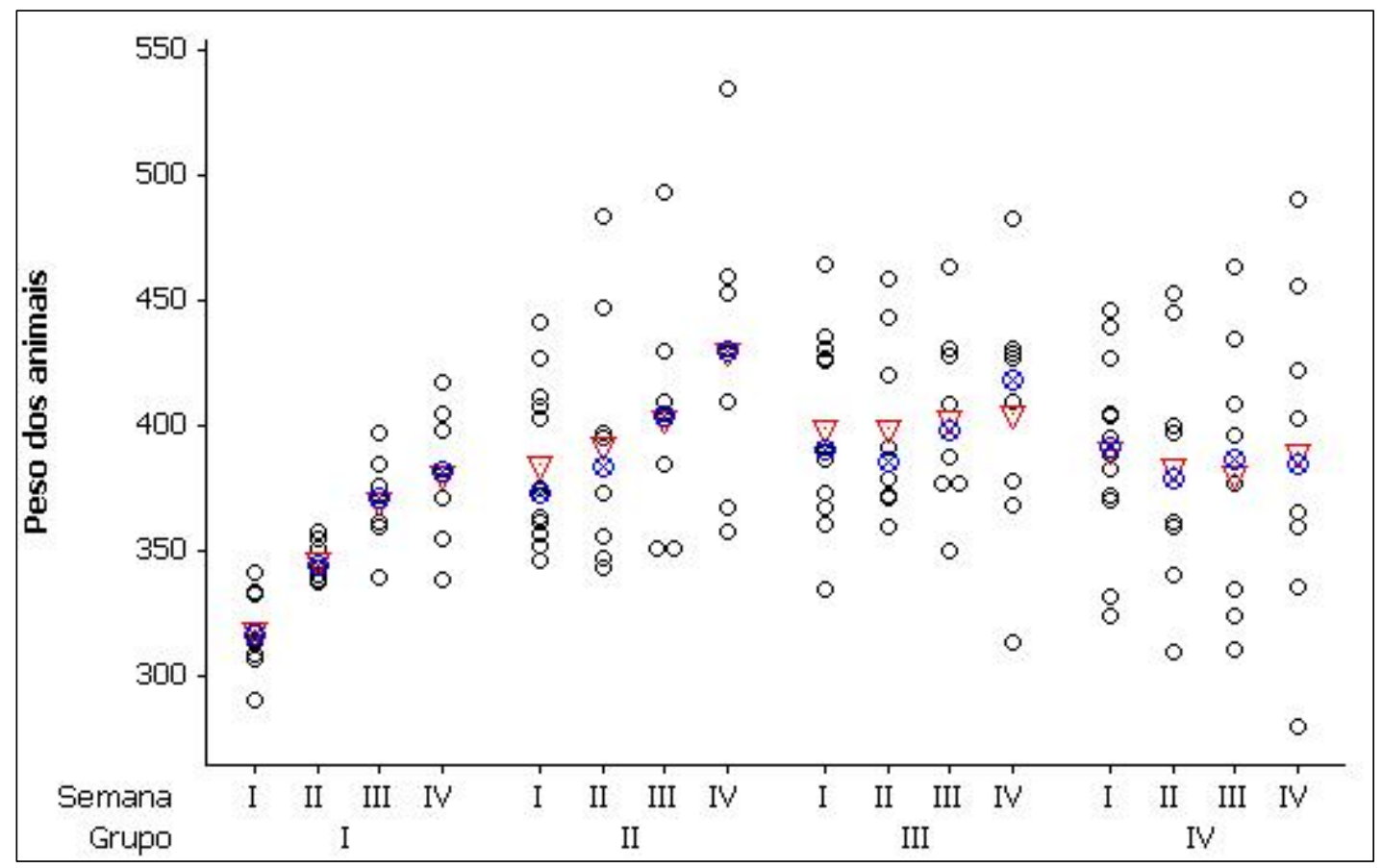

Figura 10 - Comparações entre os grupos segundo a evolução de peso semanal (em gramas)

Obs.:

Grupo I - 4 semanas dieta padrão.

Grupo II - indução de esteatose 3 semanas +3 semanas de tratamento com dieta padrão. Grupo III - indução de esteatose 3 semanas + 3 semanas de tratamento com dieta padrão acrescida de colina.

Grupo IV - indução de esteatose 3 semanas + 3 semanas de tratamento com dieta padrão acrescida de FOS.

O triângulo representa a média.

O círculo representa a mediana. 


\subsection{Análise do nitrogênio urinário}

Observou-se diminuição na dosagem de nitrogênio urinário excretado nos Grupos II, III e IV na fase de tratamento em relação ao Grupo controle. Porém quando se compara as fases do experimento não se observou diferença estatística (Tabela 8 ).

Tabela 8 - Valores de média e desvio padrão do nitrogênio urinário $\left(\mathrm{gN}_{2} /\right.$ volume total / 24 hs) dos grupos e comparação intra e intergrupos

\begin{tabular}{cccccc}
\hline Grupo & controle & fase I & fase II & \multicolumn{2}{c}{ comparação } \\
\hline I & $0.32 \pm 0.08$ & - & - & - & - \\
II & - & $0.13 \pm 0.08$ & $0.22 \pm 0.10$ & fase I - fase II • fase II GII - G I * * \\
III & - & $0.13 \pm 0.10$ & $0.06 \pm 0.02$ & fase I-fase II • fase II GIII - G I * * \\
IV & - & $0.20 \pm 0.25$ & $0.21 \pm 0.08$ & fase I-fase II & fase II GIV - G I * * \\
\hline
\end{tabular}

- Comparação entre as médias das fases

$¥$ Comparação entre as médias dos grupos na fase de tratamento e a média do grupo controle ${ }^{*} p<0.05$

fase I: Indução da esteatose

fase II:Tratamento 


\subsection{Análise da amônia urinária}

Não foi observada diferença estatística quando se comparou os grupos com o Grupo controle, na fase de tratamento. Quando se comparou as fases, dentro de um mesmo grupo, observou-se aumento da excreção urinária de amônia somente no Grupo III (Tabela 9).

Tabela 9 - Valores de média e desvio padrão da amônia urinária $\left(\mathrm{gN}_{2}\right.$ / volume total / 24 hs) dos grupos e comparação intra e intergupos

\begin{tabular}{cccccc}
\hline Grupo & controle & fase I & fase II & \multicolumn{2}{c}{ comparação } \\
\hline I & $0.030 \pm 0.06$ & - & - & - & - \\
II & - & $0.016 \pm 0.007$ & $0.016 \pm 0.008$ & fase I - fase II • fase II GII - G I $¥$ \\
III & - & $0.012 \pm 0.009$ & $0.040 \pm 0.020$ & fase I - fase II * * fase II GIII - G I¥ \\
IV & - & $0.011 \pm 0.008$ & $0.021 \pm 0.006$ & fase I - fase II • & fase II GIV - G I $¥$
\end{tabular}

- Comparação entre as médias das fases

$¥$ Comparação entre as médias dos grupos na fase de tratamento e a média do grupo controle ${ }^{*} \mathrm{p}<0.05$

fase I: Indução da esteatose

fase II:Tratamento 


\subsection{Análise do colesterol total e triacilgliceróis séricos}

\subsubsection{Colesterol total}

Observou-se uma redução estatisticamente significativa no colesterol total do Grupo IV tratado com FOS, quando se comparou com os valores basais e com Grupo controle (Tabela 10).

Tabela 10 - Valores de média e desvio padrão do colesterol total (mg / dL) dos grupos e comparação intra e intergupos

\begin{tabular}{ccccccc}
\hline $\begin{array}{c}\text { Grup } \\
\text { O }\end{array}$ & $\begin{array}{c}\text { control } \\
\mathbf{e}\end{array}$ & basal & fase I & fase II & \multicolumn{2}{c}{ comparação } \\
\hline I & $73 \pm 11$ & - & - & - & - & - \\
II & - & $71 \pm 11$ & $63 \pm 12$ & $65 \pm 14$ & basal-fasell • * & fase II GII-G I $¥$ \\
III & - & $68 \pm 9$ & $64 \pm 11$ & $73 \pm 13$ & basal-fasell • & fase II GIII-G I $¥$ \\
IV & - & $67 \pm 10$ & $60 \pm 9$ & $56 \pm 11$ & basal-fasell • * & fase II GIV-G I $¥$ * \\
\hline
\end{tabular}

- Comparação entre as médias das fases

$¥$ Comparação entre as médias dos grupos na fase de tratamento e a média do grupo controle ${ }^{*} p<0.05$

fase I: Indução da esteatose

fase II:Tratamento 


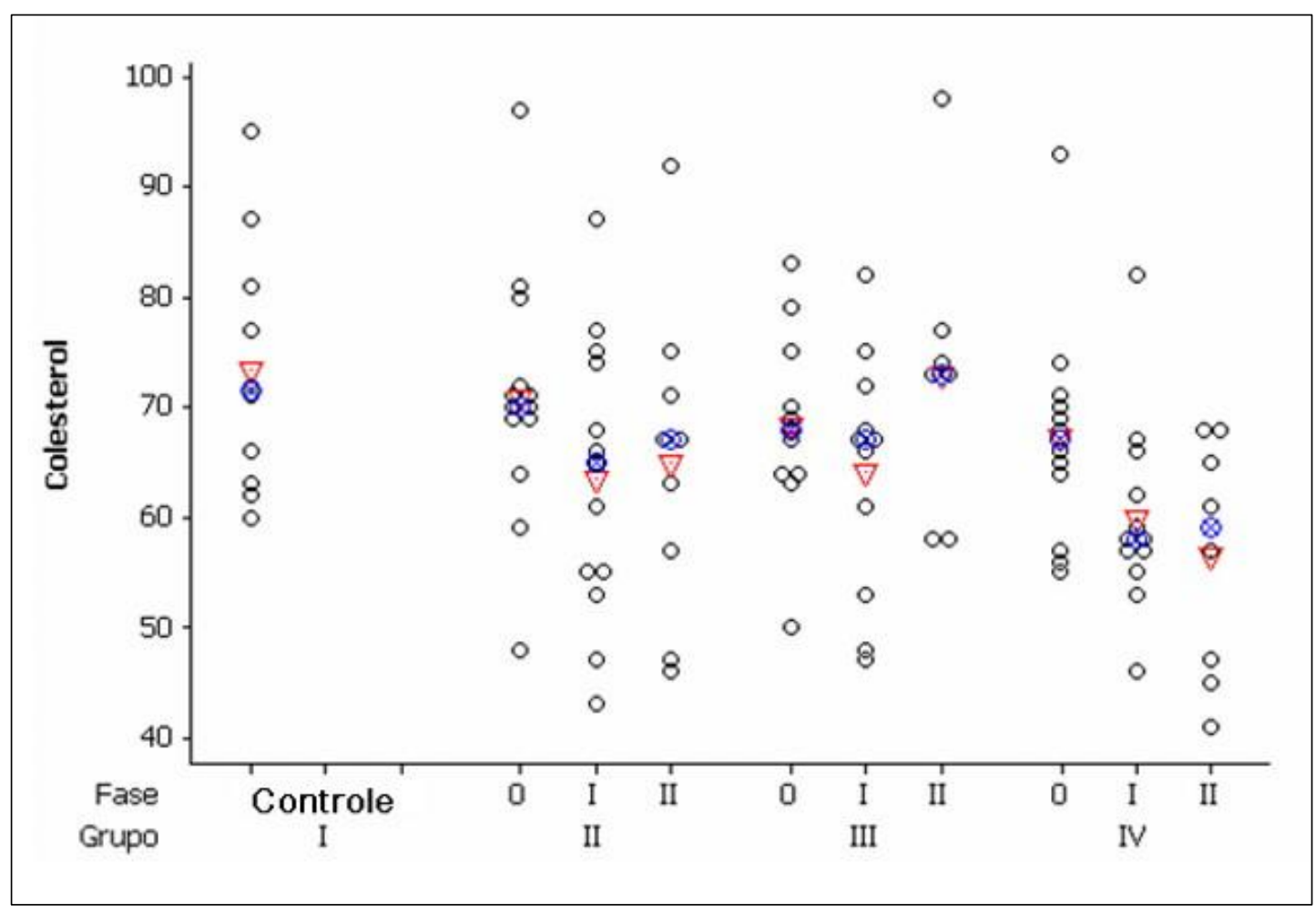

Figura 11 - Comparações entre os grupos e entre as fases segundo a dosagem de colesterol total $(\mathrm{mg} / \mathrm{dL})$

Obs.:

fase 0: coletada na fase basal

fase I: coletada ao término da fase I

fase II: coletada ao término da fase II

Obs.:

Grupo I - 4 semanas dieta padrão

Grupo II - indução de esteatose 3 semanas +3 semanas de tratamento com dieta padrão Grupo III - indução de esteatose 3 semanas +3 semanas de tratamento com dieta padrão acrescida de colina

Grupo IV - indução de esteatose 3 semanas + 3 semanas de tratamento com dieta padrão acrescida de FOS

O triângulo representa a média.

O círculo representa a mediana. 


\subsubsection{Triacilgliceróis séricos}

Observou-se uma redução dos níveis de triacilgliceróis séricos nos animais, da fase II para a basal estatisticamente significativa em todos os grupos. Quando se compara os grupos com o controle também se encontra $p<0.05$ em todos os grupos (Tabela 11).

Tabela 11 - Valores de média e desvio padrão do triacilgliceróis sérico (mg / $\mathrm{dL}$ ) dos grupos e comparação intra e intergrupos

\begin{tabular}{ccccccc}
\hline Grupo & controle & basal & fase I & fase II & \multicolumn{2}{c}{ comparação } \\
\hline I & $80 \pm 22$ & - & - & - & - & - \\
II & - & $104 \pm 33$ & $75 \pm 38$ & $50 \pm 10$ & basal-fasell • * & fase II GII-G I $*$ * \\
III & - & $112 \pm 33$ & $63 \pm 27$ & $46 \pm 8$ & basal-fasell • * & fase II GIII-G I ¥ * \\
IV & - & $115 \pm 30$ & $64 \pm 28$ & $51 \pm 17$ & basal-fasell • * & fase II GIV-G I $*$ * \\
\hline
\end{tabular}

- Comparação entre as médias das fases

¥ Comparação entre as médias dos grupos na fase de tratamento e a média do grupo controle ${ }^{*} p<0.05$

fase I: Indução da esteatose

fase II:Tratamento 


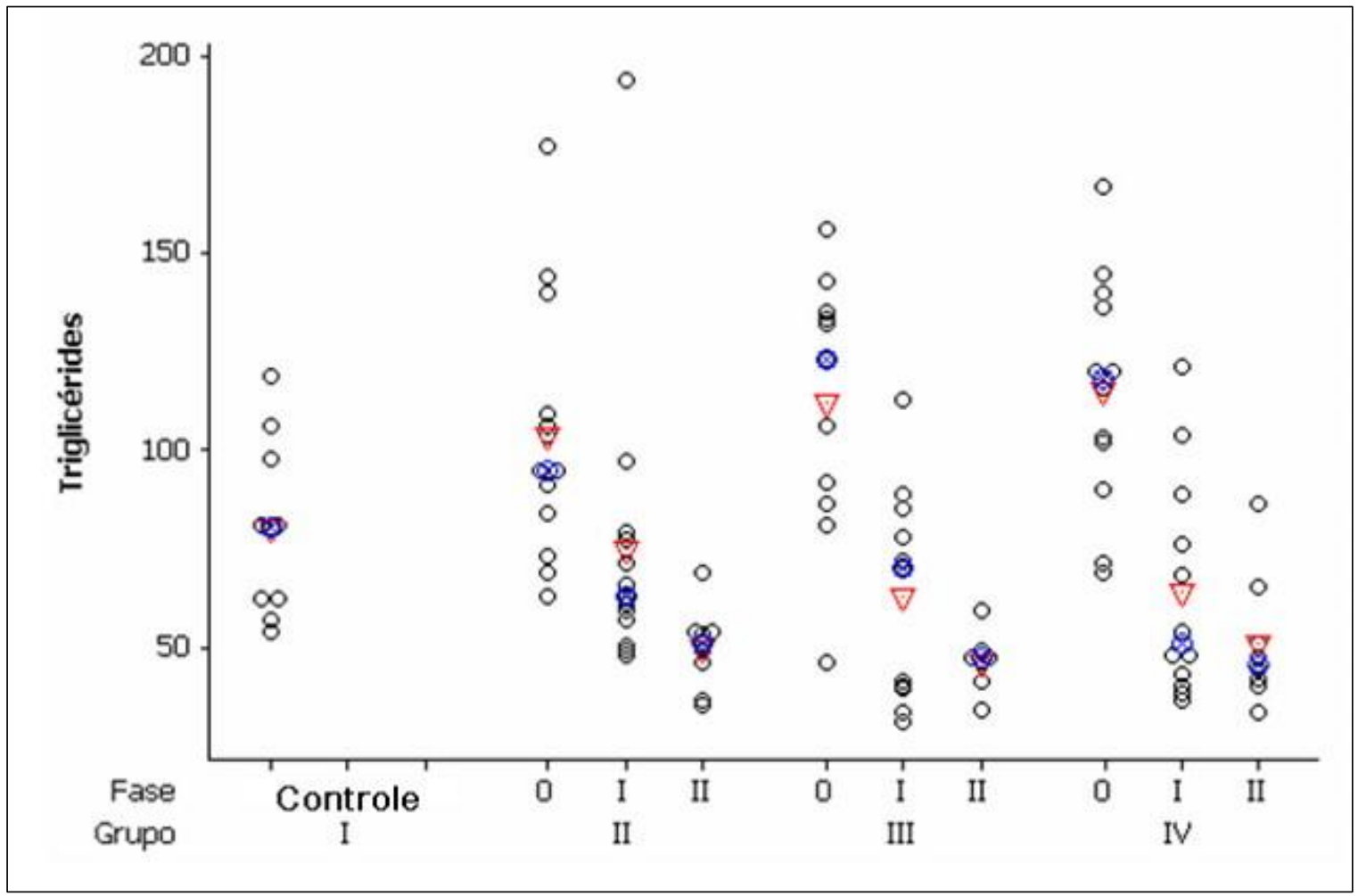

Figura 12 - Comparações entre os grupos e entre as fases segundo a dosagem de triacilgliceróis séricos $(\mathrm{mg} / \mathrm{dL})$

fase 0: coletada na fase basal

fase I: coletada ao término da fase I

fase II: coletada ao término da fase II

Obs.:

Grupo I - 4 semanas dieta padrão

Grupo II - indução de esteatose 3 semanas + 3 semanas de tratamento com dieta padrão Grupo III - indução de esteatose 3 semanas + 3 semanas de tratamento com dieta padrão acrescida de colina

Grupo IV - indução de esteatose 3 semanas + 3 semanas de tratamento com dieta padrão acrescida de FOS

O triângulo representa a média.

O círculo representa a mediana. 


\subsection{Análise do peso úmido de fígado e coração}

\subsubsection{Peso úmido do coração}

Não foi observada diferença estatística em relação ao peso úmido do coração dos animais dos Grupos II, III e IV quando se comparou as fases do experimento e em relação ao Grupo controle (Tabela 12).

Tabela 12 - Valores de média e desvio padrão do peso úmido do coração (gramas) dos grupos e comparação intra e intergrupos

\begin{tabular}{cccccc}
\hline Grupo & controle & fase I & fase II & \multicolumn{2}{c}{ comparação } \\
\hline I & $1.20 \pm 0.3$ & - & - & - & - \\
II & - & $1.24 \pm 0.05$ & $1.24 \pm 0.13$ & fase I- fase II • & fase II GII - G I $¥$ \\
III & - & $1.33 \pm 0.15$ & $1.23 \pm 0.16$ & fase I- fase II • & fase II GIII - G I \\
IV & - & $1.20 \pm 0.05$ & $1.24 \pm 0.21$ & fase I- fase II • fase II GIV - G I $¥$ \\
\hline
\end{tabular}

- Comparação entre as médias das fases

$¥$ Comparação entre as médias dos grupos na fase de tratamento e a média do grupo controle ${ }^{*} \mathrm{p}<0.05$

fase I: Indução da esteatose

fase II:Tratamento 


\subsubsection{Peso úmido do fígado}

Em relação ao peso úmido hepático, não se observa um aumento entre as fases do experimento. Quando se comparou os Grupos II, II e IV com o Controle, encontrou-se aumento do peso úmido hepático $(p<0.05)$ em todos os grupos (Tabela 13).

Tabela 13 - Valores de média e desvio padrão do peso úmido do fígado (gramas) dos grupos e comparação intra e intergrupos

\begin{tabular}{cccccc}
\hline $\begin{array}{c}\text { Grup } \\
\text { O }\end{array}$ & controle & fase I & fase II & comparação \\
\hline I & $9.6 \pm 1.1$ & - & - & - & - \\
II & - & $11.8 \pm 0.8$ & $11.2 \pm 1.8$ & fase I - fase II & fase II GII - G I $¥$ * \\
III & - & $11.3 \pm 1.5$ & $11.3 \pm 1.3$ & fase I - fase II • fase II GIII - G I¥ * \\
IV & - & $11.7 \pm 0.9$ & $11.5 \pm 2.0$ & fase I - fase II • fase II GIV - G I¥* \\
\hline
\end{tabular}

- Comparação entre as médias das fases

$¥$ Comparação entre as médias dos grupos na fase de tratamento e a média do grupo controle ${ }^{*} \mathrm{p}<0.05$

fase I: Indução da esteatose

fase II:Tratamento 


\subsection{Análise do nitrogênio tecidual}

\subsubsection{Análise do nitrogênio tecidual hepático}

Não foram encontradas diferenças significativas entre 0 nitrogênio tecidual hepático dos grupos induzidos à esteatose e o Grupo controle (Tabela 14).

Tabela 14 - Valores de média e desvio padrão do nitrogênio tecidual hepático (gramas) dos grupos e comparação intra e intergrupos

\begin{tabular}{|c|c|c|c|c|}
\hline Grupo & controle & fase I & fase II & comparação \\
\hline $\mathbf{I}$ & $0.8 \pm 0.3$ & - & - & - \\
\hline II & - & $0.9 \pm 0.5$ & $0.9 \pm 0.3$ & fase II GII - GI $¥$ \\
\hline III & - & $0.9 \pm 0.1$ & $1.0 \pm 0.1$ & fase I - fase II $\bullet$ fase II GIII - GI $¥$ \\
\hline IV & - & $1.0 \pm 0.05$ & $0.9 \pm 0.1$ & fase I - fase II $\bullet$ fase II GIV - G I $¥$ \\
\hline
\end{tabular}

- Comparação entre as médias das fases

$¥$ Comparação entre as médias dos grupos na fase de tratamento e a média do grupo controle ${ }^{*} \mathrm{p}<0.05$

fase I: Indução da esteatose

fase II:Tratamento 


\subsubsection{Análise do nitrogênio tecidual cardíaco}

O nitrogênio tecidual analisado no tecido cardíaco não foi um parâmetro que sofreu variações e, portanto não teve significância estatística quando analisado durante as diferentes fases do experimento, bem como quando se comparou os grupos na fase de tratamento e o Grupo controle (Tabela 15).

Tabela 15 - Valores de média e desvio padrão do nitrogênio tecidual cardíaco (gramas) dos grupos e comparação intra e intergrupos

\begin{tabular}{|c|c|c|c|c|}
\hline $\begin{array}{c}\text { Grup } \\
0\end{array}$ & controle & fase I & fase II & comparação \\
\hline I & $0.11 \pm 0.03$ & - & - & - \\
\hline II & - & $0.12 \pm 0.02$ & $0.10 \pm 0.03$ & fase I- fase II - fase II GII - G I $¥$ \\
\hline III & - & $0.12 \pm 0.01$ & $0.11 \pm 0.01$ & fase I- fase II - fase II GIII - G I $¥$ \\
\hline IV & - & $0.11 \pm 0.01$ & $0.11 \pm 0.02$ & fase I -fase II • fase II GIV-G I $¥$ \\
\hline
\end{tabular}

- Comparação entre as médias das fases

$¥$ Comparação entre as médias dos grupos na fase de tratamento e a média do grupo controle ${ }^{*} p<0.05$

fase I: Indução da esteatose

fase II:Tratamento 


\subsection{Análise da gordura tecidual}

\subsubsection{Análise da gordura tecidual hepática}

Foi evidente o aumento da gordura tecidual hepática na fase I e estatisticamente significativo a diminuição dos níveis de gordura tecidual da fase I para fase II nos grupos que receberam suplementação de colina e FOS (Tabela 16).

Tabela 16 - Valores de média e desvio padrão da gordura tecidual hepática (gramas) dos grupos e comparação intra e intergrupos

\begin{tabular}{cccccc}
\hline $\begin{array}{c}\text { Grup } \\
\text { o }\end{array}$ & controle & fase I & fase II & \multicolumn{2}{c}{ comparação } \\
\hline I & $0.5 \pm 0.18$ & - & - & - & - \\
II & - & $0.84 \pm 0.3$ & $0.6 \pm 0.3$ & fase I - fase II • & Fase II GII - G I $~$ \\
III & - & $1.58 \pm 0.5$ & $0.7 \pm 0.1$ & fase I-fase II • * & Fase II GIII - G I $¥$ \\
IV & - & $1.25 \pm 0.5$ & $0.7 \pm 0.1$ & fase I-fase II • * & fase II GIV-GI $¥$ \\
\hline
\end{tabular}

- Comparação entre as médias das fases

¥ Comparação entre as médias dos grupos na fase de tratamento e a média do grupo controle ${ }^{*} p<0.05$

fase I: Indução da esteatose

fase II:Tratamento 


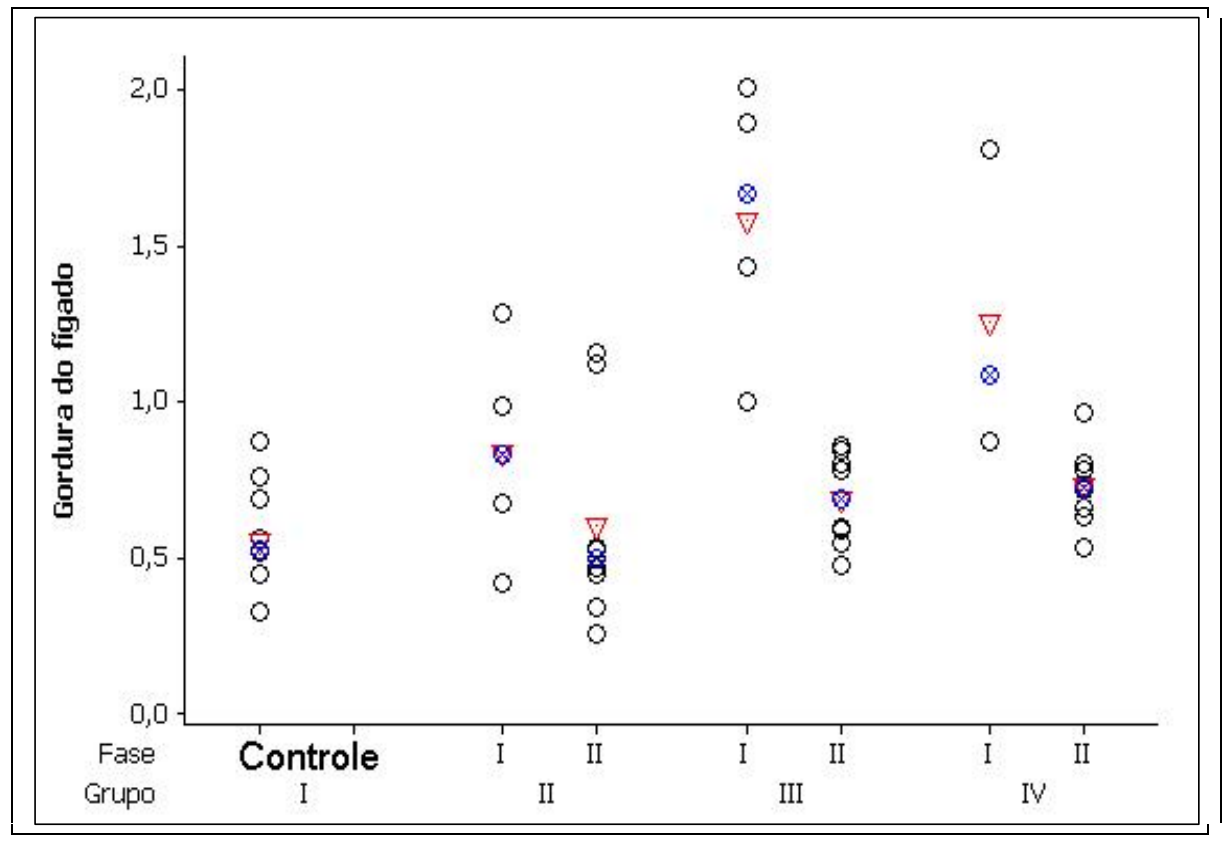

Figura 13 - Comparações entre os grupos e entre as fases segundo a gordura tecidual hepática (em gramas)

fase I: Indução da esteatose

fase II: Tratamento

Obs.:

Grupo I - 4 semanas dieta padrão

Grupo II - indução de esteatose 3 semanas +3 semanas de tratamento com dieta padrão Grupo III - indução de esteatose 3 semanas + 3 semanas de tratamento com dieta padrão acrescida de colina

Grupo IV - indução de esteatose 3 semanas + 3 semanas de tratamento com dieta padrão acrescida de FOS

O triângulo representa a média.

O círculo representa a mediana. 


\subsubsection{Análise da gordura tecidual cardíaca}

Observou-se diminuição dos níveis de gordura tecidual cardíaca nos animais dos Grupos III e IV com $p<0.05$, quando se comparou as diferentes fases do experimento (Tabela 17). Não foram encontradas diferenças estatísticamentes significativas, quando se comparou os grupos que receberam nutrientes na fase II com o Grupo controle.

Tabela 17 - Valores de média e desvio padrão da gordura tecidual cardíaca (gramas) dos grupos e comparação intra e intergrupos

\begin{tabular}{cccccc}
\hline Grupo & controle & fase I & fase II & \multicolumn{2}{c}{ comparação } \\
\hline I & $0.07 \pm 0.01$ & - & - & - & - \\
II & - & $0.05 \pm 0.03$ & $0.05 \pm 0.01$ & fase I - fase II • & Fase II GII - G I $¥$ * \\
III & - & $0.14 \pm 0.03$ & $0.08 \pm 0.02$ & fase I - fase II • * & Fase II GIII - G I ¥ \\
IV & - & $0.12 \pm 0.04$ & $0.07 \pm 0.01$ & fase I - fase II • * & Fase II GIV - G I $¥$ \\
\hline
\end{tabular}

- Comparação entre as médias das fases

¥ Comparação entre as médias dos grupos na fase de tratamento e a média do grupo controle ${ }^{*} p<0.05$

fase I: Indução da esteatose

fase II:Tratamento 


\subsection{Análise do estresse oxidativo pela dosagem de vitamina $E$, malondialdeído (MDA) e glutationa reduzida (GSH) no tecido hepático}

\subsubsection{Dosagem de vitamina $E$}

Observou-se um aumento significativo na concentração hepática de vitamina $\mathrm{E}$, quando os animais passaram da fase I para a fase II em todos os grupos. Porém, dos nutrientes suplementados somente a colina foi capaz de aumentar as concentrações hepáticas de vitamina E, em relação ao Grupo controle (Tabela 18).

Tabela 18 - Valores de média e desvio padrão de vitamina $E$ tecidual $(\mu \mathrm{mol}$ Vitamina E/grama tecido) dos grupos e comparação intra e intergrupos

\begin{tabular}{cccccc}
\hline Grupo & controle & Fase I & fase II & \multicolumn{2}{c}{ comparação } \\
\hline I & $149 \pm 90$ & - & - & - & - \\
II & - & $54 \pm 14$ & $249 \pm 66$ & fase I - fase II • * & fase II GII - G I $*$ * \\
III & - & $96 \pm 22$ & $307 \pm 82$ & fase I - fase II • * & fase II GIII - G I $*$ \\
IV & - & $70 \pm 6$ & $217 \pm 56$ & fase I - fase II • * & fase II GIV - G I $~$ \\
\hline
\end{tabular}

- Comparação entre as médias das fases

$¥$ Comparação entre as médias dos grupos na fase de tratamento e a média do grupo controle ${ }^{*} \mathrm{p}<0.05$

fase I: Indução da esteatose fase II:Tratamento 


\subsubsection{Dosagem de malondialdeído (MDA)}

Não se observou significância estatística na concentração de MDA, quando se comparou a fase de indução de esteatose e de tratamento, ou esta fase com o Grupo controle (Tabela 19).

Tabela 19 - Valores de média e desvio padrão de MDA (nmoles/ mg proteína) dos grupos e comparação intra e intergrupos

\begin{tabular}{cccccc}
\hline $\begin{array}{c}\text { Grup } \\
\text { o }\end{array}$ & controle & fase I & fase II & \multicolumn{2}{c}{ comparação } \\
\hline I & $0.15 \pm 0.021$ & - & - & - & - \\
II & - & $0.18 \pm 0.029$ & $0.18 \pm 0.021$ & fase I-fase II & fase II GII-G I $¥$ \\
III & - & $0.18 \pm 0.027$ & $0.18 \pm 0.027$ & fase I-fase II & fase II GIII-G I $¥$ \\
IV & - & $0.18 \pm 0.013$ & $0.17 \pm 0.028$ & fase I-fase II & fase II GIV-G I $¥$ \\
\hline
\end{tabular}

- Comparação entre as médias das fases

¥ Comparação entre as médias dos grupos na fase de tratamento e a média do grupo controle ${ }^{*} \mathrm{p}<0.05$

fase I: Indução da esteatose

fase II:Tratamento 


\subsubsection{Dosagem de glutationa reduzida (GSH)}

Observou-se um aumento significante $(p<0.05)$ na concentração de GSH em todos os grupos da fase I para a fase II. Dos animais suplementados com nutrientes, somente o Grupo III (suplementado com colina), teve níveis de glutationa reduzida hepática maiores que o Grupo controle (Tabela 20).

Tabela 20 - Valores de média e desvio padrão de GSH ( $\mu \mathrm{mol}$ GSH/ grama proteína) dos grupos e comparação intra e intergrupos

\begin{tabular}{cccccc}
\hline Grupo & controle & fase I & fase II & \multicolumn{2}{c}{ comparação } \\
\hline I & $33 \pm 6$ & - & - & - & - \\
II & - & $23 \pm 7$ & $40 \pm 8$ & fase I - fase II • * & fase II GII - G I $¥$ \\
III & - & $22 \pm 1$ & $46 \pm 13$ & fase I - fase II • * & fase II GIII - G I ¥ * \\
IV & - & $25 \pm 7$ & $38 \pm 14$ & fase I - fase II • * & fase II GIV - G I $¥$ \\
\hline
\end{tabular}

- Comparação entre as médias das fases

¥ Comparação entre as médias dos grupos na fase de tratamento e a média do grupo controle ${ }^{*} p<0.05$

fase I: Indução da esteatose

fase II:Tratamento 


\subsection{Análise histopatológica}

Não foram encontrados sinais de infiltração gordurosa em nenhum tecido cardíaco analisado. Encontramos esteatose hepática em $83 \%$ dos casos, por avaliação histológica, após sacrifício na fase I, ou seja, de doze animais que receberam indução somente dois não foi verificado indícios de esteatose (Tabela 21).

Tabela 21 - Animais que desenvolveram esteatose hepática na fase I

Grupo II

Grupo III

Grupo IV
$100 \%$ dos animais analisados $100 \%$ dos animais analisados $50 \%$ dos animais analisados

fase I: Indução a esteatose

Mesmo não recebendo dieta hiperglicídica, foi encontrado esteatose hepática leve em um animal do Grupo controle.

Ao final da fase II observou-se esteatose hepática leve, mesmo após tratamento, em quatro animais sendo um animal do Grupo II, um animal do Grupo III e dois animais do Grupo IV (Tabela 22).

Tabela 22 - Animais que apresentaram esteatose hepática após fase II

Grupo II (3 semanas de tratamento com dieta padrão)

Grupo III (3 semanas de tratamento com dieta padrão acrescida de colina)

Grupo IV (3 semanas de tratamento com dieta padrão acrescida de FOS)
$12 \%$ dos animais analisados

$12 \%$ dos animais analisados

$25 \%$ dos animais analisados 
fase II: Tratamento

O grupo com esteatose hepática leve (até 25\% dos hepatócitos com vacúolos de gordura) constitui-se de treze animais e com esteatose hepática moderada (até $50 \%$ dos hepatócitos acometidos por vacúolos de lipídeos) foram dois animais.

A esteatose macro e microgoticular esteve presente em dez dos quinze fígados esteatóticos, sendo que em cinco deles a característica da esteatose era exclusivamente microgoticular. Também se observou presença de infiltrado inflamatório mononuclear discreto no espaço periportal em todos os cortes histológicos.

\subsubsection{Aspecto macroscópico}

O aspecto macroscópico do fígado esteatótico é mostrado na Figura 24. letra B.

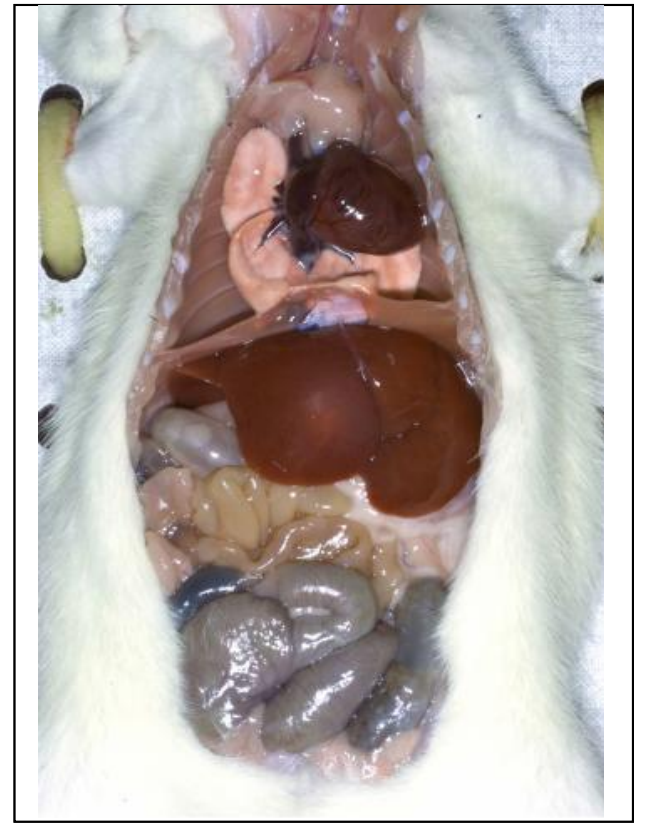

A

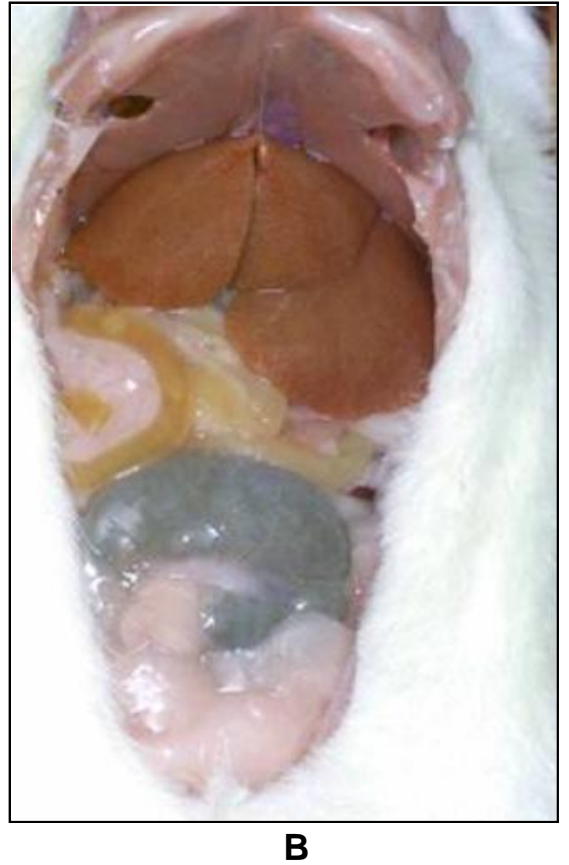


Figura 14 - Macroscopia do fígado do Grupo I, controle, (A) e do grupo que desenvolveu esteatose (B)

\subsubsection{Aspecto microscópico}

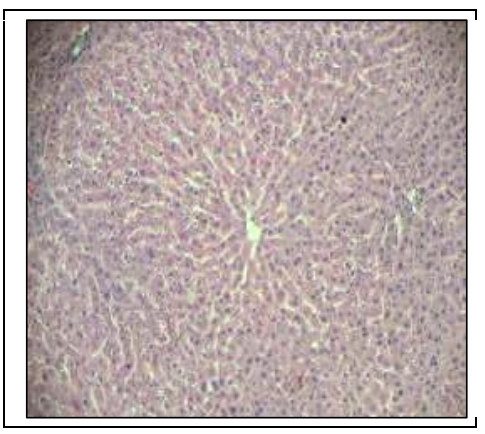

Figura 15 - Corte histológico hepático sem alterações, corado por HE. Aumento 100X . Grupo controle (Grupo I)

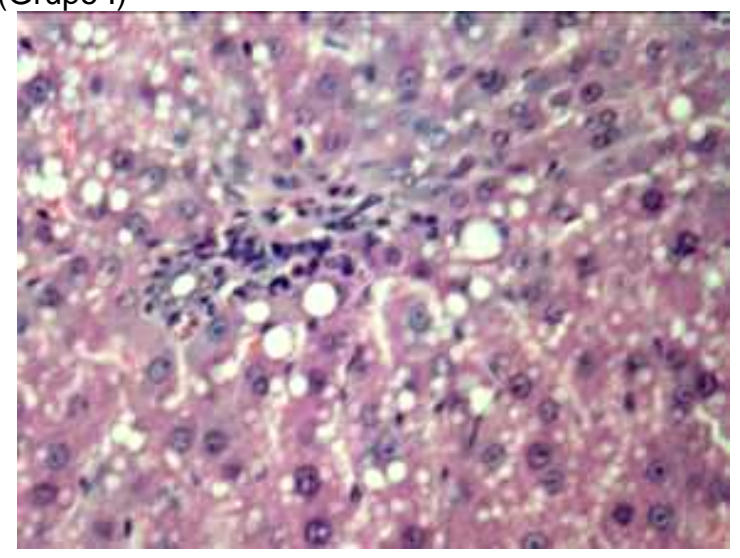

Figura 16 - Corte histológico hepático corados por HE, evidenciando vacúolos de lipídeos (esteatose macro e microgoticular). Aumento 200x. Grupo III fase I

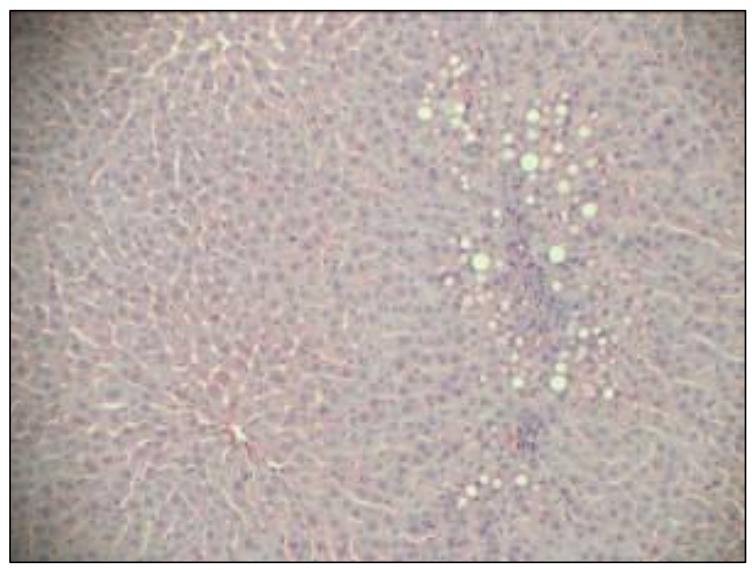

Figura 17 - Corte histológico hepático corados por HE, evidenciando vacúolos de lipídeos (esteatose macro e microgoticular). Aumento 100X. Grupo II fase I 
5. DISCUSSÃO

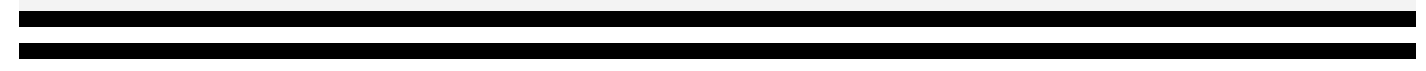


Este trabalho procurou reproduzir uma condição clínica freqüente em pacientes obesos: a presença de infiltração gordurosa hepática decorrente da dieta hiperglicídica. Assim sendo, nosso objetivo foi avaliar a possibilidade de tratamento utilizando-se a colina e o frutooligossacarídeo em ratos Wistar.

Apesar de existirem dietas clássicas para indução de esteatose experimental, como as com deficiência de colina e metionina (LIEBER et al., 2004; NANJI, 2004), no presente estudo procurou-se reproduzir uma dieta similar à ingerida pela população obesa, ou seja, com alto teor de carboidratos. Estudos recentes apontam alterações na dieta do brasileiro, com o aumento do consumo de açúcar e de gorduras saturadas associado à insuficiente consumo de frutas e hortaliças (ALVES et al., 2006).

A dieta hiperglicídica (70\% de sacarose) , no presente estudo, foi administrada por 21 dias e foi um bom método de indução de esteatose hepática, já que encontrou-se vacúolos lipídicos por meio de avaliação histológica em $83 \%$ dos animais, sacrificados pós indução. Fato concordante com experimento realizado por Bacon (1984), que encontrou esteatose hepática em cerca de $80 \%$ dos animais alimentados com dieta com $50 \%$ de sacarose por 21 dias.

De acordo com a teoria sobre o desenvolvimento da esteatose hepática, relacionado à dieta hiperglicídica, há o aumento da síntese de ácidos graxos no hepatócito, suplantando sua capacidade de metabolização e exportação conseqüente à ação lipogênica da insulina (AXEN et al., 2006). A 
hiperinsulinemia presente nesta situação favoreceria a lipogênese hepática e a lipólise periférica, ocorrendo um maior aporte de ácidos graxos para o fígado.

O mecanismo pelo qual as moléculas de carbono originários de carboidratos (glicose, frutose, lactose etc.) são transformados em ácidos graxos é chamado de lipogênese de novo, que é altamente ativa em roedores (PARKS, 2002). Algumas enzimas que participam desse mecanismo como a acetil-CoA carboxilase (ACC) e a ácido graxo sintase podem sofrer incremento na sua expressão. Desta forma, dietas hiperglicídicas estimulam consideravelmente a lipogênese, aumentando a expressão de enzimas lipogênicas e predispondo ao aumento do aporte de ácidos graxos ao fígado (LETEXIER et al., 2003; POLACOW et al., 2007).

Com relação à ingestão alimentar, os animais induzidos à esteatose e posteriormente tratados sempre tiveram uma ingestão semanal inferior ao grupo controle, e evoluíram com ganho de peso menos significativo nas duas últimas semanas de tratamento. Isso pode ser explicado pela própria mudança da dieta ou ao estresse relacionado ao estudo. Apesar disso, todos os animais evoluíram com ganho de peso durante o experimento.

Ressalta-se, no entanto, que alguns animais mesmo recebendo dieta hiperglicídica não desenvolveram esteatose hepática. Nesta situação, sugerese que se deva a própria variabilidade biológica, ou ao tempo de indução da esteatose. A infiltração gordurosa hepática encontrada na maioria dos animais foi de grau leve e moderado, o que poderia ser justificado pela duração do experimento ou pela concentração de sacarose presente na dieta. Bacon 
(1984), observou que, em dietas enriquecidas com sacarose, o grau de infiltração gordurosa hepática era proporcional ao grau de concentração de sacarose na dieta. Um único animal do Grupo controle apresentou sinais de esteatose hepática leve. Fazendo-se um paralelo com o ser humano, tal condição pode ocorrer também em crianças e adultos saudáveis, sem representar uma condição patológica (KIM et al., 2004).

Quanto ao fato dos animais não terem desenvolvido fibrose e/ou inflamação sugere que estes sejam mais resistentes à fibrogênese, necessitando de fatores adjuvantes como álcool, lipopolissacárides, diabetes, (LIEBER et al., 2004; NANJI, 2004), ou que o tempo utilizado (três semanas) no experimento tenha sido insuficiente para desenvolver inflamação e fibrose. Em estudo realizado por Spolarics (2000), onde a esteatose hepática foi induzida por dieta hiperglicídica, não foi encontrado sinais de esteatohepatite e nem mesmo elevação dos marcadores de peroxidação lipídica. Já em trabalho realizado recentemente na Universidade Chulalongkorn da Tailândia, os autores utilizaram dieta com $100 \%$ de gordura por seis semanas para a indução da esteatohepatite (THONG- NGAM et al., 2007).

Observa-se, no presente trabalho, que objetivamos também avaliar os efeitos da colina e FOS sobre o estresse oxidativo hepático. Ao se analisar o tecido hepático, a adição dos nutrientes ou mesmo a dieta padrão não interferiu na concentração hepática do MDA, um marcador indireto da geração do estresse oxidativo. Esse fato pode ter ocorrido porque provavelmente não houve presença de fibrogênese hepática, conforme foi observado na análise 
histológica. O estresse oxidativo, ocorrendo no contexto onde há deposição de triglicerídeos no interior do hepatócito, seria importante na evolução da esteatose para esteatohepatite e fibrose (OLIVEIRA et al., 2002; OLIVEIRA et al., 2006a). Vários estudos têm demonstrado que as EROS estão aumentadas na esteatohepatite, enquanto os níveis de antioxidantes (vitamina $E$ e glutationa) estão diminuídos (LECLERCQ et al., 2000; LEE et al., 1995). O uso de antioxidantes, como a $\mathrm{N}$-acetilcisteína tem-se mostrado promissor na redução do estresse oxidativo na DHGNA, conforme estudo de Thong-Ngam et al. (2007). Dentre os nutrientes suplementados, a colina foi aquele responsável pelas mais altas concentrações de vitamina $E$ e glutationa encontradas no fígado, o que já foi observado em outros estudos que demonstram uma correlação entre a deficiência de colina e baixos níveis hepáticos de vitamina $E$ e glutationa reduzida. Estes trabalhos denotam uma forte evidência que o aumento da peroxidação lipídica ocorre quando as concentrações de vitamina E e glutationa estão diminuídas (GRATTAGLIANO et al., 2000).

Outro aspecto é que no nosso experimento foram utilizados apenas ratos machos e alguns estudos demonstraram que, expostos à condições semelhantes, ratas obesas desenvolvem esteatohepatite com maior freqüência que os machos (YANG et al., 1997). A falência hepática com esteatose microvascular da gestação, a ocorrência de EHNA associada aos estrógenos sintéticos (SETJl et al., 2006; TAKAMURA et al., 2007) e a interferência dos hormônios femininos na estrutura e função mitocondrial (PESSAYRE et al., 2002) poderiam ser alguns dos motivos para explicar porque não ocorreu 
esteatohepatite nos animais do presente estudo. No entanto, em camundongos submetidos à indução de esteatohepatite com dieta deficiente de metionina e colina, não observaram diferenças entre os sexos dos animais quanto a evolução das alterações hepáticas (KASHIREDDY et al. 2004). Recentemente Romestaing et al., (2007), da Universidade de Lion na França relataram a dificuldade de se estudar a esteatohepatite em ratos, mesmo utilizando modelo animal com ingestão de gorduras. Segundo estes autores, os roedores e outros mamíferos, possuem o tecido adiposo constituído por dois tipos celulares: o tecido adiposo unilocular constituído por adipócitos brancos ("white adipocytes"), e o tecido adiposo multilocular ou gordura marrom constituído por adipócitos pardos ("brown adipocytes"). Assim, supõe-se que os ratos podem se adaptar a ingestão calórica excessiva através da termogênese no tecido gorduroso marrom.

Quanto à classificação da esteatose encontrada nos cortes histológicos, em $86 \%$ dos fígados esteatóticos foi de grau leve e $14 \%$ foi de grau moderada. A esteatose macro e microgoticular esteve presente em $66 \%$ dos fígados esteatóticos, sendo que em $34 \%$ a característica da esteatose era exclusivamente microgoticular. Também se observou presença de infiltrado inflamatório mononuclear discreto no espaço periportal em todos os cortes histológicos. Em experimento similar realizado por Bacon (1984), foi observado a mesma distribuição zonal da esteatose encontrado no presente estudo.

Ao término do experimento, após a fase que denominamos de tratamento, a esteatose hepática esteve presente em cerca de $15 \%$ dos animais pela 
análise histopatológica. Podemos sugerir que a dieta com adição de nutrientes (colina ou FOS) não foi capaz de atuar na fisiopatogenia da esteatose hepática, já que ao final de três semanas, ainda encontramos infiltração gordurosa em tecidos hepáticos analisados. Outra possibilidade é que o tempo de duração do tratamento fosse pequeno, caso o tivéssemos ampliado encontraríamos um resultado mais satisfatório, como em trabalho de Thong-Ngam et al. (2007), que utilizou $\mathrm{N}$-acetilcisteína para tratamento da esteatohepatite por seis semanas.

Quando o coração foi analisado pela histopatologia, não foi encontrado sinais de infiltração gordurosa. A justificativa para se estudar a presença de gordura no tecido cardíaco, é que o acúmulo de lipídios no miocárdio é diretamente lesivo. $\mathrm{O}$ estudo com modelos animais de obesidade revela que 0 acúmulo intramiocárdico de triacilgliceróis provoca disfunções cardíacas como a cardiomiopatia dilatada não isquêmica (MCGAVOCK et al., 2006). Observamos que, a quantidade de gordura analisada nos tecidos hepáticos e cardíacos dos grupos suplementados com colina e FOS foram menor quando comparou-se as fases de indução e tratamento. Os efeitos da diminuição da lipogênese hepática em ratos, determinada pelo FOS, já foi relatada na literatura em trabalhos anteriores (DELZENNE, 2001). Parece que o FOS, pode diminuir a atividade de enzimas lipogênicas. Foi observado que apesar da diminuição dos níveis de gordura tecidual, não houve uma concordância direta entre a análise histológica e a quantificação da gordura tecidual. Tal fato poderia ser explicado por diversos fatores: a amostra aleatória para análise da 
histologia de uma região do tecido não corresponder a amostra no qual foi determinado a gordura dosada; as características individuais de cada animal no que diz respeito ao metabolismo hepático; a amostra do tecido a ser analisado, para a dosagem da gordura ter sido pouco representativa da constituição real do órgão. Outra possibilidade é de que a redução da quantidade de gordura dosada ter sofrido influência de dois estímulos: a retirada da indução da esteatose e o início do tratamento com os nutrientes que foi concomitante. No entanto, observamos que foi considerável o aumento do peso do fígado naqueles grupos induzidos à esteatose em relação ao Grupo controle, o que pode ser explicado pelo aumento da quantidade de gordura hepática.

Em relação aos níveis séricos de lipídeos, a colina na dieta, foi capaz de diminuir significativamente os triacilgliceróis, em relação aos seus níveis basais, assim como o frutooligossacarídeo e a dieta padrão. Trabalhos anteriores evidenciam que a suplementação de colina associada à cafeína e carnitina promovem a redução dos níveis séricos e aumento da concentração no músculo esquelético de triacilgliceróis (HONGU et al., 2000). Também o FOS foi relacionado à diminuição dos níveis de triacilglicerol sérico em experimento onde foi suplementado em dieta na concentração de $10 \%$ (DELZENNE et al., 2001; BUSSEROLES et al., 2003).

Porém quando se analisa o efeito da suplementação de nutrientes na colesterolemia, somente o frutooligossacarídeo foi capaz de reduzí-la em relação aos basais. Tal fato se deve aos efeitos hipocolesterolêmicos do FOS já relatados na literatura. (DELZENNE et al., 2001; KAUR et al., 2002; PASSOS 
et al., 2003). Estudos em animais (DELZENNE et al., 1999; KOK et al.,1998; LESNIEWSKA et al., 2006) detectaram uma queda de $83 \%$ e $59 \%$ de colesterol sérico em ratos alimentados com 1 e $5 \%$ de FOS, respectivamente. Este efeito foi acompanhado pelo aumento significativo de excreção de esteróis e lipídeos nas fezes.

Quando analisamos os efeitos dos nutrientes no metabolismo nitrogenado, os animais que receberam colina e FOS, excretaram menor quantidade de nitrogênio urinário. Isto pode ter ocorrido provavelmente porque nenhum dos nutrientes foi suficiente para alterar o metabolismo protéico. Sun et al., (2007) encontrou resultados semelhantes quando suplementou metionina em cabras e observou excreção diminuída de nitrogênio urinário e uréia plasmática. No grupo que recebeu colina, e considerando que a mesma é um produto nitrogenado, poderíamos esperar um aumento da excreção urinária de nitrogênio, o que não ocorreu.

Já em relação à amônia urinária, encontramos um aumento significativo somente no grupo suplementado com colina. Talvez esse achado poderia ser explicado pelo próprio metabolismo da via de degradação da colina com formação de amônia como produto intermediário.

O presente trabalho apresenta algumas limitações inerentes à utilização de modelos animais para o estudo da esteatose hepática. Utilizou-se ratos de linhagem sem modificações genéticas e as dietas foram preparadas no nosso laboratório, a partir de ingredientes in natura, o que poderia acarretar algum viés ao estudo. Um modelo animal que apresente resistência insulínica, 
aumento do aporte de ácidos graxos e dificuldade de excreção de triacilgliceróis, poderia desenvolver esteatose hepática não alcoólica de forma semelhante aos humanos, mas os modelos animais por vezes apresentam suas limitações.

Considerando-se que, no presente trabalho a indução de esteatose foi realizada por dieta hiperglicídica, são necessários outros estudos para determinar se, em esteatoses induzidas por outros modelos experimentais, a colina e o FOS poderiam promover uma forma de tratamento. Será importante estabelecer seus efeitos benéficos com mais exatidão e quantificar as doses adequadas, a fim de oferecer eficácia sem oferecer riscos de toxicidade e avaliar os efeitos colaterais através do uso.

Os questionamentos levantados para este estudo mostram principalmente a importância do tema, que vem sendo estudado em diversos centros de pesquisa pelo mundo, e no próprio laboratório de nutrição da FMRP-USP. 
6. CONCLUSÕES

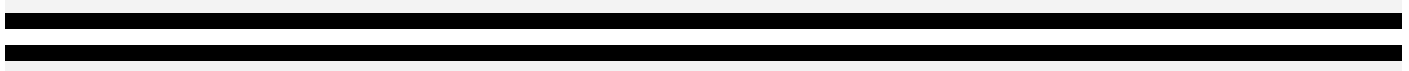


1) A dieta hiperglicídica utilizada, foi um bom método de indução de esteatose, sendo encontrado presença de vacúolos lipídicos em 83\% dos fígados submetidos à análise histológica.

2) O frutooligossacarídeo foi o único nutriente capaz de reduzir os níveis de colesterol sérico, em relação aos seus níveis basais, quando suplementado após indução de esteatose.

3) A colina foi o nutriente capaz de aumentar os níveis hepáticos de vitamina E e glutationa reduzida, quando suplementada pós indução de esteatose.

4) Os níveis de MDA permaneceram inalterados quando os animais foram submetidos à indução de esteatose ou receberam suplementação de nutrientes, provavelmente porque não houve desenvolvimento de fibrose e/ou inflamação.

5) Nenhum dos nutrientes empregados (colina e FOS) foi eficaz na redução da quantidade de gordura do fígado, pela análise histológica. 
7. ANEXOS

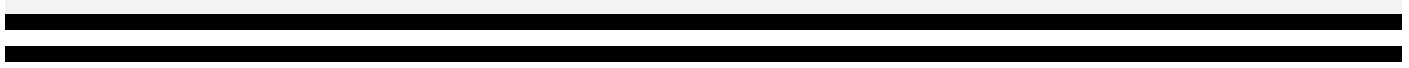




\subsection{Ingestão alimentar semanal}

Tabela 1: Média semanal de ingestão alimentar do Grupo I, em gramas

\begin{tabular}{|c|c|c|c|c|c|}
\hline Grupo & Animal & 1 semana & $2^{\mathrm{a}}$ semana & $3^{\mathrm{a}}$ semana & $4^{\mathrm{a}}$ semana \\
\hline \multirow{10}{*}{1} & 1 & 160 & 159 & 232 & 270 \\
\hline & 2 & 189 & * & * & * \\
\hline & 3 & 190 & 228 & 250 & 192 \\
\hline & 4 & 166 & 142 & 248 & 199 \\
\hline & 5 & 173 & 190 & 220 & 204 \\
\hline & 6 & 187 & 197 & 167 & 251 \\
\hline & 7 & 162 & 175 & 226 & 222 \\
\hline & 8 & 187 & 150 & 144 & 211 \\
\hline & 9 & 161 & * & * & * \\
\hline & 10 & 178 & 210 & 217 & 152 \\
\hline
\end{tabular}


Tabela 2: Evolução da ingestão alimentar em gramas, valores em média, dos Grupos II, III e IV

\begin{tabular}{|c|c|c|c|c|c|c|c|}
\hline Grupo & Animal & $1^{a}$ semana & $2^{\mathrm{a}}$ semana & $3^{a}$ semana & $4^{\mathrm{a}}$ semana & $5^{\mathrm{a}}$ semana & 6⿳亠口了 semana \\
\hline \multirow{12}{*}{ II } & 1 & 152 & 168 & 167 & 145 & 201 & 171 \\
\hline & 2 & 137 & 124 & 130 & $*$ & $*$ & $*$ \\
\hline & 3 & 148 & 149 & 145 & 143 & 178 & 109 \\
\hline & 4 & 101 & 100 & 126 & 141 & 169 & 122 \\
\hline & 5 & 118 & 124 & 146 & 150 & 201 & 137 \\
\hline & 6 & 110 & 124 & 117 & * & * & * \\
\hline & 7 & 137 & 170 & 153 & * & * & * \\
\hline & 8 & 142 & 177 & 151 & 144 & 124 & 168 \\
\hline & 9 & 137 & 124 & 134 & 135 & 171 & 104 \\
\hline & 10 & 190 & 161 & 170 & 181 & 182 & 137 \\
\hline & 11 & 141 & 157 & 149 & * & * & * \\
\hline & 12 & 101 & 115 & 131 & 143 & 175 & 121 \\
\hline \multirow{12}{*}{ III } & 1 & 169 & 188 & 163 & 129 & 212 & 120 \\
\hline & 2 & 170 & 160 & 169 & 122 & 189 & 208 \\
\hline & 3 & 159 & 127 & 143 & * & * & * \\
\hline & 4 & 153 & 162 & 163 & 138 & 166 & 200 \\
\hline & 5 & 162 & 110 & 136 & * & * & * \\
\hline & 6 & 162 & 209 & 185 & * & * & $*$ \\
\hline & 7 & 127 & 148 & 154 & 143 & 198 & 155 \\
\hline & 8 & 132 & 161 & 146 & * & * & $*$ \\
\hline & 9 & 119 & 170 & 139 & 129 & 148 & 130 \\
\hline & 10 & 115 & 156 & 153 & 160 & 216 & 119 \\
\hline & 11 & 119 & 183 & 161 & 160 & 178 & 166 \\
\hline & 12 & 121 & 140 & 140 & 129 & 193 & 118 \\
\hline \multirow{12}{*}{ IV } & 1 & 131 & 148 & 139 & 109 & 131 & 130 \\
\hline & 2 & 160 & 182 & 171 & 136 & 160 & 162 \\
\hline & 3 & 181 & 176 & 178 & 145 & 170 & 170 \\
\hline & 4 & 161 & 154 & 157 & * & * & * \\
\hline & 5 & 155 & 118 & 140 & 140 & 136 & 136 \\
\hline & 6 & 146 & 158 & 157 & * & * & * \\
\hline & 7 & 165 & 151 & 158 & 116 & 147 & 145 \\
\hline & 8 & 175 & 187 & 186 & 192 & 182 & 180 \\
\hline & 9 & 177 & 199 & 188 & * & * & * \\
\hline & 10 & 148 & 162 & 155 & * & $*$ & * \\
\hline & 11 & 106 & 171 & 139 & 180 & 149 & 147 \\
\hline & 12 & 135 & 180 & 155 & 180 & 160 & 160 \\
\hline
\end{tabular}




\subsection{Evolução do peso dos animais}

Tabela 3: Evolução de peso semanal, em gramas, dos animais do Grupo I

\begin{tabular}{|c|c|c|c|c|c|c|}
\hline Grupo & $\begin{array}{c}\text { Anima } \\
\text { I }\end{array}$ & $\begin{array}{c}\text { Início do } \\
\text { experimento }\end{array}$ & $\begin{array}{c}1^{\mathrm{a}} \\
\text { semana }\end{array}$ & $\begin{array}{c}2^{\mathbf{a}} \\
\text { semana }\end{array}$ & $\begin{array}{c}3^{\mathbf{a}} \\
\text { semana }\end{array}$ & $\begin{array}{c}4^{\mathbf{a}} \\
\text { semana }\end{array}$ \\
\hline \multirow{10}{*}{ I } & 1 & 287 & 342 & 355 & 376 & 405 \\
\hline & 2 & 307 & 334 & * & * & * \\
\hline & 3 & 292 & 314 & 358 & 397 & 418 \\
\hline & 4 & 289 & 291 & 341 & 385 & 383 \\
\hline & 5 & 280 & 309 & 339 & 362 & 371 \\
\hline & 6 & 296 & 318 & 345 & 370 & 398 \\
\hline & 7 & 298 & 315 & 351 & 372 & 381 \\
\hline & 8 & 300 & 333 & 344 & 340 & 339 \\
\hline & 9 & 298 & 319 & * & * & * \\
\hline & 10 & 276 & 307 & 338 & 360 & 355 \\
\hline
\end{tabular}


Tabela 4: Evolução de peso semanal, em gramas, dos animais do Grupo II, III e IV

\begin{tabular}{|c|c|c|c|c|c|c|c|c|}
\hline Grupo & Animal & $\begin{array}{c}\text { Início do } \\
\text { experimento }\end{array}$ & $\begin{array}{c}1^{\mathrm{a}} \\
\text { semana }\end{array}$ & $\begin{array}{c}2^{\mathbf{a}} \\
\text { semana }\end{array}$ & $\begin{array}{c}3^{\mathbf{a}} \\
\text { semana }\end{array}$ & $\begin{array}{c}4^{\mathrm{a}} \\
\text { semana }\end{array}$ & $\begin{array}{c}5^{\mathbf{a}} \\
\text { semana }\end{array}$ & $\begin{array}{c}6 \text { a } \\
\text { semana }\end{array}$ \\
\hline \multirow{12}{*}{ II } & 1 & 312 & 341 & 395 & 442 & 484 & 494 & 535 \\
\hline & 2 & 322 & 325 & 350 & 408 & * & * & * \\
\hline & 3 & 290 & 313 & 331 & 364 & 344 & 351 & 368 \\
\hline & 4 & 282 & 296 & 292 & 346 & 373 & 403 & 431 \\
\hline & 5 & 286 & 298 & 321 & 372 & 395 & 410 & 460 \\
\hline & 6 & 302 & 284 & 302 & 357 & * & * & * \\
\hline & 7 & 272 & 289 & 341 & 403 & * & * & * \\
\hline & 8 & 295 & 316 & 374 & 427 & 447 & 430 & 453 \\
\hline & 9 & 283 & 308 & 332 & 375 & 397 & 405 & 429 \\
\hline & 10 & 300 & 332 & 386 & 362 & 347 & 351 & 358 \\
\hline & 11 & 293 & 316 & 348 & 412 & * & * & * \\
\hline & 12 & 278 & 280 & 306 & 352 & 356 & 385 & 410 \\
\hline \multirow{12}{*}{ III } & 1 & 296 & 341 & 392 & 431 & 392 & 431 & 431 \\
\hline & 2 & 263 & 206 & 265 & 335 & 372 & 388 & 427 \\
\hline & 3 & 315 & 355 & 376 & 390 & * & * & * \\
\hline & 4 & 296 & 331 & 380 & 436 & 459 & 464 & 483 \\
\hline & 5 & 312 & 288 & 304 & 361 & $*$ & $*$ & $*$ \\
\hline & 6 & 309 & 342 & 416 & 465 & * & * & * \\
\hline & 7 & 277 & 320 & 342 & 392 & 420 & 409 & 378 \\
\hline & 8 & 305 & 343 & 380 & 426 & * & * & * \\
\hline & 9 & 276 & 298 & 345 & 373 & 360 & 377 & 369 \\
\hline & 10 & 284 & 294 & 374 & 427 & 444 & 428 & 429 \\
\hline & 11 & 319 & 327 & 362 & 387 & 379 & 377 & 410 \\
\hline & 12 & 296 & 296 & 342 & 368 & 371 & 350 & 314 \\
\hline \multirow{12}{*}{ IV } & 1 & 283 & 288 & 320 & 372 & 397 & 409 & 422 \\
\hline & 2 & 286 & 316 & 376 & 446 & 453 & 464 & 491 \\
\hline & 3 & 293 & 314 & 351 & 404 & 362 & 335 & 366 \\
\hline & 4 & 275 & 268 & 332 & 389 & * & * & * \\
\hline & 5 & 297 & 326 & 339 & 383 & 400 & 396 & 403 \\
\hline & 6 & 301 & 324 & 366 & 395 & * & * & * \\
\hline & 7 & 298 & 335 & 374 & 427 & 445 & 435 & 456 \\
\hline & 8 & 302 & 307 & 314 & 370 & 360 & 377 & 360 \\
\hline & 9 & 266 & 312 & 375 & 440 & * & * & * \\
\hline & 10 & 292 & 321 & 339 & 405 & * & * & * \\
\hline & 11 & 297 & 272 & 335 & 324 & 310 & 311 & 280 \\
\hline & 12 & 264 & 314 & 341 & 332 & 341 & 324 & 336 \\
\hline
\end{tabular}




\subsection{Análise da amônia e do nitrogênio urinário}

Tabela 5: Valores de urina de 24hs, amônia e nitrogênio urinário total ( $\mathrm{Gn}_{2} /$ volume total/24hs) do Grupo I

\begin{tabular}{ccccc}
\hline Grupo & Animal & Amônia Urinária & Nitrogênio Urinário & $\begin{array}{c}\text { Urina de } \\
\mathbf{2 4 h s} \\
(\mathbf{m l})\end{array}$ \\
\hline & 1 & 0.22 & 0.36 & 22 \\
2 & 0 & 0.36 & 12 \\
3 & 0.01 & 0.34 & 13 \\
4 & 0.01 & 0.28 & 22 \\
1 & 5 & 0.01 & 0.3 & 14 \\
& 6 & 0.01 & 0.21 & 9 \\
7 & 0.01 & 0.22 & 14 \\
& 8 & 0.01 & 0.37 & 16 \\
9 & 0.02 & 0.26 & 27 \\
& 10 & 0.05 & 480 & 14 \\
\hline
\end{tabular}


Tabela 6: Valores de nitrogênio urinário nas fase I e fase II, $\left(\mathrm{Gn}_{2} /\right.$ volume total/24hs) ,nos Grupos II, III e IV

\begin{tabular}{|c|c|c|c|}
\hline Grupo & Animal & $\begin{array}{c}\text { Nitrogênio } \\
\text { fase I }\end{array}$ & $\begin{array}{c}\text { Nitrogênio } \\
\text { fase II }\end{array}$ \\
\hline \multirow{12}{*}{ II } & 1 & 0.150 & 0.25 \\
\hline & 2 & & * \\
\hline & 3 & 0.16 & 0.1 \\
\hline & 4 & 0.14 & 0.09 \\
\hline & 5 & & 0.14 \\
\hline & 6 & 0.15 & * \\
\hline & 7 & 0.32 & * \\
\hline & 8 & 0.14 & 0.35 \\
\hline & 9 & 0.13 & 0.15 \\
\hline & 10 & 0.13 & 0.34 \\
\hline & 11 & 0.14 & * \\
\hline & 12 & 0.12 & 0.3 \\
\hline \multirow{12}{*}{ III } & 1 & 0.11 & 0.02 \\
\hline & 2 & 0.11 & 0.07 \\
\hline & 3 & 0.31 & * \\
\hline & 4 & 0.08 & 0.09 \\
\hline & 5 & 0.05 & * \\
\hline & 6 & 0.32 & * \\
\hline & 7 & 0.03 & 0.07 \\
\hline & 8 & 0.28 & * \\
\hline & 9 & 0.03 & 0.03 \\
\hline & 10 & 0.11 & 0.05 \\
\hline & 11 & 0.07 & 0.03 \\
\hline & 12 & 0.14 & 0.08 \\
\hline \multirow{12}{*}{ IV } & 1 & 0.11 & 0.16 \\
\hline & 2 & 0.12 & 0.29 \\
\hline & 3 & 0.01 & 0.07 \\
\hline & 4 & 0.5 & * \\
\hline & 5 & 0.13 & 0.32 \\
\hline & 6 & 0.27 & * \\
\hline & 7 & 0.1 & 0.25 \\
\hline & 8 & 0.1 & 0.25 \\
\hline & 9 & 0.1 & * \\
\hline & 10 & 0.9 & * \\
\hline & 11 & 0.08 & 0.18 \\
\hline & 12 & 0.02 & 190 \\
\hline
\end{tabular}


Tabela 7: Valores de urina de 24 h e amônia urinária $\left(G n_{2} /\right.$ volume total/24hs) na fase I e fase II, nos Grupos II, III e IV

\begin{tabular}{|c|c|c|c|c|c|}
\hline Grupo & Animal & $\begin{array}{c}\text { Amônia } \\
\text { Urinária fase I }\end{array}$ & $\begin{array}{c}\text { Urina de 24h } \\
(\mathrm{ml}) \\
\text { fase I }\end{array}$ & $\begin{array}{l}\text { Amônia Urinária } \\
\text { fase II }\end{array}$ & $\begin{array}{c}\text { Urina de } 24 \\
\text { h (mI) } \\
\text { fase II }\end{array}$ \\
\hline \multirow{12}{*}{ II } & 1 & 0.012 & 8 & 0.02 & 12 \\
\hline & 2 & 0.01 & 12 & * & $*$ \\
\hline & 3 & 0.01 & 6 & 0.01 & 3 \\
\hline & 4 & 0.01 & 6 & 0.01 & 4 \\
\hline & 5 & $¥$ & $¥$ & 0.01 & 9 \\
\hline & 6 & 0.01 & 5 & * & * \\
\hline & 7 & 0.02 & 11 & * & * \\
\hline & 8 & 0.02 & 15 & 0.03 & 17 \\
\hline & 9 & 0.01 & 9 & 0.01 & 13 \\
\hline & 10 & 0.03 & 14 & 0.03 & 16 \\
\hline & 11 & 0.02 & 7 & * & $*$ \\
\hline & 12 & 0.01 & 10 & 0.02 & 12 \\
\hline \multirow{12}{*}{ III } & 1 & 0.02 & 8 & 0.01 & 4 \\
\hline & 2 & 0.02 & 8 & 0.05 & 18 \\
\hline & 3 & * & * & * & * \\
\hline & 4 & 0.01 & 4 & 0.06 & 16 \\
\hline & 5 & * & * & * & * \\
\hline & 6 & * & * & * & * \\
\hline & 7 & 0 & 1 & 0.05 & 11 \\
\hline & 8 & * & * & * & * \\
\hline & 9 & 0 & 2 & 0.02 & 8 \\
\hline & 10 & 0.02 & 7 & 0.04 & 11 \\
\hline & 11 & 0.01 & 4 & 0.02 & 5 \\
\hline & 12 & 0.02 & 9 & 0.06 & 14 \\
\hline \multirow{12}{*}{ IV } & 1 & 0 & 7 & 0.02 & 6 \\
\hline & 2 & 0.01 & 7 & 0.03 & 11 \\
\hline & 3 & 0.01 & 6 & 0.01 & 3 \\
\hline & 4 & * & * & * & * \\
\hline & 5 & 0.01 & 9 & 0.02 & 20 \\
\hline & 6 & * & * & * & * \\
\hline & 7 & 0.01 & 8 & 0.03 & 11 \\
\hline & 8 & 0.03 & 8 & 0.03 & 10 \\
\hline & 9 & * & * & * & * \\
\hline & 10 & * & * & * & * \\
\hline & 11 & 0.01 & 11 & 0.02 & 16 \\
\hline & 12 & 0.01 & 10 & 0.02 & 7 \\
\hline
\end{tabular}




\subsection{Análise do colesterol total e triacilgliceróis séricos}

Tabela 8: Valores de Colesterol e Triacilgliceróis Basais do Grupo I

\begin{tabular}{cccc}
\hline Grupo & Animal & $\begin{array}{c}\text { Colesterol } \\
(\mathbf{m g} / \mathbf{d L})\end{array}$ & $\begin{array}{c}\text { Triacilgliceróis } \\
(\mathbf{m g} / \mathbf{d L})\end{array}$ \\
\hline 1 & 87 & 54 \\
2 & 77 & 62 \\
& 3 & 71 & 80 \\
& 4 & 72 & 57 \\
1 & 5 & 95 & 81 \\
6 & 63 & 62 \\
& 7 & 62 & 98 \\
8 & 66 & 81 \\
9 & 81 & 106 \\
\hline
\end{tabular}


Tabela 9: Valores de Colesterol (CT) e Triacilgliceróis (TGL), em mg/dL, Basais; da fase I e fase II, dos Grupos II, III e IV, respectivamente

\begin{tabular}{|c|c|c|c|c|c|c|c|}
\hline $\begin{array}{c}\text { Grup } \\
0\end{array}$ & $\underset{I}{\text { Anima }}$ & CT basal & CT fase I & CT fase II & TGL basal & TGL fase I & TGL fase II \\
\hline \multirow{12}{*}{ II } & 1 & 97 & 68 & 92 & 177 & 71 & 53 \\
\hline & 2 & 80 & 65 & * & 95 & 79 & $*$ \\
\hline & 3 & 70 & 47 & 47 & 63 & 50 & 35 \\
\hline & 4 & 72 & 66 & 57 & 73 & 77 & 54 \\
\hline & 5 & 81 & 55 & 67 & 144 & 194 & 49 \\
\hline & 6 & 59 & 53 & * & 104 & 61 & * \\
\hline & 7 & 71 & 75 & $*$ & 84 & 49 & $*$ \\
\hline & 8 & 69 & 55 & 63 & 69 & 57 & 36 \\
\hline & 9 & 64 & 61 & 46 & 140 & 97 & 69 \\
\hline & 10 & 70 & 77 & 75 & 95 & 59 & 51 \\
\hline & 11 & 48 & 43 & * & 106 & 63 & * \\
\hline & 12 & 69 & 74 & 67 & 91 & 48 & 46 \\
\hline \multirow{12}{*}{ III } & 1 & 69 & 67 & 73 & 133 & 40 & 47 \\
\hline & 2 & 68 & 72 & 74 & 123 & 70 & 41 \\
\hline & 3 & 50 & 48 & * & 106 & 78 & $*$ \\
\hline & 4 & 83 & 66 & 77 & 132 & 113 & 49 \\
\hline & 5 & 64 & 61 & * & 156 & 72 & $*$ \\
\hline & 6 & 67 & 68 & * & 86 & 89 & * \\
\hline & 7 & 63 & 67 & 58 & 81 & 31 & 47 \\
\hline & 8 & 64 & 53 & * & 143 & 41 & * \\
\hline & 9 & 79 & 82 & 98 & 135 & 39 & 59 \\
\hline & 10 & 70 & 47 & 58 & 92 & 85 & 46 \\
\hline & 11 & 75 & 75 & 73 & 46 & 33 & 34 \\
\hline & 12 & 71 & 87 & 71 & 109 & 66 & 54 \\
\hline \multirow{12}{*}{ IV } & 1 & 56 & 59 & 45 & 167 & 76 & 86 \\
\hline & 2 & 55 & 46 & 41 & 120 & 121 & 42 \\
\hline & 3 & 66 & 57 & 68 & 103 & 54 & 47 \\
\hline & 4 & 57 & 53 & * & 71 & 48 & * \\
\hline & 5 & 69 & 55 & 47 & 136 & 89 & 33 \\
\hline & 6 & 71 & 58 & * & 116 & 38 & * \\
\hline & 7 & 65 & 58 & 57 & 145 & 104 & 51 \\
\hline & 8 & 93 & 82 & 65 & 140 & 43 & 40 \\
\hline & 9 & 74 & 57 & * & 102 & 68 & * \\
\hline & 10 & 68 & 62 & * & 69 & 48 & * \\
\hline & 11 & 70 & 67 & 68 & 120 & 36 & 65 \\
\hline & 12 & 64 & 66 & 61 & 90 & 40 & 44 \\
\hline
\end{tabular}




\subsection{Análise do peso úmido de fígado e coração}

Tabela 10: Peso úmido dos órgãos, em gramas, (fígado e coração) dos Grupos I, II, III e IV

\begin{tabular}{|c|c|c|c|}
\hline Grupo & Animal & Fígado & Coração \\
\hline \multirow{10}{*}{ I } & 1 & 10.3 & 1.3 \\
\hline & 2 & 8.8 & 1.1 \\
\hline & 3 & 11.8 & 1.3 \\
\hline & 4 & 9.1 & 1.1 \\
\hline & 5 & 10.2 & 1.2 \\
\hline & 6 & 10.5 & 1.2 \\
\hline & 7 & 9.5 & 1.1 \\
\hline & 8 & 8.2 & 2 \\
\hline & 9 & 8.5 & 0.9 \\
\hline & 10 & 9.3 & \\
\hline \multirow{12}{*}{ II } & 1 & 12.9 & 1.4 \\
\hline & 2 & 12.4 & 1.3 \\
\hline & 3 & 9.5 & 1 \\
\hline & 4 & 13.2 & 1.3 \\
\hline & 5 & 10.2 & 1.1 \\
\hline & 6 & 12.3 & 1.2 \\
\hline & 7 & 10.7 & 1.3 \\
\hline & 8 & 10.6 & 1.4 \\
\hline & 9 & 13.3 & 1.2 \\
\hline & 10 & 8.8 & 1.1 \\
\hline & 11 & 11.8 & 1.2 \\
\hline & 12 & 10.8 & 1.3 \\
\hline \multirow{12}{*}{ III } & 1 & 13.1 & 1.3 \\
\hline & 2 & 10.1 & 1.3 \\
\hline & 3 & 11.7 & 1.2 \\
\hline & 4 & 13.3 & 1.5 \\
\hline & 5 & 9.2 & 1.3 \\
\hline & 6 & 13 & 1.5 \\
\hline & 7 & 10.6 & 1.3 \\
\hline & 8 & 11.4 & 1.3 \\
\hline & 9 & 11.1 & 1.1 \\
\hline & 10 & 11.1 & 1 \\
\hline & 11 & 11 & 1.3 \\
\hline & 12 & 10 & 1 \\
\hline \multirow{11}{*}{ IV } & 1 & 13.3 & 1.1 \\
\hline & 2 & 13.1 & 1.4 \\
\hline & 3 & 11.3 & 1.3 \\
\hline & 4 & 11.3 & 1.2 \\
\hline & 5 & 11.1 & 1.3 \\
\hline & 6 & 11.2 & 1.1 \\
\hline & 7 & 14.1 & 1.6 \\
\hline & 8 & 11.7 & 1.2 \\
\hline & 9 & 13.1 & 1.2 \\
\hline & 10 & 11.2 & 1.1 \\
\hline & 11 & 8.9 & 0.9 \\
\hline
\end{tabular}




\subsection{Análise do nitrogênio tecidual}

Tabela 11: Dados do nitrogênio tecidual coração e fígado do Grupo controle

\begin{tabular}{ccccc}
\hline Animal & $\begin{array}{c}\text { Gramas de } \\
\text { nitrogênio no } \\
\text { tecido úmido } \\
\text { (coração) }\end{array}$ & $\begin{array}{c}\text { Gramas de } \\
\text { proteína no } \\
\text { tecido úmido } \\
\text { (coração) }\end{array}$ & $\begin{array}{c}\text { Gramas de } \\
\text { nitrogênio no tecido } \\
\text { úmido } \\
\text { (fígado) }\end{array}$ & $\begin{array}{c}\text { Gramas de } \\
\text { proteína no } \\
\text { tecido úmido } \\
\text { (fígado) }\end{array}$ \\
\hline 1 & 0.11 & 0.68 & 0.83 & 5.17 \\
2 & 0.13 & 0.82 & 0.72 & 4.49 \\
3 & 0.11 & 0.68 & 1.04 & 6.49 \\
4 & 0.1 & 0.61 & 0.39 & 2.46 \\
5 & 0.1 & 0.62 & 1.27 & 7.93 \\
6 & 0.11 & 0.67 & 1.03 & 6.42 \\
7 & 0.09 & 0.55 & 0.57 & 3.55 \\
8 & 0.18 & 1.12 & 0.67 & 4.19 \\
10 & 0.08 & 0.52 & 0.83 & 5.21 \\
\hline
\end{tabular}


Tabela 12: Dados do nitrogênio tecidual coração e fígado do Grupo II

\begin{tabular}{ccccc}
\hline Animal & $\begin{array}{c}\text { Gramas de } \\
\text { nitrogênio no } \\
\text { tecido úmido } \\
\text { (coração) }\end{array}$ & $\begin{array}{c}\text { Gramas de } \\
\text { proteína no tecido } \\
\text { úmido } \\
\text { (coração) }\end{array}$ & $\begin{array}{c}\text { Gramas de } \\
\text { nitrogênio no } \\
\text { tecido úmido } \\
\text { (fígado) }\end{array}$ & $\begin{array}{c}\text { Gramas de } \\
\text { proteína no } \\
\text { tecido úmido } \\
\text { (fígado) }\end{array}$ \\
\hline 1 & 0.13 & 0.78 & 1.57 & 9.78 \\
2 & 0.15 & 0.94 & 1.01 & 6.3 \\
3 & 0.04 & 0.26 & 0.17 & 1.04 \\
4 & 0.12 & 0.76 & 1.04 & 6.5 \\
5 & 0.12 & 0.72 & 0.84 & 5.23 \\
6 & 0.12 & 0.75 & 0.88 & 5.5 \\
7 & 0.13 & 0.78 & 0.9 & 5.62 \\
8 & 0.14 & 0.87 & 0.91 & 5.69 \\
9 & 0.09 & 0.57 & 1 & 6.27 \\
10 & 0.11 & 0.69 & 0.79 & 4.93 \\
11 & 0.1 & 0.6 & 0.94 & 5.87 \\
12 & 0.12 & 0.74 & 1.02 & 6.37 \\
\hline
\end{tabular}


Tabela 13: Dados do nitrogênio tecidual coração e fígado do Grupo III

\begin{tabular}{ccccc}
\hline Animal & $\begin{array}{c}\text { Gramas de } \\
\text { nitrogênio no } \\
\text { tecido úmido } \\
\text { (coração) }\end{array}$ & $\begin{array}{c}\text { Gramas de } \\
\text { 109roteína no } \\
\text { tecido úmido } \\
\text { (coração) }\end{array}$ & $\begin{array}{c}\text { Gramas de } \\
\text { nitrogênio no } \\
\text { tecido úmido } \\
\text { (fígado) }\end{array}$ & $\begin{array}{c}\text { Gramas de } \\
\text { 109roteína no } \\
\text { tecido úmido } \\
\text { (fígado) }\end{array}$ \\
\hline 1 & 0.13 & 0.8 & 1.07 & 6.66 \\
2 & 0.13 & 0.78 & 0.89 & 5.59 \\
3 & 0.11 & 0.71 & 0.74 & 4.6 \\
4 & 0.14 & 0.9 & 1.15 & 7.19 \\
5 & 0.11 & 0.68 & 0.83 & 5.18 \\
6 & 0.15 & 0.92 & 0.97 & 6.05 \\
7 & 0.12 & 0.75 & 0.91 & 5.72 \\
8 & 0.13 & 0.82 & 0.98 & 6.15 \\
9 & 0.1 & 0.63 & 0.89 & 5.57 \\
10 & 0.1 & 0.62 & 0.92 & 5.72 \\
11 & 0.13 & 0.83 & 0.91 & 5.66 \\
12 & 0.1 & 0.6 & 0.95 & 5.95 \\
\hline
\end{tabular}


Tabela 14: Dados do nitrogênio tecidual coração e fígado do Grupo IV

\begin{tabular}{ccccc}
\hline Animal & $\begin{array}{c}\text { Gramas de } \\
\text { nitrogênio no } \\
\text { tecido úmido } \\
\text { (coração) }\end{array}$ & $\begin{array}{c}\text { Gramas de } \\
\text { 110roteína no } \\
\text { tecido úmido } \\
\text { (coração) }\end{array}$ & $\begin{array}{c}\text { Gramas de } \\
\text { nitrogênio no } \\
\text { tecido úmido } \\
\text { (fígado) }\end{array}$ & $\begin{array}{c}\text { Gramas de } \\
\text { 110roteína no } \\
\text { tecido úmido } \\
\text { (fígado) }\end{array}$ \\
\hline 1 & 0.14 & 0.09 & 1.01 & 6.33 \\
2 & 0.12 & 0.77 & 0.96 & 5.97 \\
3 & 0.13 & 0.84 & 0.82 & 5.14 \\
4 & 0.13 & 0.79 & 0.96 & 5.99 \\
5 & 0.11 & 0.71 & 1.01 & 6.31 \\
7 & 0.14 & 0.9 & 1.12 & 7.02 \\
8 & 0.11 & 0.66 & 1.02 & 6.38 \\
9 & 0.11 & 0.71 & 1.02 & 6.37 \\
10 & 0.11 & 0.67 & 0.91 & 5.67 \\
11 & 0.07 & 0.42 & 0.83 & 5.16 \\
12 & 0.08 & 0.48 & 0.76 & 4.74 \\
\hline
\end{tabular}

$¥$ Material extraviado 


\subsection{Análise da gordura tecidual}

Tabela 15: Dados da gordura tecidual fígado e coração do Grupo controle

\begin{tabular}{ccccccc}
\hline Animal & $\begin{array}{c}\text { Peso total } \\
\text { tecido } \\
\begin{array}{c}\text { Úmido } \\
\text { (fígado) } \\
\text { (g) }\end{array}\end{array}$ & $\begin{array}{c}\text { Gramas de } \\
\text { gordura no } \\
\text { tecido } \\
\text { úmido } \\
\text { (fígado) } \\
\text { (g) }\end{array}$ & $\begin{array}{c}\text { \% de } \\
\text { gordura } \\
\text { no órgão } \\
\text { total } \\
\text { (fígado) }\end{array}$ & $\begin{array}{c}\text { Peso total } \\
\text { tecido } \\
\text { Úmido } \\
\text { (coração) } \\
\text { (g) }\end{array}$ & $\begin{array}{c}\text { Gramas de } \\
\text { gordura no } \\
\text { tecido } \\
\text { úmido } \\
\text { (coração) } \\
\text { (g) }\end{array}$ & $\begin{array}{c}\text { \% de } \\
\text { gordura no } \\
\text { órgão total } \\
\text { (coração) }\end{array}$ \\
\hline 1 & 10.32 & 0.33 & 3.15 & 1.290 & 0.11 & 8.55 \\
2 & 8.82 & 0.33 & 3.72 & 1.091 & 0.06 & 5.8 \\
3 & 11.83 & 0.56 & 4.72 & 1.272 & 0.08 & 6.06 \\
4 & 9.13 & 0.44 & 4.87 & 1.084 & 0.07 & 6.73 \\
5 & 10.2 & 0.52 & 5.05 & 1.169 & 0.1 & 8.24 \\
6 & 10.54 & 0.87 & 8.28 & 1.195 & 0.06 & 4.71 \\
7 & 9.51 & 0.69 & 7.21 & 1.089 & 0.07 & 6.83 \\
8 & 8.26 & 0.53 & 6.37 & 1.990 & 0.07 & 3.68 \\
10 & 9.28 & 0.76 & 8.18 & 0.944 & 0.06 & 5.78 \\
\hline
\end{tabular}


Tabela 16: Dados da gordura tecidual fígado e coração do Grupo II

\begin{tabular}{|c|c|c|c|c|c|c|}
\hline Animal & $\begin{array}{l}\text { Peso total } \\
\text { tecido } \\
\text { Úmido } \\
\text { (fígado) } \\
\text { (g) }\end{array}$ & $\begin{array}{c}\text { Gramas } \\
\text { de } \\
\text { gordura } \\
\text { no tecido } \\
\text { úmido } \\
\text { (fígado) } \\
\text { (g) }\end{array}$ & $\begin{array}{c}\text { \% de } \\
\text { gordura } \\
\text { no órgão } \\
\text { total } \\
\text { (fígado) }\end{array}$ & $\begin{array}{l}\text { Peso total } \\
\text { tecido } \\
\text { Úmido } \\
\text { (coração) } \\
\text { (g) }\end{array}$ & $\begin{array}{c}\text { Gramas de } \\
\text { gordura no } \\
\text { tecido } \\
\text { úmido } \\
\text { (coração) } \\
\text { (g) }\end{array}$ & $\begin{array}{c}\text { \% de } \\
\text { gordura no } \\
\text { órgão total } \\
\text { (coração) }\end{array}$ \\
\hline 1 & 12.91 & 0.47 & 3.66 & 1.41 & 0.04 & 3.06 \\
\hline 2 & 12.38 & 1.28 & 10.35 & 1.29 & 0.05 & 3.56 \\
\hline 3 & 9.52 & 1.16 & 12.18 & 1.03 & 0.04 & 4.18 \\
\hline 4 & 13.28 & 0.53 & 3.98 & 1.29 & 0.06 & 4.45 \\
\hline 5 & 10.28 & 1.12 & 10.94 & 1.16 & 0.04 & 3.57 \\
\hline 6 & 12.28 & 0.42 & 3.42 & 1.18 & 0.03 & 2.79 \\
\hline 7 & 10.72 & 0.67 & 6.26 & 1.28 & 0.1 & 7.67 \\
\hline 8 & 10.6 & 0.34 & 3.2 & 1.39 & 0.07 & 4.64 \\
\hline 9 & 13.34 & 0.53 & 3.94 & 1.22 & 0.05 & 4.13 \\
\hline 10 & 8.81 & 0.26 & 2.93 & 1.13 & 0.04 & 3.89 \\
\hline 11 & 11.78 & 0.99 & 8.38 & 1.22 & 0.04 & 3.03 \\
\hline 12 & 10.86 & 0.45 & 4.1 & 1.28 & 0.09 & 7.22 \\
\hline
\end{tabular}


Tabela 17: Dados da gordura tecidual fígado e do coração do Grupo III

\begin{tabular}{ccccccc}
\hline Animal & $\begin{array}{c}\text { Peso total } \\
\text { tecido } \\
\text { Úmido } \\
\text { (fígado) } \\
\text { (g) }\end{array}$ & $\begin{array}{c}\text { Gramas de } \\
\text { gordura } \\
\text { no tecido } \\
\text { úmido } \\
\text { (fígado) } \\
\text { (g) }\end{array}$ & $\begin{array}{c}\text { \% de } \\
\text { gordura } \\
\text { no órgão } \\
\text { total } \\
\text { (fígado) }\end{array}$ & $\begin{array}{c}\text { Peso total } \\
\text { tecido } \\
\text { Úmido } \\
\text { (coração) } \\
\text { (g) }\end{array}$ & $\begin{array}{c}\text { Gramas de } \\
\text { gordura no } \\
\text { tecido } \\
\text { úmido } \\
\text { (coração) } \\
\text { (g) }\end{array}$ & $\begin{array}{c}\text { \% de } \\
\text { gordura no } \\
\text { orgão total } \\
\text { (coração) }\end{array}$ \\
\hline 1 & 13.140 & 0.780 & 5.970 & 1.340 & 0.090 & 7.020 \\
2 & 10.090 & 0.800 & 7.920 & 1.330 & 0.120 & 8.800 \\
3 & 11.730 & 2.010 & 17.130 & 1.190 & 0.180 & 14.980 \\
4 & 13.360 & 0.860 & 6.440 & 1.490 & 0.110 & 7.030 \\
5 & 9.250 & 1.000 & 10.840 & 1.260 & 0.130 & 10.600 \\
6 & 13.000 & 1.890 & 14.570 & 1.550 & 0.160 & 10.250 \\
7 & 10.640 & 0.550 & 5.160 & 1.280 & 0.080 & 6.140 \\
8 & 11.420 & 1.430 & 12.550 & 1.330 & 0.090 & 7.110 \\
9 & 11.090 & 0.590 & 5.290 & 1.110 & 0.070 & 6.410 \\
10 & 11.120 & 0.850 & 7.620 & 1.020 & 0.060 & 6.130 \\
11 & 11.050 & 0.600 & 5.410 & 1.280 & 0.120 & 9.110 \\
12 & 10.040 & 0.470 & 4.720 & 1.010 & 0.070 & 6.920 \\
\hline
\end{tabular}


Tabela 18: Dados da gordura tecidual fígado e do coração do Grupo IV

\begin{tabular}{ccccccc}
\hline Animal & $\begin{array}{c}\text { Peso total } \\
\text { tecido } \\
\text { Úmido } \\
\text { (fígado) } \\
\text { (g) }\end{array}$ & $\begin{array}{c}\text { Gramas de } \\
\text { gordura } \\
\text { no tecido } \\
\text { úmido } \\
\text { (fígado) } \\
\text { (g) }\end{array}$ & $\begin{array}{c}\text { \% de } \\
\text { gordura } \\
\text { no órgão } \\
\text { total } \\
\text { (fígado) }\end{array}$ & $\begin{array}{c}\text { Peso total } \\
\text { tecido } \\
\text { Úmido } \\
\text { (coração) } \\
\text { (g) }\end{array}$ & $\begin{array}{c}\text { Gramas de } \\
\text { gordura no } \\
\text { tecido } \\
\text { úmido } \\
\text { (coração) } \\
\text { (g) }\end{array}$ & $\begin{array}{c}\text { \% de } \\
\text { gordura no } \\
\text { órgão total } \\
\text { (coração) }\end{array}$ \\
\hline 1 & 13.310 & 0.800 & 6.040 & 1.100 & 0.070 & 6.040 \\
2 & 13.150 & 0.720 & 5.460 & 1.390 & 0.080 & 5.460 \\
3 & 11.270 & 0.960 & 8.550 & 1.290 & 0.110 & 8.550 \\
4 & 11.320 & 0.880 & 7.730 & 1.230 & 0.100 & 7.730 \\
5 & 11.130 & 0.730 & 6.580 & 1.310 & 0.090 & 6.580 \\
7 & 14.130 & 0.660 & 4.670 & 1.640 & 0.080 & 4.670 \\
8 & 11.710 & 0.780 & 6.660 & 1.180 & 0.080 & 6.660 \\
9 & 13.130 & 1.810 & 13.790 & 1.260 & 0.170 & 13.790 \\
10 & 11.190 & 1.090 & 9.700 & 1.150 & 0.110 & 9.700 \\
11 & 8.890 & 0.530 & 5.990 & 0.950 & 0.060 & 5.990 \\
12 & 8.750 & 0.630 & 7.220 & 1.080 & 0.080 & 7.220 \\
\hline
\end{tabular}

Material extraviado para o rato 6 . 
7.8. Análise do estresse oxidativo pela dosagem de vitamina $E$, malondialdeído e glutationa no tecido hepático.

Tabela 19: Valores de MDA, GSH e Vitamina E dos Grupos I, II, III e IV

\begin{tabular}{|c|c|c|c|c|}
\hline Grupo & Animal & $\begin{array}{c}\text { MDA } \\
\text { (nmoles/mg proteína) }\end{array}$ & $\begin{array}{c}\text { GSH } \\
(\mu \mathrm{mol} \text { GSH/ grama proteina })\end{array}$ & $\begin{array}{c}\text { Vitamina } E \\
\text { ( } \mu \text { mol Vitamina E/g tecido) }\end{array}$ \\
\hline \multirow{10}{*}{1} & 1 & 0.16 & 31.7 & 120.6 \\
\hline & 2 & 0.18 & 21.1 & 16.7 \\
\hline & 3 & 0.14 & 35.5 & 106 \\
\hline & 4 & 0.18 & 38.7 & 217.3 \\
\hline & 5 & 0.14 & 33.4 & 93.5 \\
\hline & 6 & 0.16 & 39.9 & 183.8 \\
\hline & 7 & 0.15 & 31.4 & 193.9 \\
\hline & 8 & 0.15 & 39.2 & 206.3 \\
\hline & 9 & 0.17 & 27.4 & 39.6 \\
\hline & $\frac{10}{1}$ & $\begin{array}{l}0.11 \\
0.15\end{array}$ & $\frac{30}{27.6}$ & $\begin{array}{l}310.9 \\
216.9\end{array}$ \\
\hline \multirow{11}{*}{ II } & 2 & 0.22 & 32.9 & 44.8 \\
\hline & 3 & 0.17 & 34.1 & 309 \\
\hline & 4 & 0.19 & 53.4 & 258.4 \\
\hline & 5 & 0.19 & 35.9 & 109.5 \\
\hline & 6 & 0.19 & 16.2 & 65.1 \\
\hline & 7 & 0.16 & 25.1 & 66.8 \\
\hline & 8 & 0.2 & 39.3 & 273.4 \\
\hline & 9 & 0.16 & 40.7 & 230.6 \\
\hline & 10 & 0.21 & 43.8 & 311.6 \\
\hline & 11 & 0.16 & 18.1 & 37.7 \\
\hline & 12 & 0.2 & 46 & 286.9 \\
\hline \multirow{12}{*}{ III } & 1 & 0.19 & 43.4 & 218.6 \\
\hline & 2 & 0.15 & 24.7 & 159.8 \\
\hline & 3 & 0.22 & 20.3 & 124 \\
\hline & 4 & 0.18 & 48 & 406.9 \\
\hline & 5 & 0.17 & 20.6 & 103.3 \\
\hline & 6 & 0.17 & 23 & 86.7 \\
\hline & 7 & 0.22 & 52.7 & 312.7 \\
\hline & 8 & 0.16 & 22.6 & 71.8 \\
\hline & 9 & 0.18 & 34 & 347.5 \\
\hline & 10 & 0.19 & 43.8 & 304.5 \\
\hline & 11 & 0.13 & 50.1 & 328.8 \\
\hline & 12 & 0.19 & 68.5 & 378.4 \\
\hline \multirow{11}{*}{ IV } & 1 & 0.19 & 45.7 & 172.7 \\
\hline & 2 & 0.16 & 31.9 & 248.9 \\
\hline & 3 & 0.23 & 66.3 & 203.4 \\
\hline & 4 & 0.18 & 20.6 & 62.3 \\
\hline & 5 & 0.15 & 24.8 & 211.5 \\
\hline & 6 & 0.17 & 19.3 & 71.1 \\
\hline & 7 & 0.17 & 22.6 & 142.7 \\
\hline & 8 & 0.16 & 38.2 & 202.7 \\
\hline & 9 & 0.2 & 35.6 & 77.1 \\
\hline & 10 & 0.18 & 23 & 70.5 \\
\hline & 11 & 0.15 & 46.1 & 331.9 \\
\hline
\end{tabular}




\subsection{Análise histopatológica}

Tabela 20: Animais que desenvolveram esteatose hepática

\begin{tabular}{|c|c|c|c|}
\hline Grupo & & & Classificação da esteatose \\
\hline Grupo I & $\begin{array}{c}\text { Animal } \\
10\end{array}$ & & Esteatose macro e microgoticular discreto. \\
\hline & fase I & fase II & \\
\hline Grupo II & $\begin{array}{c}\text { Animais } \\
2,6,7 \text { e } 11\end{array}$ & $\begin{array}{c}\text { Animal } \\
3\end{array}$ & $\begin{array}{l}\text { Todos os animais com esteatose macro e } \\
\text { microgoticular discreto, exceto animal } 6 \text { com } \\
\text { esteatose moderada. }\end{array}$ \\
\hline Grupo III & $\begin{array}{l}\text { Animais } \\
3,5,6 \text { e } 8\end{array}$ & $\begin{array}{c}\text { Animal } \\
10\end{array}$ & $\begin{array}{l}\text { Todos os animais com esteatose macro e } \\
\text { microgoticular discreto, exceto animal } 3 \text { com } \\
\text { esteatose moderada. }\end{array}$ \\
\hline Grupo IV & $\begin{array}{l}\text { Animais } \\
9 \text { e } 10\end{array}$ & $\begin{array}{l}\text { Animais } \\
3 \text { e } 11 .\end{array}$ & $\begin{array}{l}\text { Todos os animais com esteatose macro e } \\
\text { microgoticular discreto. }\end{array}$ \\
\hline
\end{tabular}




\subsection{Delineamento experimental}

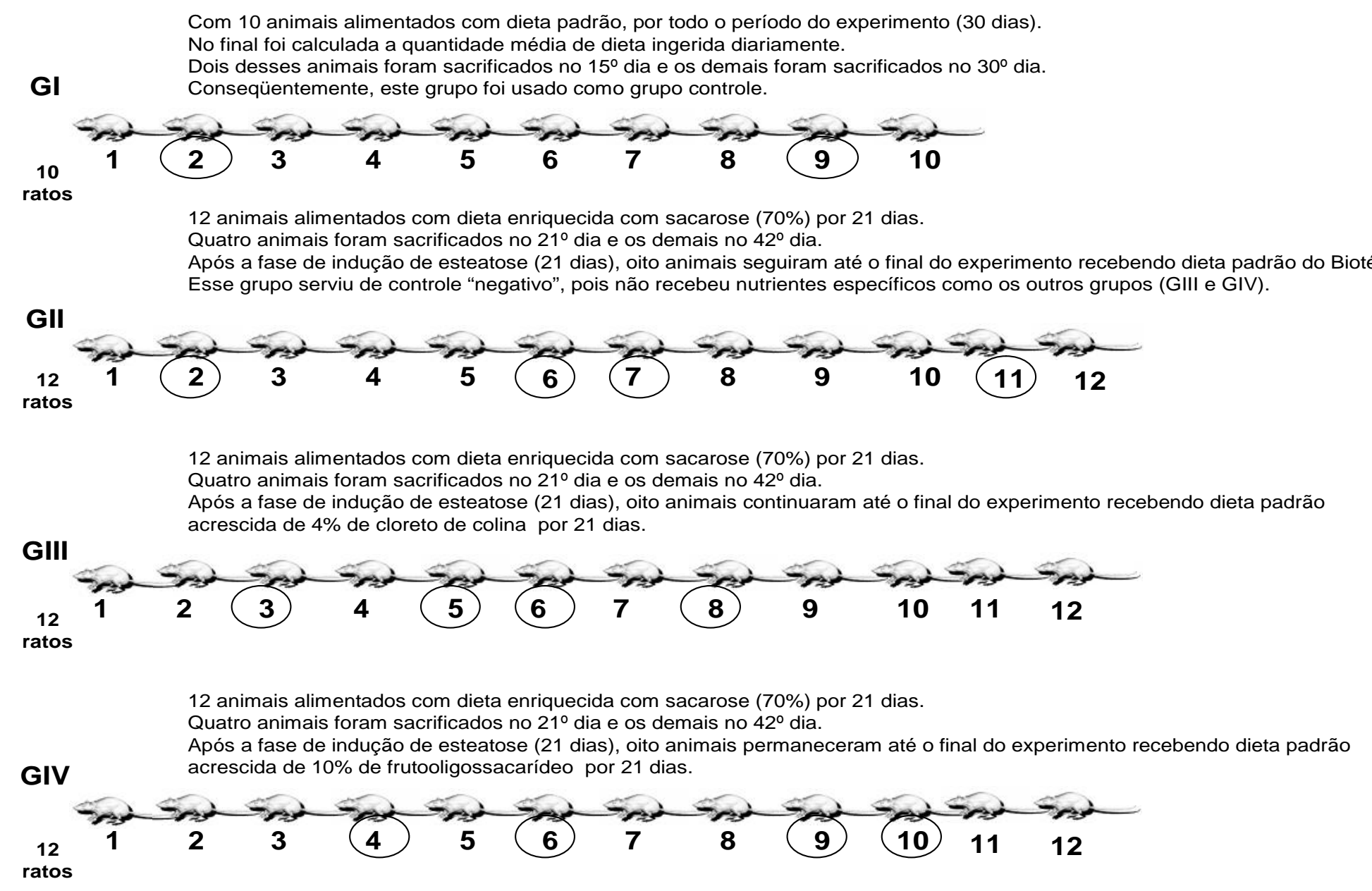




\section{REFERÊNCIAS BIBLIOGRÁFICAS}


Adams LA, Angulo P, Lindor KD. Nonalcoholic fatty liver disease. CMAJ. 2005 Mar 29;172(7):899-905.

Akbar $\mathrm{DH}$, Kawther $\mathrm{AH}$. Non-alcoholic fatty liver disease and metabolic syndrome: what we know and what we don't know. Med Sci Monit. 2006 Jan;12(1):RA23-6.

Alter MJ. Epidemiology of hepatitis C virus infection. World J Gastroenterol. 2007 May 7;13(17):2436-41.

Alter MJ, Armstrong GL, Wasley A, Simard EP, McQuillan GM, Kuhnert WL. The prevalence of hepatitis C virus infection in the United States, 1999 through 2002. Ann Intern Med. 2006 May 16;144(10):705-14.

Alves ALS, Olinto MTA, Costa JSD, Bairros FS, Balbinotti MAA. Padrões alimentares de mulheres adultas residentes em área urbana no sul do Brasil. Rev. Saúde Pública [periódico na Internet]. 2006 Out [citado 2007 Out 15] ; 40(5): 865-873. Disponível em: http://www.scielo.br.

Angelico F, Del Ben M, Conti R, Francioso S, Feole K, Fiorello S, Cavallo MG, Zalunardo B, Lirussi F, Alessandri C, Violi F. Insulin resistance, the metabolic syndrome, and nonalcoholic fatty liver disease. J Clin Endocrinol Metab. 2005 Mar;90(3):1578-82.

Angelico M, Della Guardia P. Review article: hepatobiliary complications associated with total parenteral nutrition. Aliment Pharmacol Ther. 2000 May;14 Suppl 2:54-7.

Angulo P, Hui JM, Marchesini G, Bugianesi E, George J, Farrell GC, Enders F, Saksena S, Burt AD, Bida JP, Lindor K, Sanderson SO, Lenzi M, Adams LA, Kench J, Therneau TM, Day CP. The NAFLD fibrosis score: a noninvasive system that identifies liver fibrosis in patients with NAFLD. Hepatology. 2007 Apr;45(4):846-54. 
Angulo P, Keach JC, Batts KP, Lindor KD. Independent predictors of liver fibrosis in patients with nonalcoholic steatohepatitis. Hepatology. 1999; 30:1356-62.

Angulo P. Nonalcoholic Fatty Liver Disease. New England J Med. 2002; 346:1221-29.

Angulo P. Nonalcoholic fatty liver disease and liver transplantation. Liver Transpl. 2006 Apr;12(4):523-34.

AOAC. AOAC Official Methods of Analysis of AOAC International. P. Cunnif (ed). 16th ed. Arlington AOAC (EUA), 1995. v. I e II.

Arnaud J,Gueguen S, Pirollet P, Leroy P, Guilland JC, Paille F, Siest G, Visvikis $S$, Hercberg $S$, Herbeth $B$. Changes in serum retinol, alpha-tocopherol, vitamin $\mathrm{C}$, carotenoids, zinc and selenium after micronutrient supplementation during alcohol rehabilitation. J Am Coll Nutr. 2003 Aug;22(4):303-10.

Assumpção RTMD, Machado Filho CAS. Uso dermatológico da fosfatidilcolina. Arq Med ABC. 2006;31(1):41-5.

Assy N, Grozovski M, Bersudsky I, Szvalb S, Hussein O. Effect of insulinsensitizing agents in combination with ezetimibe, and valsartan in rats with nonalcoholic fatty liver disease. World J Gastroenterol. 2006 Jul 21;12(27):4369-76.

Axen KV, Axen K. Very low-carbohydrate versus isocaloric high-carbohydrate diet in dietary obese rats. Obesity (Silver Spring). 2006 Aug;14(8):1344-52

Bacon BR, Park CH, Fowell EM, McLaren CE. Hepatic steatosis in rats fed diets with varying concentrations of sucrose. Fundamental and Applied Toxicology.1994;4:819-26.

Benchimol AK, Cardoso IS, Fandino J, Bittar T, Freitas S, Coutinho WF. Nonalcoholic steatohepatitis induced by fast weight loss during the use of intragastric balloon--a case report. Arq Bras Endocrinol Metabol. 2007 Jun;51(4):631-4. 
Browning JD, Horton JD. Molecular mediators of hepatic steatosis and liver injury. J Clin Invest. 2004; 114(2):147-152.

Browning JD, Szczepaniak LS, Nurenberg P, Leonard D, Reingold JS, Grundy $\mathrm{S}$, Hobbs HH, Dobbins RL. Magnetic resonance spectroscopy to measure hepatic triglyceride content: prevalence of hepatic steatosis in the general population. Am J Physiol Endocrinol Metab. 2005 Feb;288(2):E462-8.

Brunt EM, Ramrakhiani S, Cordes BG, Neuschwander-Tetri BA, Janney CG, Bacon BR, Di Bisceglie AM. Concurrence of histologic features of steatohepatitis with other forms of chronic liver disease. Mod Pathol. 2003 Jan;16(1):49-56.

Buege JA, Svingen BA, O'Neal FO, Aust SD. The mechanism of NADPHdependent lipid peroxidation. The propagation of lipid peroxidation. J Biol Chem. 1979 Jul 10;254(13):5892-9.

Bugianesi E, Pagotto U, Manini R, Vanni E, Gastaldelli A, de lasio R, Gentilcore E, Natale S, Cassader M, Rizzetto M, Pasquali R, Marchesini G. Plasma adiponectin in nonalcoholic fatty liver is related to hepatic insulin resistance and hepatic fat content, not to liver disease severity. J Clin Endocrinol Metab. 2005 Jun;90(6):3498-504.

Busserolles J, Gueux E, Rock E, Demigne C, Mazur A, Rayssiguier Y. Oligofructose protects against the hypertriglyceridemic and pro-oxidative effects of a high fructose diet in rats. J Nutr. 2003 Jun;133(6):1903-8.

Conway EJ. Apparatus for the micro-determination of certain volatile substances: The blood ammonia, with observations on normal human blood. Biochem J. 1935 Dec;29(12):2755-72.

Copaci I, Micu L, Voiculescu. The role of cytokínes in non-alcoholíc steatohepatitis a systematic review. J.Gastroíntestin Liver Dis. 2006;(15) 363373. 
Cotrim HP, Andrade ZA, Parana R, Portugal M, Lyra LG, Freitas LAR. Nonalcoholic steatohepatitis: a toxic liver disease in industrial workers. Liver. 1999; (19): 299-304.

Cotrim HP, Carvalho F, Siqueira AC, Lordelo M, Rocha R, De Freitas LA. Nonalcoholic fatty liver and insulin resistance among petrochemical workers. JAMA. 2005 Oct 5;294(13):1618-20

Cotrim HP, Carvalho FM, Silvany Neto AM, Mendes JL, Nascimento AL, Lima Junior AS, Cunha TO. Liver enzyme abnormalities among oil refinery workers Rev Saude Publica. 2006 Feb;40(1):92-8.

Dam-Larsen S, Franzmann M, Andersen IB, Christoffersen P, Jensen LB, Sorensen TI, Becker U, Bendtsen F. Long term prognosis of fatty liver: risk of chronic liver disease and death. Gut. 2004 May;53(5):750-5.

Das UN . Metabolic syndrome $X$ an inflammatory condition? (Review). Exp Biol Med (Maywood). 2002; 227(11):989-97.

Day CP. Non-alcoholic steatohepatitis (NASH): where are we now and where are we going? Gut. 2002 May;50(5):585-8.

De Lima VM, de Oliveira CP, Sawada LY, Barbeiro HV, de Mello ES, Soriano FG, Alves VA, Caldwell SH, Carrilho FJ. Yo jyo hen shi ko, a novel Chinese herbal, prevents nonalcoholic steatohepatitis in ob/ob mice fed a high fat or methionine-choline-deficient diet. Liver Int. 2007 Mar;27(2):227-34.

Delzenne NM, Kok N. Effects of fructans-type prebiotics on lipid metabolism. Am J Clin Nutr. 2001 Feb;73(2 Suppl):456S-458S.

Delzenne NM, Kok NN. Biochemical basis of oligofructose - induced hypolipidemia in animal models. J Nutr. 1999 Jul;129(7 Suppl):1467S-70S.

Dentin R, Benhamed F, Hainault I, Fauveau V, Foufelle F, Dyck JR, Girard J, Postic C. Liver-specific inhibition of ChREBP improves hepatic steatosis and insulin resistance in ob/ob mice. Diabetes. 2006 Aug;55(8):2159-70. 
Diehl AM, Li ZP, Lin HZ, Yang SQ. Cytokines and the pathogenesis of nonalcoholic steatohepatitis. Gut. 2005 Feb;54(2):303-6.

Diehl AM. Nonalcoholic steatosis and steatohepatitis IV. Nonalcoholic fatty liver disease abnormalities in macrophage function and cytokines. Am J Physiol Gastrointest Liver Physiol. 2002 Jan;282(1):G1-5.

Duncan BB, Schmidt MI, Chambless LE, Folsom AR, Carpenter M, Heiss G. Fibrinogen, other putative markers of inflammation, and weight gain in middleaged adults - The ARIC study. Atherosclerosis Risk in Communities. Obes Res. 2000;8(4):279-86.

Dutta A, Dutta SK. Vitamin E and its role in the prevention of atherosclerosis and carcinogenesis: a review. J Am Coll Nutr. 2003 Aug;22(4):258-68.

Duvnjak M, Lerotic I, Barsic N, Tomasic V, Virovic Jukic L, Velagic V. Pathogenesis and management issues for non-alcoholic fatty liver disease. World J Gastroenterol. 2007 Sep 14;13(34):4539-4550.

Enriori PJ, Evans AE, Sinnayah P, Cowley MA. Leptin resistance and obesity. Obesity (Silver Spring). 2006; Suppl 5:254S-258S.

Ersoz G, Gunsar F, Karasu Z, Akay S, Batur Y, Akarca US. Management of fatty liver disease with vitamin $E$ and $C$ compared to ursodeoxycholic acid treatment. Turk J Gastroenterol. 2005 Sep;16(3):124-8.

Feldsine P, Abeyta C, Andrews WH; AOAC International methods committee guidelines for validation of qualitative and quantitative food microbiological official methods of analysis. J AOAC Int. 2002 Sep-Oct;85(5):1187-200.

Flamm SL, Blei AT, Rinella ME, Alonso E, Rao S, Whitington P, Fryer J, Abecassis M, Superina R, Body mass index as a predictor of hepatic steatosis in living liver donors. Liver Transpl. 2001 May;7(5):409-14.

Freitas AC, Freitas DT, Parolin MB, Campos AC, Coelho JC. Nonalcoholic fatty liver disease: evolution after gastric bypass. Arq Gastroenterol. 2007 JanMar;44(1):49-53. 
Grattagliano I, Vendemiale G, Caraceni P, Domenicalli M, Nardo B, Cavallari A, Trevisani F. Starvation impairs antioxidant defense in fatty livers of rats fed a choline-deficient diet. J Nutr. 2000;130(9):2131-6.

Georgescu EF, Georgescu M. Therapeutic options in non-alcoholic steatohepatitis (NASH). Are all agents alike? Results of a preliminary study. J Gastrointestin Liver Dis. 2007 Mar;16(1):39-46.

Hamaguchi M, Kojima T, Takeda N, Nakagawa T, Taniguchi H, Fujii K, Omatsu T, Nakajima T, Sarui H, Shimazaki M, Kato T, Okuda J, Ida K. The metabolic syndrome as a predictor of nonalcoholic fatty liver disease. Ann Intern Med. 2005 Nov 15;143(10):722-8.

Hartge MM, Unger T, Kintscher U. The endothelium and vascular inflammation in diabetes. Diab Vasc Dis Res. 2007 Jun;4(2):84-8.

Hasler CM. The changing face of functional foods. J. Am. Coll. Nutr. 2000;19:499-506.

Hongu N, Sachan DS. Caffeine, carnitine and choline supplementation of rats decreases body fat and serum leptin concentration as does exercise. The Journal of nutrition. 2000. 130: 152-157.

Isselbacher KJ, Rebouças G. Studies on the pathogenesis of the ethanolinduced fatty liver. I. Synthesis and oxidation of fatty acids by the liver. J Clin Invest. 1961 Aug;40:1355-62.

Iwaki T, Ishizaki K, Kinoshita S, Tanaka H, Fukunari A, Tsurufuji M, Imada T. Protective effects of ursodeoxycholic acid on chenodeoxycholic acid-induced liver injury in hamsters. World J Gastroenterol. 2007 Oct 7;13(37):5003-8.

Jaffe ER, Wissler RW, Beneditt EP. The importance of methionine and choline in the arrest of dietary cirrhosis of the liver in the rat. Am J Pathol. 1950 Sep;26(5):951-67.

Kashireddy PR, Rao MS. Sex differences in choline-deficient diet-induced steatohepatitis in mice. Exp Biol Med (Maywood). 2004 Feb;229(2):158-62. 
Kaur N, Gupta AK. Applications of inulin and oligofructose in health and nutrition. J. Biosci. 2002; 27:703-14.

Kern PA, Saghizadeh M, Ong, JM, Sosch, RJ, Deem, R, Simsolo RS. The expression of tumor necrosis factor in human adipose tis sue. Regulation by obesity, weigth loss and relationship to lipoprotein lipase. J Clin Invest. 1995; 95: 2111-9.

Kim HJ, Kim HJ, Lee KE, Kim DJ, Kim SK, Ahn CW, Lim SK, Kim KR, Lee HC, Huh KB, Cha BS. Metabolic significance of nonalcoholic fatty liver disease in nonobese, nondiabetic adults.Arch Intern Med. 2004 Oct 25;164(19):2169-75

Kleiner DE, Brunt EM, Van Natta M, Behling C, Contos MJ, Cummings OW, et al. Design and validation of a histological scoring system for nonalcoholic fatty liver disease. Hepatology. 2005;41:1313-21.

Kok NN, Morgan LM, Williams CM, Roberfroid MB, Thissen JP, Delzenne NM.Insulin, glucagon-like peptide 1. glucose-dependent insulinotropic polypeptide and insulin-like growth factor I as putative mediators of the hypolipidemic effect of oligofructose in rats.J Nutr. 1998 Jul;128(7):1099-103.

Konstantinides FN, Boehm KA, Radmer WJ, Storm MC, Adderly JT, Weisdorf SA, Cerra FB. Pyrochemiluminescence: real-time, cost-effective method for determining total urinary nitrogen in clinical nitrogen-balance studies. Clin Chem. 1988 Dec;34(12):2518-20.

Koteish A, Roskams T, Yang SQ, Durnez A, DeVos R, Huang X, Achten R, Verslype $C$, Diehl AM. Oxidative stress and oval cell accumulation in mice and humans with alcoholic and nonalcoholic fatty liver disease. Am J Pathol. 2003 Oct;163(4):1301-11.

Leclercq IA, Farrell GC, Field J, Sell DR, Gonzalez FJ, Robertson, GR. CYP2E 1 and CYP4A as microsomal catalysts of lipid peroxides in murine nonalcoholic steatohepatitis. J Clin Invest. 2000; 105(8):1067-75. 
Lee KS, Buck M, Houglum K, Chojkier M. Activation of hepatic stellate cells by TGF alpha and collagen type I is mediated by oxidative stress through c-myb expression. J Clin Invest. 1995 Nov;96(5):2461-8.

Lesniewska V, Rowland I, Cani PD, Neyrinck AM, Delzenne NM, Naughton PJ. Effect on components of the intestinal microflora and plasma neuropeptide levels of feeding Lactobacillus delbrueckii, Bifidobacterium lactis, and inulin to adult and elderly rats. Appl Environ Microbiol. 2006 Oct;72(10):6533-8.

Letexier D, Pinteur C, Large V, Frering V, Beylot M. Comparison of the expression and activity of the lipogenic pathway in human and rat adipose tissue. J Lipid Res. 2003 Nov;44(11):2127-34.

Lieber CS, Leo MA, Mak KM, Xu Y, Cao Q, Ren C, Ponomarenko A, DeCarli LM. Model of nonalcoholic steatohepatitis. Am J Clin Nutr. 2004 Mar;79(3):5029.

Lopez Dieguez Puerta M, Casal Esteban V, Barbado Hernandez FJ, Gil Guerrero L, Rodriguez Molinero MA, Larrauri J, Vazquez Rodriguez JJ. Nonalcoholic steatohepatitis, the enigma of bad progression. An Med Interna. 2005 Feb;22(2):85-7.

Ludwig J, Viggiano TR, Mcgill DB, Ott BJ. Nonalcoholic steatohepatitis. Mayo Clinic experiences with a hitherto unnamed disease. Mayo Clin. Proc. 1980; 55:434-8.

Luo J, Van Yperselle M, Rizkalla SW, Rossi F, Bornet FR, Slama G. Chronic consumption of short-chain fructooligosaccharides does not affect basal hepatic glucose production or insulin resistance in type 2 diabetics. J Nutr. 2000 Jun;130(6):1572-7.

Madan K, Batra Y, Gupta DS, Chander B, Anand Rajan KD, Singh R, Panda SK, Acharya SK. Vitamin E-based therapy is effective in ameliorating transaminasemia in nonalcoholic fatty liver disease. Indian J Gastroenterol. 2005 Nov-Dec;24(6):251-5. 
Marchesini G, Bogdanova K, Poczatkova H, Uherkova L, Riegrova D, Rypka M, Feher J, Vesely J. Non-alcoholic fatty liver disease (NAFLD) - a novel common aspect of the metabolic syndrome. Biomed Pap Med Fac Univ Palacky Olomouc Czech Repub. 2006 Jul;150(1):101-4.

Marchini JS, Lambertini CR, Ferriolli E, Dutra de Oliveira JE. Obese women on a low energy rice and bean diet: effects of leucine, arginine or glycine supplementation on protein turnover. Braz J Med Biol Res. 2001 Oct;34(10):1277-83.

Marotta F, Harada M, Goh KL, Lorenzetti A, Gelosa F, Minelli E. Phytotherapeutic compound YHK exerts an inhibitory effect on early stage of experimentally-induced neoplastic liver lesions. Annals of Hepatology. 2006; 5(4)268-272.

Mattos AA. Esteato-hepatite não-alcoólica. J. Bras. Gastroenterol. 2005 Out./Dez; 5(4):160-165.

McGavock JM, Victor RG, Unger RH, Szczepaniak LS; American College of Physicians and the American Physiological Society. Adiposity of the heart, revisited. Ann Intern Med. 2006 Apr 4;144(7):517-24

Mendler MH, Kanel G, Govindarajan S. Proposal for a histological scoring and grading system for non-alcoholic fatty liver disease.Liver Int. 2005 Apr;25(2):294-304.

Mestre Prates JA, Pereira Mateus CMR. Componentes com actividade fisiológica dos alimentos de origem animal. Revista Portuguesa de Ciências Veterinárias. 2002; 97:3-12.

Molis C, Flourie B, Ouarne F, Gailing MF, Lartigue S, Guibert A, Bornet F, Galmiche JP. Digestion, excretion, and energy value of fructooligosaccharides in healthy humans. Am J Clin Nutr. 1996 Sep;64(3):324-8. 
Moon D, Lee S, Hwang S, Kim K, Ahn C, Park K, Ha T, Song G. Resolution of severe graft steatosis following dual-graft living donor liver transplantation. Liver Transpl. 2006 Jul;12(7):1156-60.

Nanji AA. Animal models of nonalcoholic fatty liver disease and steatohepatitis. Clin Liver Dis. 2004; 8(3):559-74.

Nishimura M, Yamaguchi M, Naito S, Yamauchi A. Soybean oil fat emulsion to prevent TPN-induced liver damage: possible molecular mechanisms and clinical implications. Biol Pharm Bull. 2006 May;29(5):855-62.

Oliveira CP, Coelho AM, Barbeiro HV, Lima VM, Soriano F, Ribeiro C, Molan NA, Alves VA, Souza HP, Machado MC, Carrilho FJ. Liver mitochondrial dysfunction and oxidative stress in the pathogenesis of experimental nonalcoholic fatty liver disease. Braz J Med Biol Res. 2006 Feb;39(2):189-94.

Oliveira CP, da Costa Gayotto LC, Tatai C, Oella Bina BI, Janiszewski M, Lima ES, Abdalla OS, Lopasso FP, Laurindo FR, Laudanna AA. Oxidative stress in the pathogenesis of nonalcoholic fatty liver disease, in rats fed with a cholinedeficient diet. J Cel! Mol Med. 2002; 6(3):399-406.

Oliveira CP, Gayotto LC, Tatai C, Della Nina BI, Lima ES, Abdalla DS, Lopasso FP, Laurindo FR, Carrilho FJ. Vitamin C and vitamin E in prevention of Nonalcoholic Fatty Liver Disease (NAFLD) in choline deficient diet fed rats. Nutr J. 2003 Oct 7;2:9.

Oliveira CP, Simplicio FI, de Lima VM, Yuahasi K, Lopasso FP, Alves VA, Abdalla DS, Carrilho FJ, Laurindo FR, de Oliveira MG. Oral administration of Snitroso-N-acetylcysteine prevents the onset of non alcoholic fatty liver disease in rats. World J Gastroenterol. 2006 Mar 28;12(12):1905-11.

Parks EJ Dietary carbohydrate's effects on lipogenesis and the relationship of lipogenesis to blood insulin and glucose concentrations. Br J Nutr. 2002 May;87 Suppl 2:S247-53. 
Passos LML, Park YK. Frutooligossacarídeos: implicações na saúde humana e utilização em alimentos. Ciência Rural. 2003; 33:385-90.

Perez Aguilar F, Benlloch S, Berenguer M, Beltran B, Berenguer J. Nonalcoholic statohepatitis: physiopathological, clinical and therapeutic implications. Rev Esp Enferm Dig. 2004 Sep;96(9):628-39; 440-8.

Pessayre D, Mansouri A, Fromenty B. Nonalcoholic steatosis and steatohepatitis. V. Mitochondrial dysfunction in steatohepatitis. Am J Physiol Gastrointest Liver Physiol. 2002 Feb;282(2):G193-9.

Petersen KF, Dufour S, Befroy D, Lehrke M, Hendler RE, Shulman GI. Reversal of nonalcoholic hepatic steatosis, hepatic insulin resistance, and hyperglycemia by moderate weight reduction in patients with type 2 diabetes. Diabetes. 2005 Mar;54(3):603-8.

Polacow VO, Lancha Junior AH. High-carbohydrate diets: effects on lipid metabolism, body adiposity and its association with physical activity and cardiovascular disease risk. Arq Bras Endocrinol Metabol. 2007 Apr;51(3):389400

Portincasa P, Grattagliano I, Palmieri VO, Palasciano G. The emerging problem of nonalcoholic steatohepatitis (NASH).Rom J Gastroenterol. 2005 Mar;14(1):43-51.

Quareshi K, Abrams GA. Metabolic liver disease of obesity and role of adipose tissue in the pathogenesis of nonalcoholic fatty liver disease. World $\mathrm{J}$ Gastroenterol. 2007 Jul 14;13(26):3540-53.

Raubenheimer PJ, Nyirenda MJ, Walker BR. A choline-deficient diet exacerbates fatty liver but attenuates insulin resistance and glucose intolerance in mice fed a high-fat diet. Diabetes. 2006 Jul;55(7):2015-20.

Reis KAA, Roquete MLV, Penna FJ. Esteatohepatite não-alcoólica na infância e adolescência: revisão. Pediatria (Sao Paulo). 2001;23(4):298-304. 
Reddy JK, Rao MS. Lipid metabolism and liver inflammation. II. Fatty liver disease and fatty acid oxidation. Am J Physiol Gastrointest Liver Physiol. 2006 May;290(5):G852-8.

Reeves PG, Nielsen FH, Fahey GC Jr. AIN-93 purified diets for laboratory rodents: final report of the American Institute of Nutrition ad hoc writing committee on the reformulation of the AIN-76A rodent diet. J Nutr. 1993 Nov;123(11):1939-51.

Romestaing C, Piquet MA, Bedu E, Rouleau V, Dautresme M, HourmandOllivier I, Filippi C, Duchamp C, Sibille B. Long term highly saturated fat diet does not induce NASH in Wistar rats.Nutr Metab (Lond). 2007 Feb 21;4:4.

Sahai A, Malladi P, Pan X, Paul R, Melin-Aldana H, Green RM, Whitington PF. Obese and diabetic $\mathrm{db} / \mathrm{db}$ mice develop marked liver fibrosis in a model of nonalcoholic steatohepatitis: role of short-form leptin receptors and osteopontin. Am J Physiol Gastrointest Liver Physiol. 2004 Nov;287(5):G1035-43.

Saito T, Misawa K, Kawata S. Fatty liver and non-alcoholic steatohepatitis. Intern Med. 2007;46(2):101-3. Epub 2007 Jan 15.

Salgado Junior W, dos Santos JS, Sankarankutty AK, de Castro e Silva O. Nonalcoholic fatty liver disease and obesity. Acta Cir Bras. 2006;21 Suppl 1:728.

Sass DA, Shakil AO. Fulminant hepatic failure. Liver Transpl. 2005 Jun;11(6):594-605.

Setji TL, Holland ND, Sanders LL, Pereira KC, Diehl AM, Brown AJ. Nonalcoholic steatohepatitis and nonalcoholic Fatty liver disease in young women with polycystic ovary syndrome. J Clin Endocrinol Metab. 2006 May;91(5):1741-7.

Sheth SG, Gordon FD, Chopra S. Nonalcoholic steatohepatitis. Ann Intern Med 1997;126:137-45. 
Siebler J, Galle PR. Treatment of nonalcoholic fatty liver disease. World J Gastroenterol. 2006 Apr 14;12(14):2161-7.

Skogerboe KJ, Labbe RF, Rettmer RL, Sundquist JP, Gargett AM. Chemiluminescent measurement of total urinary nitrogen for accurate calculation of nitrogen balance. Clin Chem. 1990 May;36(5):752-5.

Solga S, Alkhuraishe AR, Clark JM, Torbenson M, Greenwald A, Diehl AM, Magnuson T. Dietary composition and nonalcoholic fatty liver disease. Dig Dis Sci. 2004 Oct;49(10):1578-83.

Soloni FG. Simplified manual micromethod for determination of serum triglycerides. Clin Chem. 1971 Jun;17(6):529-34.

Spolarics Z, Meyenhofer M. Augmented resistance to oxidative stress in fatty rat livers induced by a short-term sucrose-rich diet. Biochimica et Biophysica Acta. 2000;1487:190-200.

Stadtman TC, Elliott P. Studies on the enzymic reduction of amino acids. II. Purification and properties of D-proline reductase and a proline racemase from Clostridium sticklandii. J Biol Chem. 1957 Oct;228(2):983-97.

Sun $\mathrm{ZH}$ et al. Effects of dietary methionine and lysine sources on nutrient digestion, nitrogen utilization, and duodenal amino acid flow in growing goat. J.Anim Sci. 2007;85:3340-3347

Sundaram SS, Whitington PF, Green RM. Steatohepatitis develops rapidly in transgenic mice overexpressing Abcb11 and fed a methionine-choline-deficient diet. Am J Physiol Gastrointest Liver Physiol. 2005 Jun;288(6):G1321-7.

Svegliati-Baroni G, Candelaresi C, Saccomanno S, Ferretti G, Bachetti T, Marzioni M, De Minicis S, Nobili L, Salzano R, Omenetti A, Pacetti D, Sigmund S, Benedetti A, Casini A. A model of insulin resistance and nonalcoholic steatohepatitis in rats: role of peroxisome proliferator-activated receptor-alpha and n-3 polyunsaturated fatty acid treatment on liver injury. Am J Pathol. 2006 Sep;169(3):846-60. 
Tamura S, Shimomura I. Contribution of adipose tissue and de novo lipogenesis to nonalcoholic fatty liver disease. J Clin Invest. 2005 May;115(5):1139-42.

Takamura T, Shimizu A, Komura T, Ando H, Zen Y, Minato H, Matsushita E, Kaneko S. Selective estrogen receptor modulator raloxifene-associated aggravation of nonalcoholic steatohepatitis. Intern Med. 2007;46(9):579-81

Tarantino G. Should nonalcoholic fatty liver disease be regarded as a hepatic illness only? World J Gastroenterol. 2007 Sep 21;13(35):4669-72.

Thong-Ngam D, Samuhasaneeto S, Kulaputana O, Klaikeaw N. Nacetylcysteine attenuates oxidative stress and liver pathology in rats with nonalcoholic steatohepatitis. World J Gastroenterol. 2007 Oct 14;13(38):5127-32.

Tsukamoto H. Fat paradox in liver disease. Keio J Med. 2005 Dec;54(4):190-2.

Wang H, Khaoustov VI, Krishnan B, Cai W, Stoll B, Burrin DG, Yoffe B. Total parenteral nutrition induces liver steatosis and apoptosis in neonatal piglets. J Nutr. 2006 Oct;136(10):2547-52.

Yang SQ, Lin HZ, Lane MD, Clemens M, Diehl AM. Obesity increases sensitivity to endotoxin liver injury: implications for the pathogenesis of steatohepatitis. Proc Natl Acad Sci U S A. 1997 Mar 18;94(6):2557-62.

Yoshikawa J, Amachi S, Shinoyama H, Fujii T. Purification and some properties of beta-fructofuranosidase I formed by Aureobasidium pullulans DSM 2404. J Biosci Bioeng. 2007 May;103(5):491-3.

Zamin Jr I, Mattos AA, Perin C, Ramos GZ. A importância do índice AST/ALT no diagnóstico da esteatohepatite não alcoólica. Arq. Gastroenterol. 2002; 39:22-6.

Zeisel SH. Nutrigenomics and metabolomics will change clinical nutrition and public health practice: insights from studies on dietary requirements for choline. Am J Clin Nutr. 2007 Sep;86(3):542-8. 